UNIVERSIDAD NACIONAL DE LA PLATA

FACULTAD de HuMANIDADES Y CIENCIAS DE LA EDUCACIÓN SeCRetaría de Posgrado

\title{
¿CÓMO APRENDEN LOS ENTRENADORES A ENSEÑAR RUGBY?
}

El caso de los entrenadores de rugby de M14 en los clubes del Gran La Plata

Juan Casajús

Tesis para optar al grado de Magister en Deporte

Director: Prof. Mg. Carlos Gabriel Carballo

Septiembre de 2019 


\section{DEDICATORIA}

A Jorgelina por recorrer el camino de la vida juntos y darle alegría a mi corazón; a mis hijos Juan José, Josefina y Joaquín, por su entendimiento y acompañamiento en esta tozudez por buscar y lograr objetivos.

A mis padres y a mi hermana Cecilia, agradecimiento infinito por repetir y entender que "todo llega".

A mis amigos, parte fundamental de mi vida, quienes aportan sus conocimientos y fortalezas cada día, y muchas veces bien cerca de una cancha de rugby. 


\section{AGRADECIMIENTOS}

A la Universidad Nacional de La Plata (UNLP) y en especial a la Facultad de Humanidades y Ciencias de la Educación (FaHCE), al Profesorado en Educación Física (PUEF) y a la Maestría en Deporte por la formación recibida tanto en lo académico como en lo personal.

Al Prof. Mg. Carlos Gabriel Carballo por su impulso al inicio de mi carrera académica; me siento afortunado de haber realizado esta tesis bajo su supervisión, gracias por su ayuda, sugerencias y paciencia.

A mis colegas de la Facultad de la Cátedra Educación Física 4, por su apoyo en la realización de la tesis.

A toda la gran familia del Club de Rugby Los Tilos, por permitirme practicar el juego, conocer mis amigos e intentar mejorar como persona.

A los jugadores y jugadoras de rugby, los más importantes, sobre todo en sus etapas formativas.

A los entrenadores y entrenadoras de rugby con quienes acompaño sus inquietudes y ganas de formarse siendo amateurs, además de compartir preocupaciones y capacidad de superación.

A los clubes de rugby, lugar de contención y de mejora constante para compartir momentos.

A todas las personas que han hecho posible la elaboración de esta tesis. 


\section{¿CÓMO APRENDEN LOS ENTRENADORES A ENSEÑAR RUGBY?}

El caso de los entrenadores de rugby de M14 en los clubes del Gran La Plata Juan Casajús

Waiho he pātaiana, he kahaui te kaha.

(Deja que sigan las preguntas; la habilidad de una persona está en hacer preguntas) Proverbio maorí 


\section{¿CÓMO APRENDEN LOS ENTRENADORES A ENSEÑAR RUGBY?}

El caso de los entrenadores de rugby de M14 en los clubes del Gran La Plata

\section{INTRODUCCION}

\subsection{Presentación}

\subsection{Estado de la cuestión}

\subsection{Problema de Investigación}

\section{EXPERIENCIAS Y TRAYECTORIAS}

\subsection{Sobre el contenido de este capítulo}

2.2. Análisis de las entrevistas a los entrenadores

2.2.1. El vínculo con el rugby y la edad de inicio

2.2.2. El aporte de familiares

2.2.3. Recuerdan su pasado

2.2.4. El entrenador y el compromiso grupal

2.2.5. El entrenador, exigencias y hostilidad

2.2.6. El temor a empezar a jugar. Entender al jugador

2.2.7. Nadie hizo todo, todos hicieron algo

2.2.8. Del resultado te das cuenta después

2.2.9. El entrenador que jugó y el que no jugó

2.2.10. A la distancia, cambia

2.2.11. "Entrenás repitiendo como te entrenaban" 


\subsection{Del dato empírico a la elaboración teórica}

2.3.1. El oficio del investigador: la construcción de biografías

2.3.2. El oficio de entrenador: la construcción de una práctica

2.3.3. El oficio de entrenador: la adquisición de un capital

\subsection{Bibliografía del capítulo}

\section{FORMACIÓN}

\subsection{Sobre el contenido de este capítulo}

\subsection{Análisis de las entrevistas a los entrenadores}

3.2.1. Matriz de formación

3.2.2. "Me siento entrenador de rugby"

3.2.3. El entrenador se ve de afuera

3.2.4. La formación de un entrenador de rugby

3.2.5. Los entrenadores apasionados y los valores

3.2.6. "Los entrenadores necesitamos capacitarnos"

3.2.7. Actividades de formación complementarias

3.2.8. "Los entrenadores también jugamos como árbitros"

3.2.9. “¿Qué cambié?": la actitud autocrítica

\subsection{Del dato empírico a la elaboración teórica}

3.3.1. La formación del entrenador y su matriz de aprendizaje

3.3.2. Los entrenadores frente al desafío de la formación

\subsection{Bibliografía del capítulo}




\section{CONTENIDOS Y MODOS DE ENSEÑANZA}

\subsection{Sobre el contenido de este capítulo}

\subsection{Análisis de las entrevistas a los entrenadores}

4.2.1. ¿Qué es importante al enseñar en el rugby?

4.2.2. La forma propia de entrenar

4.2.3. Lo que necesita un jugador al finalizar M14

4.2.4. De niños a jugadores: cambio de categoría

4.2.5. El legado: la marca de cada club

4.2.6. La identidad del club de rugby

4.2.7. El temor en la enseñanza

4.2.8. La contención y el reconocimiento: "iY lo que yo disfruto!"

4.3. Del dato empírico a la elaboración teórica

4.3.1. Acerca del contenido

4.3.2. Acerca de la enseñanza

4.4. Bibliografía del capítulo

5. CONCLUSIONES

6. BIBLIOGRAFÍA 


\section{INTRODUCCIÓN}

"Hay sin duda en nuestra sociedad, y me imagino que también en todas las otras,

(...) una especie de sordo temor contra esos acontecimientos, contra esa masa de cosas dichas, contra la aparición de todos esos enunciados, contra todo lo que puede haber alli de violento, de discontinuo, de batallador,

y también de desorden y de peligroso, contra ese gran murmullo incesante y desordenado de discurso."

(Foucault, 1970)

\subsection{Presentación}

La revisión de las experiencias y trayectorias de los entrenadores de rugby puede mejorar el bienestar y el desarrollo del deporte, al mismo tiempo que, puede legitimar nuevas formas de intervención. Una investigación requiere que el investigador asuma dos condiciones: una, relacionada con la necesidad de someter al análisis el objeto que se propone investigar y otra, vinculada a que asuma como propio el contenido que produjo en su investigación (De Marziani, 2014).

El rugby requiere de estos estudios y la investigación es una de las formas con las que se cuenta para lograr ese efecto. Una de las actitudes más destacadas que puede asumir el investigador es realizar un aporte cultural a la vida deportiva mediante la producción de saberes. Investigar es invertir en el desarrollo social y cultural de una sociedad, y en esta dinámica, el desarrollo científico debe ser pensado sin lugar a dudas como una herramienta de acrecentamiento de derechos. 
Quien lleva adelante la investigación busca encontrar elementos (evidencias) de que algo puede modificarse, de que siempre hay algo que puede ser estudiado y revisado, aunque esas evidencias sólo permitirán un conocimiento aproximado, producto de un continuo diálogo entre él y su trabajo. El hecho de investigar es un camino utópico que nunca debería de acabar. El transcurrir de los capítulos escritos, se conforma en consecuencia, en un recorrer ese camino, desandando aquellos estudios categóricos y normalizadores con los que el rugby se ha ido construyendo, estableciendo a la reflexión y a la revisión como los recursos fundamentales de profundización y al sujeto como su verdadero objeto de estudio.

Presentar al rugby como un juego que nació como un simple pasatiempo hace casi 200 años y que fue evolucionando hasta transformarse en un deporte que acapara a millones de espectadores en el mundo, que se ha transformado en una estructura global alrededor de la cual se han construido enormes estadios, se ha creado una intrincada estructura administrativa y se han diseñado complejas estrategias, no sería un inicio adecuado para esta tesis. Adherir a una visión intencionalmente ingenua, deshistorizada y profundamente acrítica no es una buena ayuda para entender ningún fenómeno social. Eludir la compleja trama política, económica e institucional para aproximarse a un hecho sólo serán garantías de reproducción de ese hecho a partir de la naturalización de sus características.

No obstante lo señalado, el rugby no deja de ser un deporte -lo cual, en principio, lo define como una competencia sometida a reglas fijadas por 
instituciones-, un juego de equipo (nada menos que 15 integrantes por bando) y de contacto (o de colisión), en el que su emblemático balón ovalado es transportado corriendo hacia adelante para poder apoyarlo detrás de la línea final del equipo contrario con el afán de sumar puntos. Así de simple. ¿Por qué un juego aparentemente tan simple merece nuestra atención? ¿Acaso escrutará esta tesis aspectos relativos a su crecimiento y su complejización reglamentaria e institucional? No: esta tesis se propone establecer cómo aprendieron a enseñarlo sus entrenadores, porque aspira a ser un aporte, un insumo a esa formación; y para ello es preciso entender el contexto.

La Unión de Rugby de Buenos Aires (URBA) agrupa en la actualidad a 91 clubes que se ubican en diferentes categorías según su rendimiento deportivo (para ser precisos, seis en la actualidad: Top 12, Primera A, Primera B, Primera C, Segunda y Tercera). También congrega 30 equipos en el ámbito empresarial y 20 en el universitario. Esto equivale a decir que se encuentran federados más de 43.000 jugadoras y jugadores, desde los 6 años en adelante. ${ }^{1}$ De este modo, la URBA es la unión regional más grande del mundo. Por su parte, la Unión Argentina de Rugby cuenta con más de 122.000 jugadores y jugadoras (incluso con un crecimiento bruto del 20,14\% en el periodo 2013-2017) y 503 clubes distribuidos por todo el territorio argentino. ${ }^{2}$

A pesar de estas magnitudes y las considerables diferencias entre las instituciones participantes, existe un denominador en común (compartido

1 Datos estadísticos proporcionados por el Área de Competencias URBA, 2018.

2 Datos estadísticos proporcionados por el Área de Competencias UAR, 2018. 
entre las diferentes uniones regionales de rugby de Argentina): por un lado, no existen registros oficiales de entrenadores, entrenadoras, colaboradores a nivel de clubes, ni de unión regional, ni de unión nacional; por otro, los entrenadores de los planteles infantiles y juveniles representan un grupo numeroso de voluntarios sostenidos por el compromiso y el entusiasmo. Esta condición es ciertamente paradojal, puesto que este capital de colaboradores ad honorem representa, a la vez, una fortaleza y una debilidad. Fortaleza, pues existe una tradición poderosa de sostener el deporte desde la identificación institucional, con un fuerte componente de generosidad; debilidad, pues no es mucho lo que puede exigírseles a esos voluntarios que ofrecen su escaso tiempo libre para la formación de niños y jóvenes.

En el sentido de lo expuesto, la formación de los entrenadores de rugby es una pieza fundamental para asegurar el crecimiento de este deporte en base a una planificación responsable. Uno de los aspectos poco o nulamente estudiados de esa formación en nuestro medio es cómo llegan esos entrenadores a conformar un saber y cómo lo transmiten. Existen esfuerzos recientes de las uniones por difundir métodos y estrategias de enseñanza y planificación, por mejorar el conocimiento y la interpretación de las reglas, por considerar cada vez de manera más trascendente los aspectos ligados a la seguridad, por afianzar los valores considerados tradicionales en el rugby (disciplina, respeto, integridad, pasión, solidaridad). No obstante, existen generaciones de entrenadores "formados" de manera informal, vocacional, asistemática y, por qué no decirlo, contradictoria y carente de fundamentos. 
Esta tesis, al reconocer esos recorridos, intenta hacer un aporte que consistirá en el relevamiento de esos saberes previos, su origen y sus significados en el convencimiento de que las orientaciones producidas en los diferentes niveles institucionales serán mejor recibidas y más eficaces si tienen la intención de producir un encuentro respetuoso con esas experiencias preliminares.

\subsection{Estado de la cuestión}

Tal como se expresa en las Leyes del Juego de Rugby (World Rugby, 2018), ${ }^{3}$ la integridad, la pasión, la solidaridad, la disciplina y el respeto son las características que definen al rugby. Principalmente, éstos son los valores que tienen como objetivo garantizar que este deporte mantenga su identidad tanto dentro como fuera del campo. Por ello, se cree que el rugby transmite altos valores educativos y fomenta las capacidades individuales (Parise, Pagani, Cremascoli, \& lafrate, 2015). ${ }^{4}$

3 World Rugby (2018) Leyes del Juego. Dublin, ISBN: 978-1-907506-91-8.

4 Parise, M.; Pagani, A.; Cremascoli, V. y lafrate, Raffaella. (2015) Rugby, Self-perception and prosocial behaviour: evidence from the italian. "Rugby Project for Schools". Las Palmas, España: Revista Iberoamericana de Psicología del Ejercicio y el Deporte, vol. 10, núm. 1, pp. 57-61. 
Los estilos de vida de los jugadores de rugby se han alterado en los últimos años, debido a la institución de los Campeonatos Mundiales, entre otros torneos, y del profesionalismo.

En un deporte como el rugby que cuenta con casi 200 años de historia, ${ }^{5}$ y con el espíritu amateur como estandarte, recién en 1987 se realiza la primera copa del mundo de rugby en Nueva Zelanda y Australia y a partir de allí, en 1995, se declara el profesionalismo de forma abierta, cambiando la posible manera de formación del jugador.

La copa del mundo de rugby es el tercer evento deportivo del mundo, detrás de los Juegos Olímpicos de Verano y la copa del mundo de fútbol FIFA, por sus dimensiones e impacto mediático. Estos datos son un claro indicador de la creciente popularidad del deporte desde el inicio hasta la última copa del mundo celebrada en el año 2015 en Inglaterra. Otro modo de medir su llegada es la cuestión económica: la citada copa mundial generó 2.000 millones de libras esterlinas. ${ }^{6}$

También otras competencias como el tradicional Seis Naciones del hemisferio norte (torneo anual que incluyó en principio a Inglaterra, Gales,

\footnotetext{
5 La placa conmemorativa en la ciudad de Rugby, Condado de Warwick, Inglaterra, reza: “...donde el joven William Webb Ellis, en 1823, quien con fina desobediencia de las reglas del fútbol, tomó el balón en sus manos y corrió hacia delante originando así la característica distintiva del rugby".

6 "World Cup 2015 will bring in $£ 2$ bn, but there will be no Usain Bolt tax break for the big stars". The Thelegraph. 26 de marzo de 2013. Consultado el 26 de marzo de 2013.
} 
Escocia e Irlanda, que poco después integró a Francia y en las últimas décadas a Italia), el Rugby Championship del hemisferio sur (desde 2012 con la participación de Nueva Zelanda, Australia, Sudáfrica y Argentina) y el Circuito Mundial de la modalidad de Seven (juego de 7 jugadores) que se realiza desde 1999 amplían la difusión del rugby y las posibilidades de muchos jugadores de participar en distintas instancias internacionales de competencia. En cuanto al rugby jugado por mujeres, en 1991 la IRB (International Rugby Board, hoy World Rugby) comenzó a organizar la Copa del Mundo de Rugby Femenino, en 2009 la Copa del Mundo de Rugby (modalidad Seven) y en 2011 la Serie Mundial de Rugby 7 Femenino. Finalmente, la reincorporación del rugby, también en su modalidad Seven, tanto femenino como masculino, en la última edición de los Juegos Olímpicos (Río de Janeiro, 2016) contribuyó a darle visibilidad a este deporte. ${ }^{7}$

Con todas estas nuevas situaciones se podría decir que quien juega al rugby está cambiando; pero, ¿̇es posible afirmar lo mismo de quienes lo enseñan? La concepción del que juega, ¿comienza a cambiar la forma del que enseña las destrezas del jugador con alguna posibilidad de ser profesional? Es de destacar que en la actualidad todos los jugadores que llegan a las academias de formación (instancia previa al profesionalismo) aprenden sus destrezas individuales y grupales en los clubes y de ahí la importancia de conocer de qué manera los entrenadores los van formando.

7 El rugby masculino de 15 jugadores fue disciplina olímpica hasta 1924 y regresó al Programa Olímpico en Rio 2016 en modalidad de 7 jugadores, en este caso masculino y femenino. 
En la búsqueda de la información hemos ordenado distintos textos de la siguiente manera:

\subsubsection{Textos que cuentan historias, anécdotas, curiosidades 0 expresan los valores y el "espíritu del rugby".}

La mayoría de estos textos no contribuyen a conformar el estado de la cuestión, pues no aportan investigaciones relevantes o no ofrecen datos específicos para el tema de la tesis. No obstante, relevar este material es muy importante pues da cuenta de un contexto, de lo que podría llamarse una "cultura del rugby", donde lo que se desprende desde el juego y quienes lo juegan puede llegar a otros ámbitos.

- Pichot, A. (2012). El juego manda. Ciudad Autónoma de Buenos Aires: Editorial Planeta.

En esta autobiografía del ex capitán del Seleccionado Argentino de Rugby con más trascendencia en la historia del rugby argentino, y escrita en Buenos Aires, se hace hincapié en experiencias deportivas positivas y personales, con relatos sobre manejos de grupos, liderazgo y respeto por los orígenes.

- Búsico, J. (2015). El rugido. Ciudad Autónoma de Buenos Aires: Club House.

Se narran los meses previos a la gira de Los Pumas por Sudáfrica en 1965 donde los jugadores reciben el cariño de la gente local quienes sufrían el régimen del apartheid. Varios episodios descriptos de esa época se constituyeron en actuales mitos. 
- Kerr, J. (2014). Legado. Buenos Aires: Club House.

Planteado a partir de la experiencia de los All Blacks neozelandeses, se escriben observaciones y prácticas desde el rugby y los campeones del mundo. Se toman desde sus prácticas lecciones de aplicación para el liderazgo y otros ámbitos.

- Galán, N. (2015). El rugby, un juego de valores. Buenos Aires: Artes Gráficas.

El autor platense despliega historias para reproducir en los más jóvenes con énfasis en los valores humanos y el compromiso. Invita a través de sus líneas a todos los que no han jugado, conociendo espíritu y valores del rugby.

- McCaw, R. (2012). The Real McCaw. Londres: Aurum Press Limited.

El jugador capitán, y que más partidos jugó en el Seleccionado de los All Blacks, cuenta como es ser un líder natural y cómo formó una cultura de esfuerzo y el respeto. Relata la formación del carácter desde joven y el acompañamiento familiar hasta transformarse en un ícono del deporte moderno.

- Tietjens, G. (2017). Legacy. Auckland: Penguin House.

Entiende que luego de entrenar 22 años los equipos de Seven de Nueva Zelanda, todo se basa en cultura y preparación física. Relata cómo se llega a través del trabajo estratégico a ser un entrenador de rugby exitoso.

- Carlin, J. (2009). El factor humano. Buenos Aires: Editorial Seix Barral.

El autor, como corresponsal en Sudáfrica, descubre la capacidad innata de Nelson Mandela como líder quien utiliza la realización del mundial de rugby de 
1995 como estrategia clara a fin de conseguir la unión de blancos y negros de forma espontánea y emocional buscando la estabilidad política del país dividido por el odio racial.

\subsubsection{Textos que desarrollan temáticas afines al entrenamiento del rugby.}

Existen diversos textos sobre la preparación física específica del jugador de rugby. Estos textos tampoco conforman el estado de la cuestión, pero es necesario relevarlos porque algunas de sus propuestas ensamblan con un conjunto de valores pregonados en el deporte (fuerza, potencia y resistencia; coraje, sacrificio, compañerismo). Inclusive, este es el tipo de material con que los profesores de educación física (especialmente los que no provienen de la práctica del rugby) se acercan al rugby y en muchos casos comienzan sus lecturas.

- Mackey, M. (2012). Entrenando Movimientos. Buenos Aires: Unión Argentina de Rugby.

El autor propone una metodología de trabajo a partir de adaptaciones del Functional Movement Screen (FMS) y sugiere una forma progresiva de trabajo con acuerdos en la estructura de los entrenamientos. Su óptica se diferencia de las tradicionales capacidades condicionantes y da respaldo bibliográfico novedoso a la monitorización del cuerpo del jugador. 
- Mackey, M. (2012). El arte de entrenar. Buenos Aires: Unión Argentina de Rugby.

Durante tres módulos se plantean los fundamentos sobre técnicas de carrera, desplazamientos y fuerza con énfasis en el rol docente del profesor en educación física.

- Price, R. (2017). Entrenar con pesas para rugby. Buenos Aires: Editorial Sports Workout.

Presenta rutinas con trabajos de sobrecarga y gimnasio para entrenamientos y partidos mostrando descripciones de entrenamiento con pesas, flexibilidad y abdominales. Muestra programas de entrenamiento con pesas específicos para rugby que puede usar a lo largo de todo el año.

- Posthumus, M. (2009). Boksmart. Physical conditioning for rugby. Ciudad del Cabo: South African Rugby Union.

Manual de preparación física de la Unión Sudafricana de Rugby (SARFU) con ejercicios por puestos, con la consigna de entrenar jugadores para un rugby seguro. Las demandas físicas del rugby son complejas y mediante evidencia científica muestra que con el entrenamiento de la fuerza, la potencia y el tamaño del jugador mejora el rendimiento del jugador.

- Luger, D. (2004). Complete conditioning for rugby. Champaign: Human Kinetics.

Libro de autor inglés, donde se proponen distintos ejercicios y driles físicos específicos del rugby con énfasis en el aumento de la velocidad, la agilidad y la 
fuerza. Plantea la necesidad de tener una planificación pautada, progresiva, cuidadosa y que tenga en cuenta al jugador mejorando su resistencia.

- Biscombe, T. (1998). Rugby. Steps to success. Champaign: Human Kinetics.

Propone una sistematización del desarrollo de las habilidades específicas del rugby, respetando etapas y sugiriendo posiciones específicas como herramientas prácticas. La progresión metodológica se muestra en sus páginas y acompañan numerosos dibujos.

- Pool, G. (1998). Modern rugby. Ciudad del Cabo: Tafelberg.

Sugiere soluciones para problemas con distintos jugadores y desafíos en varias facetas del juego. Describe características del entrenador, cómo armar un equipo, y cómo se debe acercar al movimiento general del juego proponiendo incluso jugadas en determinados lugares de la cancha de juego.

\subsubsection{Materiales que abordan de manera más amplia la enseñanza del deporte.}

Algunos textos generales de la enseñanza del deporte o específicos sobre otros deportes deberán ser recuperados, porque puede haber en ellos nociones o conceptos que se transpolan (praxiología, didáctica crítica, giro reflexivo, modelo ecológico, etc.) a la enseñanza del rugby, a la iniciación deportiva, etc.

- Blázquez Sánchez, D. (1998). La iniciación deportiva y el deporte escolar. Madrid: INDE. 
Este autor español presenta un análisis del proceso de iniciación deportiva desde la lógica interna y acciones de juego en los deportes, junto a situaciones motrices para su enseñanza. El análisis incluye perspectivas educativas, formativas, de orientación, de rendimiento, de enseñanza, social y organizativa.

- San Pedro, J. (1999). Fundamentos de táctica deportiva, análisis de la estrategia de los deportes. Buenos Aires: Editorial Gymnos.

Se tratan conceptos de táctica, estrategia, acciones de juego, enseñanza de los deportes de equipo, planificación y evaluación. El autor analiza los condicionantes del juego con el objeto de desarrollar la inteligencia motriz individual y colectiva. Abordajes sobre táctica y estrategia, la inteligencia motriz deportiva, la técnica en el deporte, análisis de los deportes de equipo e individuales, deportes de oposición, planificación y evaluación de los deportes de equipo.

- Bayer, C. (1992). La enseñanza de los deportes colectivos. Madrid: Hispano Europea.

Se plantean las bases teóricas de un método y las teorías de la transferencia del aprendizaje para finalizar con la descripción de la estructura en los juegos deportivos colectivos. Se resalta el contraste entre dos formas de enseñar los deportes llamados colectivos, o si se prefiere de cooperación y oposición: una de ellas es la basada en el paradigma clásico, centrado en la técnica, en tanto modelo correcto de ejecución de los gestos; y la otra se centra en la táctica, entendida como la continua resolución de problemas que el juego va 
planteando.

- Rieder, H. y Fischer, G. (1990). Aprendizaje motor, metodología y didáctica. Buenos Aires: Martínez Roca.

Presenta una propuesta pedagógica de utilización del juego aplicado pretendiendo ofrecer una alternativa pedagógica para la iniciación a los deportes de equipo en jugadores jóvenes.

- Rumin, J. (2006). La escuela del rugby. Buenos Aires: Editorial Stadium.

Este autor francés propone un enfoque desde el juego para el abordaje pedagógico del rugby. Expone una readecuación de la técnica, la táctica y la enseñanza en función de la actualización de las reglas de juego. Diferencia la competencia en lo que denomina la educación física escolar y en el club y propone el rugby como apoyo de la educación física y deportiva.

- Collinet, S. y Nerin, J. (2006). Rugby. ¿Cómo enseñar el deporte hoy? Buenos Aires: Editorial Stadium.

Los autores proponen criterios didácticos - pedagógicos al servicio de la organización del proceso de enseñanza aprendizaje en la escuela y en el club, en tanto medio importante en el contexto general de una dimensión formativa y competitiva. También describen actividades con más continuidad y menos fases estáticas, considerando el rugby como una actividad de alto nivel formativo.

- Salluzzi, D. (2015). El rugby desde sus principios. Buenos Aires: Universidad Maimónides. 
El autor argentino propone enseñar el rugby desde el ataque y desde la defensa llegando a propuestas a través de distintos niveles de aprendizaje. Plantea que tanto en el comienzo del aprendizaje como en la etapa de especialización el jugador debe ser formado desde el juego y para el juego.

\subsubsection{Textos específicos de enseñanza del rugby.}

Estos textos pueden ser de autores individuales o de instituciones (Academias, Uniones de rugby, por ejemplo).

- Popinciuc, C. (1975). Manual para profesores y entrenadores. Buenos Aires: Editorial Stadium.

Uno de los libros más antiguos en Argentina que se tiene referencia. El autor, con la ayuda de entrenadores traductores del Club Atlético Ferrocarril Nacional General San Martín de la primera parte del Manual de la Rugby Football Union de Inglaterra, explica distintas técnicas individuales y colectivas, explica un proceso de enseñanza de las destrezas acorde y un capítulo final sobre la táctica.

- Villepreux, P. (1995). Formación del rugby de movimiento. Buenos Aires: Editorial Stadium.

Con prólogo de Ángel Guastella, el autor francés propone un método de trabajo con ejercicios que se adaptan desde principiantes a jugadores formados. Realiza comprobaciones sobre el juego moderno y realiza aportes diciendo la importancia de la inteligencia en la formación del jugador. 
- Amigos del Rugby, boletines mensuales de aprendizaje. Área Desarrollo del Juego, Unión Argentina de Rugby (UAR). Año 2007.

Distintos escritos sobre traducciones, artículos técnicos, materiales de enseñanza del rugby con una primera llegada inusitada y muy amplia a todos los lugares electrónicos de Argentina y Sudamérica.

- Boletines técnicos mensuales. Subcomisión de desarrollo y difusión del juego, Unión de Rugby de Buenos Aires (URBA). Años 2000 - 2008. Prematch Comunicaciones.

Abordaje técnico en revistas y resúmenes de amplia difusión y llegada a los clubes con teorías y prácticas en distintas edades y etapas evolutivas. Con cuestiones de gestión, de organización, aprendizaje, nutrición y preparación física, se realiza una entrega gratuita en todos los clubes que disponían de esa oportunidad.

- Manuales de enseñanza. International Rugby Board (IRB). Año 2001. Nivel 1,2 y 3.

Material impreso con descripciones sobre las enseñanzas ideales para los coaches de todo el mundo. Los distintos niveles se aprobaban con la sola lectura del manual.

- Richarson, K. (2014). Coaching Youth Rugby: An Essential Guide for Coaches, Parents and Teachers. Londres: The Crowood Press.

Guía en inglés para entrenadores y padres; con material para prácticas divertidas enfocadas sobre el jugador joven y cómo llegar a una buena 
comunicación. Centrado en la práctica se propone el acompañamiento de un equipo de rugby. Se proponen ideas y estrategias de entrenamiento para distintos niveles de habilidades.

- Hogan, E. (2014). Rugby Drills: 125 Activities to improve Your Coaching Sessions. Londres: The Crowood Press.

Se trata de una colección con diversas actividades para mejorar los entrenamientos en todos los niveles de juego. Organizado según las fases de juego, cada capítulo comienza con acciones simples y paso a paso se complejizan. El autor inglés plantea distintas necesidades para los especialistas y equipamiento denominado necesario.

- Usero, F. (2014). La escuela de rugby, lecciones de rugby. Madrid: XV Ediciones.

Este autor español aborda preceptos de la iniciación en el rugby con un enfoque en la enseñanza y el aprendizaje con contenidos a desarrollar en el rugby de base. El legado de Francisco Usero es una trilogía que recopila los principales trabajos del autor; referente en el rugby español desde hace más de 25 años, siempre dedicado a la formación de los jugadores de rugby y al desarrollo del propio juego.

\subsubsection{Textos sobre las cuestiones técnicas y tácticas que convienen ser relevados.}

De ellos se nutren o pueden nutrirse las uniones (federaciones) o llegan a 
manos de coaches y entrenadores. En algunos casos, estos textos pueden formar parte del corpus de esta tesis. De fácil acceso, los entrenadores que deseen saber y conocer más a fin de posicionarse como autoridad suelen leer la siguiente bibliografía.

- Hernández, M. (2013). Rugby para pensar. Buenos Aires: Editorial Dunken.

El autor propone analizar el juego apuntando que todo en este deporte tiene un motivo, una razón y una consecuencia. Además sugiere el interés por racionalizar en análisis del juego advirtiendo una gran complejidad basada en las características de quienes lo juegan.

- Greenwood, J. (1993). Rugby total. Madrid: Ediciones Tutor.

Uno de los más tradicionales y leídos autores ingleses analiza y desarrolla todas las cuestiones técnicas y tácticas para un rugby seguro jugado de igual manera por todos los jugadores. Propone sistemas de entrenamiento dirigidos al desarrollo de la efectividad individual y grupal.

- Alred, D. (2016). El principio de la presión. Buenos Aires: Club House.

Pensado más allá del rugby, el autor desglosa como manejar las situaciones de stress con distintos principios y abordajes. La presión como una constante en la vida y su manejo como habilidad con exposición de ocho principios. Propone aprovechar la presión para convertirla en ventaja a favor.

- Saccone, F. (2016). Rugby mental. Buenos Aires: Editorial Dunken.

Aparecen también los entrenamientos mentales. La experiencia y la intuición no alcanzan por lo que los aspectos emocionales influyen en 
cuestiones del juego. El autor aborda la comunicación, el poder de la palabra, trabajo en equipo y concentración para jugadores y referees.

- Blackburn, M. (2013). Coaching rugby sevens. Londres: Bloomsbury Publishing Plc.

Con especial énfasis en los principios del espacio, el encuadre y el movimiento, el autor y especialista de Seven inglés explica el ataque y la defensa en el Seven. Realiza su aporte al desarrollo de las reglas y cómo jugar con el real conocimiento de las mismas. Destrezas individuales y de equipo con la idea final de aprender siempre son analizadas en este libro.

- McGregor, L. (2011). Touch, Pause, engage! Ciudad del Cabo: Ball Publishers.

Usando las voces de preparación del scrum, la autora trabaja con el rugby sudafricano desde la etapa inicial Amadeus hasta ser Springbok, máximo galardón sudafricano. Su análisis es sobre etapas iniciales, escolares, la pasión y la barrera étnica, con el correspondiente llamado a la disciplina y espíritu de superación en equipo.

- Roberts, M. (2010). Rugby. The player's handbook. Londres: Sterling Publising.

La autora inglesa desarrolla, para entrenadores y referees, ejercicios, prácticas, entrenamientos y juegos, junto a distintas estrategias tácticas. Realiza un repaso por la historia del rugby, cómo jugar, los días de entrenamiento y partido e incluso cómo iniciarse en las tareas de entrenador 
y hasta la invitación a ser referee.

1.2.6. Materiales que manifiestan planes generales de formación y desarrollo de jugadores con las siglas LTPD (desarrollo del jugador a largo plazo) y en algunos casos abordan la formación de los entrenadores.

Se trata de guías, grillas y matrices producidas desde las grandes Uniones del TIER $1,{ }^{8}$ destinadas a "bajar líneas" de formación y ordenar conceptos.

La Academia de Rugby de Auckland perteneciente a la Unión de Rugby de Nueva Zelanda (NZRU) presenta un plan con patrones de desarrollo del jugador, alineados en criterios provinciales y nacionales. Desde edades básicas e iniciales hasta All Blacks, con tres ejes denominados identificación, desarrollo y jugadores elite. El programa de desarrollo del jugador en sus distintas etapas, considera incluso la necesidad de que los jugadores puedan aprender de buenos entrenadores.

Por otra parte, el programa de la Unión Sudafricana de Rugby (SARFU) hace hincapié en la formación de entrenadores. Observado por la unión nacional pero llevado a cabo por las uniones provinciales, utilizan un recurso denominado "Play The Game" con distintos niveles: Introducción al rugby, desarrollo de destrezas del rugby, análisis y preparación de entrenadores y

8 Países participantes que pertenecen al ranking del primer grupo mundial de World Rugby (WR). 
finalmente coaching para Sevens.

Desde la Unión Australiana de Rugby (ARU) muestran su planificación involucrando incluso a las escuelas. Utilizan el curso Smart Rugby (fue documento base durante mucho tiempo en los cursos iniciales de Argentina), y luego clasifican tres grupos de edades (Niños: 6-12; Jóvenes: 13-18 y Adultos: más de 19 años) y luego los jugadores son identificados como Participante de club o escuelas, Jugador en desarrollo, Jugador de talento emergente y Jugador de rendimiento.

En el hemisferio norte una unión que realiza su aporte es la Unión Escocesa de Rugby (SRU). Entiende el proceso de formación de jugador como una continuidad y la divide en etapas nombradas como base fundamental, aprender a jugar, desarrollo del jugador, aprender a competir, entrenar para competir y entrenar para ganar. Sugiere que el entrenador tenga experiencia en cada etapa y que las calificaciones que permitan estar al frente del grupo estén en línea con organismos gubernamentales.

La Unión de Rugby de Gales (WRU) expone su plan de formación de jugadores y lo denomina de "Minis al Millenium", haciendo referencia a su impotente estadio en Cardiff. Lo divide en el juego, desarrollo del talento, desarrollo del jugador y desarrollo del entrenador. Desarrolla la idea del juego para hombres y mujeres, proponiendo que cada jugador tiene el derecho de tener experiencias bien organizadas y con buenos entrenadores que ofrezcan correctas progresiones en edades y etapas desde los clubes y escuelas hasta lograr representar al país. 
Por su parte la Unión Irlandesa de Rugby (IRFU) denomina su modelo "de 6 a 6 naciones", pensado y centrado en el jugador sobre cinco áreas específicas: técnica, táctica, física, mental y estilo de vida. Promueve los cursos para entrenadores de todos los niveles, entendiendo que todos deben estar apropiadamente entrenados y cualificados para trabajar en todas las etapas del modelo. Remarca que su modelo no busca que sus jugadores sean de clase mundial sino maximizar el potencial de los jugadores de acuerdo a sus propias posibilidades y ambiciones.

También la Unión Inglesa de Rugby (RFU) expone su plan de desarrollo siendo el más ambicioso ya que contempla jugadores y entrenadores. Toma como base el Programa World Rugby (IRB) Rugby Ready ${ }^{9}$ quien ha sido pensado para educar, ayudar y apoyar a jugadores, entrenadores, referees, en la preparación y entrenamiento del rugby reduciendo los riegos de lesiones. Luego propone su formación en niveles por categoría (enfocados entre 7 y 12 años, 13 y 18 años, adultos participativos, desarrolladores de talentos, adultos rendimiento y elite) y por niveles (entrenadores nuevos, entrenadores en desarrollo, entrenadores propiamente dichos, avanzados y expertos).

\subsubsection{Cursos digitalizados para entrenadores de la World Rugby, ex IRB.}

Finalmente, y con el paso de los años y la consiguiente actualización de

9 Curso Rugby Ready, diseñado por World Rugby en 2007. Se puede realizar su descarga 2014 online en https://rugbyready.worldrugby.org/pdfs/rugby_ready_book_2014_es.pdf 
contenidos, la IRB -hoy World Rugby- comenzó a digitalizar sus cursos de entrenadores. Este tipo de formación de formadores en el mundo del rugby ha sido motivo de escritura en países de habla sajona. Esto permite a cada participante transformarse en ser entrenador Nivel 1, Nivel 2, Nivel 3, Educador y Trainner. A los mismos se pueden acceder de forma presencial o en forma online (incluye también aplicaciones en los teléfonos celulares en formato app para sistema operativo iOS y Android). ${ }^{10}$

\subsubsection{Situación en Argentina.}

El rastreo de estudios previos en la Argentina sobre la temática planteada no aporta datos significativos, al menos en los últimos veinte años; el rugby se ha transformado en profesional (a partir del Mundial de Sudáfrica en 1995) y eso podría haber derivado en cambios más profundos en la formación de entrenadores que, a su vez, implicaran instancias de formación continua. A fines del año 1995, como resultado de una reorganización en la Unión Argentina de Rugby (UAR) se crea la Unión de Rugby de Buenos Aires (URBA). En su primer manual de enseñanza la URBA, desde el Área de Difusión relata: "El entrenador tiene como función la de comunicar y enseñar las destrezas individuales, de unidad y de equipo; pero además podemos decir que también su función es la de formar integralmente al futuro jugador transmitiéndole

\footnotetext{
10 World Rugby, Sitio de coaching del rugby. Recuperado de https://coaching. worldrugby.org/?page=160\&language=es
} 
hábitos saludables, valores humanos y de juego limpio; pero también tiene como función la de gestionar todos los recursos económicos, materiales y humanos que tiene a su alcance. De esto podemos deducir que el entrenador tiene tres funciones fundamentales: a) técnicas, b) humanas y c) de gestión."

Lejos de la presencia de una propuesta escrita concreta y con criterio de continuidad de los clubes o de la Unión (URBA), en la actualidad estamos ante la necesidad que plantean los actores (padres, madres, managers, idóneos), en un escenario actual de niños y jóvenes que disponen de información y que condiciona las formas de enseñanza, al menos de forma sistemática.

De la mano del contexto social contemporáneo, el clima institucional es considerado un factor clave en el análisis de la temática planteada. En cada club existen factores que pueden colaborar en la necesidad de distintas situaciones, como la exigencia física, las situaciones de violencia, el ausentismo, la falta de claridad en las reglas, las operaciones ambiguas ante la inconducta (como utilizar el esfuerzo físico a modo de sanción), la irrelevancia de las normas desde el punto de vista de los jugadores, la existencia de relaciones conflictivas entre entrenadores y directivos, una dirigencia o conducción inactiva o ausente, bajos recursos y una alta tasa de jugadores por entrenador.

\subsection{Problema de Investigación}

Esta investigación pretende analizar la formación de los entrenadores de 
rugby que se desempeñan en las etapas formativas de la ciudad de La Plata y alrededores, conformando el denominado Gran La Plata (Provincia de Buenos Aires, Argentina), en particular la de aquellos que entrenan las divisiones denominadas M14. Esta división resulta clave pues representa la transición del rugby infantil al juvenil y el comienzo de una etapa competitiva para los jugadores de rugby. Partimos del supuesto de que el saber de los entrenadores es un complejo en el que se cruzan: a) una formación que, a los fines de este trabajo, llamaremos primaria o inicial; b) una importante cuota de voluntarismo ligada al compromiso institucional con el club; c) un conjunto de significados no del todo explícitos, relativos a las prácticas que se desarrollan en las instituciones deportivas con rugby; d) una serie de mensajes no siempre articulados que emanan de las uniones o de sus áreas de formación y desarrollo.

En este marco, existen dos caminos fundamentales a desandar: a) por un lado, una minuciosa recopilación de un material bibliográfico que dé cuenta tanto del saber acumulado en la formación como de las probables lecturas a las acceden los entrenadores; b) un trabajo de campo consistente en entrevistas en profundidad a los entrenadores (head coaches) de las divisiones mencionadas en los clubes de la región del Gran La Plata: La Plata Rugby Club, Club de Rugby Los Tilos, Club San Luis, Club Universitario de La Plata, Albatros Rugby Club, Berisso Rugby Club y Ensenada Rugby Club.

Con ambos elementos, se podrá establecer los usos de distintas herramientas, tales como las formas de entrenar (organización, tareas, 
fundamentos), el lenguaje empleado y los recursos teóricos disponibles en la formación de jugadores de rugby infantiles y juveniles. Entendemos que conocer esa formación, sus puntos de apoyo, sus elementos sensibles, es indispensable para desarrollar programas de formación continua eficaces y sostenidos para los entrenadores, que permitan la integración de saberes y disminuyan las resistencias a la actualización. Por su parte, una formación pensada de este modo podrá contribuir también a acercar las expectativas de las nuevas generaciones de jugadores -como se señaló, marcada por el incremento de competencias nacionales e internacionales y por el horizonte de una eventual práctica profesional- con las experiencias, el compromiso y los saberes de los actuales entrenadores. 


\section{EXPERIENCIAS Y TRAYECTORIAS}

\subsection{Sobre el contenido de este capítulo}

El presente capítulo y los dos subsiguientes cuentan con una sencilla estructura. En primer lugar, se organizan las categorías nativas -es decir, lo que los entrenadores dicen en sus entrevistas- en grupos de expresiones que permitan la comprensión de sus posiciones en torno a ítems discretos y significativos, para luego analizar esos dichos en términos empíricos (apartado 2.2.); se pretende de este ejercicio dos cosas: analizar pormenorizadamente las expresiones de los informantes sin fragmentar excesivamente el conjunto de su discurso y mantener en suspenso la teoría para evitar sobreimprimir significados a esas expresiones originales.

En segundo lugar (apartado 2.3.) se procede a confrontar ese análisis preliminar con los enunciados teóricos de las fuentes bibliográficas seleccionadas. También en este caso el propósito es doble: por un lado, poner a prueba la sustentabilidad y validez de los enunciados del apartado anterior; por otro, dotar de mayor generalidad a esos enunciados con el fin de atribuirles aplicabilidad no sólo a ésta sino a otras investigaciones de similar tenor.

Si bien puede decirse que toda la tesis recorre un sendero que se asienta en los rasgos biográficos de los entrenadores entrevistados, este capítulo es el que, seguramente, más anclaje tenga en la historia personal de los 
informantes que han prestado su testimonio y opiniones. Sostenemos esto pues consideramos que hablar de "experiencias y trayectorias" remite a la infancia y juventud de los entrenadores en cuestión, infancias y juventudes que, aunque "contadas en clave de rugby", conforman una matriz de rasgos casi indelebles que será volcada de muy diversas maneras en sus prácticas como enseñantes del deporte. Como se verá, no sólo les adjudicarán a sus antiguos entrenadores el mérito de haberse enamorado de su deporte, sino que los modos de aquellos instructores son una suerte de "metro patrón", una referencia omnipresente en sus prácticas, a veces imitándolos, otras rechazándolos, pero siempre referenciales.

A partir de lo dicho, se convocan a escena numerosos actores: familiares, amigos, antiguos entrenadores, jugadores a los que se entrenó, compañeros de equipo. También se reavivan recuerdos, cargados de afectos y de identificaciones positivas, pero exentos de experiencias en las cuales el temor jugó su papel. En este rumbo aparecen elementos vinculados al papel de las instituciones, al valor del compromiso, al reconocimiento del trabajo de los otros. Y por último, se justiprecian el esfuerzo y las exigencias, se despliegan ejercicios de autorreflexión, se ponderan los hechos en plazos largos, se asumen autocríticas.

Dado que lo que presentamos es una historia de prácticas, el concepto mismo de práctica social, de habitus y de capital aportados por Bourdieu han resultado de gran ayuda, del mismo modo que las consideraciones sobre trayectorias biográficas de Cornejo y otras. 


\subsection{Análisis de las entrevistas a los entrenadores}

\subsubsection{El vínculo con el rugby y la edad de inicio}

En todos los casos, los actuales entrenadores narran sus comienzos en el deporte en la infancia o en los primeros años de adolescencia. Únicamente uno de ellos comienza a practicar el deporte a edad muy temprana (cinco años) y otro ya cursando los estudios secundarios. Con lo cual la relación entre infancia y deporte está inscripta en la experiencia de los entrevistados.

"Yo arranqué jugando en pre décima infantil, tendría 5 años. (...) Arranqué jugando en pre décima, éramos 20 chicos me acuerdo".

<ref.>P 6: Encuesta006D.rtf - 6:1 [ (5:5)]>

"En el año 86, yo estudiaba en el Colegio Industrial y un preceptor nos dio un pequeño volante para invitarnos a jugar al rugby (...) [cerca del] estadio provincial, (...) que estaba a una cuadra [de mi casa], y fui con mi amigo el negro A., y a partir del año 86 se creó el vínculo. A esta altura de la vida lo sigo manteniendo".

<ref.>P 5: Encuesta005C.docx.rtf - 5:1 [ (5:5)]>

Por otra parte, la presencia de un familiar sosteniendo el vínculo con esa primera experiencia es casi unánime: puede tratarse del padre, de la madre, de una hermana o de otro lazo tan fuerte como los primarios (amigos). De modo tal que, en la biografía de los entrevistados, también se produce un nexo importante entre club y familia.

Hay que destacar que todos los entrevistados recuerdan quién los llevó y quién fue su primer entrenador como dato sobresaliente por sobre otros datos significativos en las edades de inicio. Incluso como dato a retomar también se identifica la división a la que comenzaban a pertenecer. 
"La que me lleva al club era mi vieja en el año 73, fines de 1973; y el que me recibe junto a mi vieja, es un tal J.A., el Turco A., que me entrenó durante 3 o 4 años. En ese momento se llamaba pre décima porque no me daba la edad y yo la hice dos veces".

$<$ ref.>P 2: Entrevista002P.docx.rtf - 2:1 [ (5:5)]>

En este apartado hemos distinguido las siguientes variables: a) la edad de inicio en el rugby como jugador de los actuales entrenadores, b) el género, tanto de las personas que los acercaron a la práctica como de aquellas que ejercieron el rol de entrenador y c) la trayectoria (como entrenador, larga o corta, exitosa o no) de sus entrenadores en su etapa de jugador. Vívidos en el recuerdo de los entrevistados, estos elementos gravitan en el tipo de vínculo de ellos con sus jugadores y en el compromiso que generan en ellos.

"A mí me llevó un amigo que se llamaba G., a lo que en ese momento era club $A$, no existía el club B. Y habrá sido a los 12 años".

$<$ ref.>P 1: Entrevista001S.docx.rtf - 1:1 [ (5:5)]>

"Yo llegué al club C por mi hijo (...) después de llevarlo un tiempo, de acompañarlo a él, me enganché a entrenar. Me pareció una experiencia totalmente muy buena, quedé, me enganché...".

$<$ ref.>P 3: Entrevista003A.docx.rtf - 3:1 [ (5:5)]>

"Yo llegué al club a los 9 años. (...) El primo de mi papá fue quien empezó en algunas reuniones familiares empezó a poner la idea de querer llevarnos a jugar (...) [Hasta que] una de mis hermanas más grandes, me dijo "yo te llevo".

<ref. $>$ P 4: Entrevista004X.docx.rtf - 4:1 [ (5:5)>

\subsubsection{El aporte de los familiares}

La función de los familiares presentes se nota como constitutiva en muchos casos. Se los nombra como colaboradores permanentes al costado de la cancha. Los reconocen como personas que ayudan en hacer la comida, que se encargan del cuidado de los niños y jóvenes y que incluso colaboran en cortar 
el pasto. Sin embargo, cuando asumen la tarea de entrenadores su participación parece tomar otra dimensión. Hay padres que comienzan a entrenar para estar cerca de sus hijos, pero son criticados por ser solamente meros reproductores de ejercicios. Aceptan que puedan sumarse a la fuerza amateur de voluntades, pero parecería ser necesario que aquellos o aquellas que se incorporan deban pasar por una etapa de formación básica como entrenadores e incorporar el espíritu propio de cada club.

“Los padres se han sumado en '¿qué necesitas?' Padres que también dicen que mientras ustedes se entrenan yo hago los patys, o los días sábados hacemos algo de comer. Siempre están. $O$ vamos a laburar al predio nuevo y siempre están. Ver una madre con una bordeadora cortando el pasto en la cancha, es fuerte. No se ve siempre". $<$ ref. $>$ P 3: Entrevista003A.docx.rtf - 3:18 [ (35:35)]>

"Entonces nos ha pasado en el club, que hay padres que empezaron a entrenar y de repente los ves que hacen un ejercicio de los entrenamientos de los All Blacks, ${ }^{11}$ y le decís 'para qué los hacés', y dice 'lo vi y me gustó', y los chicos le dicen 'pará, hacé esto que te va a servir para...' Básicamente lo que yo haría es formarlos en las técnicas básicas, y darle una línea de principios, que diga mirá como nosotros conocemos el club, queremos que hagan tackle, manejo, pase de pelota, que aprendan a hacer ruck, y enseñarles esas cosas para que ellos no tengan tanta información en la cabeza y tengan que demostrarles a los chicos que saben. Porque bajan un entrenamiento de los All Blacks, y les rompen la cabeza a los pibes, viste".

$\langle$ ref.>P 6: Entrevista006D.rtf - 6:14 [(25:25)]>

Muchos relatos manifiestan que también hay casos donde se nota la ausencia de familia en el club. Debido a lo expresado, en ocasiones los entrenadores pasan a ser los referentes principales en la vida de los niños y adolescentes.

"El tema de abrazar, agarrar, tocarse, lo hacen con mucho temor. Temor ya que el tacto que ellos sienten es a través de un golpe, de la calle, de la familia, de un amigo. Entonces empezamos a que se toquen, a que se agarren, a que se empujen. A tener cuidado con

11 Seleccionado nacional de rugby de Nueva Zelanda, considerado el mejor del mundo. 
el cuerpo mío, con el de mi compañero y eso lo vamos trasladando siempre en situaciones simplificadas. Que eso es uno de los roles del entrenador del rugby infantil. Simplificar algo que es difícil".

<ref.>P 7: Entrevista007M.docx.rtf - 7:23 [ (51:51)]>

\subsubsection{Recuerdan su pasado}

Las vivencias y recuerdos sobre el pasado de los entrenadores están bien frescas. Ellos evocan haber sido muy activos y recuerdan escuchar muy bien a sus entrenadores que les indicaban qué cosas tenían que hacer.

"Ahí estuve toda la semana (como) loco esperando el sábado para volver a ir. Y jugaba con mi hermano en mi casa, en el fondo, a matarnos a golpes. Uno pensaba que eso era el rugby. Mi hermano hacía taekwondo y aprovechaba y practicaba conmigo alguna que otra toma, de eso me acuerdo. Después la típica, primer regalo (era una) pelota de rugby para tener en casa y dándole contra la pared, contra el piso, contra el perro, contra los vidrios, contra todo. (Yo) era re loco del deporte".

$<$ ref.>P 7: Entrevista007M.docx.rtf - 7:4 [ (10:10)]>

"Antes era...te digo cómo me entrenaban a mí: venía L. en traje desde el estudio (es abogado) con zapatos y traje, y te hacía 'correr, entrenar'".

<ref.>P 6: Entrevista006D.rtf - 6:9 [ (19:19)]>

En sus descripciones entienden que sintieron que para poder aprender debieron confiar en sus entrenadores de alguna manera, sintiéndose seguros en ellos y dentro del equipo. Siempre al principio las entrevistas coinciden en que eran pocos niños y que gobernaba la desorganización. Nombran con especial interés el ritual de una bienvenida con palabras y de una ronda todos abrazados, mirándose a la cara y hombro con hombro, manteniendo muy presente el recuerdo de los inicios.

"Me recibió este amigo de mi papá y me llevó con el entrenador, que no me acuerdo el nombre, pero estaba con un grupito de chicos, me saludaron entre todos, ronda de bienvenida y a entrenar". 
$<$ ref.>P 7: Entrevista007M.docx.rtf - 7:3 [ (6:6)]>

Aunque aparecen algunos conceptos técnicos como jugadas, obtención y defensa, los recuerdos de los entrenadores se enfocan en la descripción de una época en la cual todo era más improvisado: no había mucho material, ni demasiada consideración por la seguridad, como así tampoco gran cantidad de familias presenciando partidos. En este contexto, rememoran las giras deportivas de intercambio. Todos los que las vivieron, cuentan lo determinante de realizar viajes deportivos, e incluso poder dormir en la casa de un nuevo amigo del rugby, pudiendo ver otras realidades y necesidades.

"Los recuerdos que tengo de esa época es que no había mucha contención en cuanto a lo rugbístico, era todo más improvisado. No había mucho material, no había muchas pelotas, ni conos, ni alambrados, ni cien mil padres mirando afuera, nada. No salías en ningún lado, o como chico, no se le daba mucha bolilla a esa parte. A fin de año hubo una gira a Tucumán, dónde lo recuerdo mucho cuando emprendo las giras de ahora, porque era todo tan distinto que no había teléfono y nada. A mí me tocó como primera experiencia a los 9 años visitar una familia en Tucumán que no tenía muchos recursos. Entre los recursos que no tenía era el teléfono. La verdad es que me tocó una casa recontra humilde, pero me atendieron 10. Hacían pan casero en el horno de barro a la mañana, era una locura. No tenían teléfono así que tuve dos días en Tucumán sin poder avisarle a mis papás con quién estaba ni con qué familia. Mis papás nunca hablaron con ellos, algo que hoy es impensado. Hoy los padres se vuelven locos si llega a pasar eso". $<$ ref. $>$ P 4: Entrevista004X.docx.rtf - 4:2 [ (6:6)]]>

"Recuerdo la primera gira que hice a Mar del Plata, también con este plantel. En ese momento fuimos a la casa de un jugador del otro club. Jugamos en el club D. Me acuerdo también que era la primera salida sin papá y mamá, a una casa que no conocés, con horarios y cosas distintas, mucha adrenalina. Viajás sólo en micro, con amigos, pero sólo sin papá y mamá. Ir al club, a la playa con todo el grupo, era otra cosa. Eso es muy bueno".

$<$ ref. $>$ P 7: Entrevista007M.docx.rtf - 7:5 [ (12:12)]>

La huella de ese pasado vivido con felicidad llega al presente: muchos de los amigos de esa época, con el paso de los años, siguen estando en contacto 
y compartiendo la vida del club y hablan de sus ganas de ir a jugar y de ir entrenamiento para poder encontrarse con sus amigos.

"Una experiencia muy linda porque al principio cuando llegás, mirás quién está, a quién conocés, a quién no conocés, la verdad que así fueron mis inicios".

$<$ ref.>P 6: Entrevista006D.rtf - 6:2 [ (5:5)]>

\subsubsection{El entrenador y el compromiso grupal}

Las descripciones de los entrevistados hacen foco en la influencia que han tenido sus entrenadores. Los relatos a la distancia, en el tiempo, reflejan un compromiso grupal con recuerdos inalterables y de real importancia para todos ellos. Así aparece, en el relato de los entrevistados, la dimensión social: el hecho de propiciar el encuentro es transmitido por sobre lo deportivo.

"Teníamos un entrenador que fue importante para todos por la influencia que tuvo. Porque no había equipo y nos dijo que si no traíamos 10 chicos más no podíamos jugar más. Y salimos a buscar más pibes para completar el equipo".

$<$ ref. $>$ P 1: Entrevista001S.docx.rtf - 1:2 [ (5:5)>

Identificamos un grupo de factores que resultan concurrentes: a) la exigencia por sumar jugadores a la división, b) la prematura participación en partidos - un sello de la experiencia compartido por todos los entrevistados-, c) el pronto reconocimiento de un agradable ambiente de compañerismo y la identificación de los que ejercen un liderazgo positivo, integrador. Este conjunto de características son las que definen un término de reiterado uso por parte de los entrenadores: el compromiso.

"J.A., El Turco A., que ahora vive en Estados Unidos. Hace como 30 años que vive allá. Fue a la edad de 8 años, me acuerdo que mi primer partido fue con el club $E$, yo fui a 
entrenar en la semana no recuerdo el día y en mi segundo o tercer entrenamiento ya estaba en cancha, con poco y nada".

$<$ ref. $>$ P 2: Entrevista002P.docx.rtf - 2:2 [ (11:11)]>

Los liderazgos no son referidos por los entrevistados como una experiencia natural o espontánea, sino como el fruto de las actitudes asumidas y transmitidas por aquellos que fueron sus entrenadores. Gestos que van del diálogo personal a la arenga grupal quedan comprendidos en esta práctica. Se destaca la perdurabilidad de esos gestos en el tiempo.

"Tuve muchos entrenadores [más adelante, los menciona a todos] desde los 9 años hasta que dejé de jugar de grande, a los 25 dejé de jugar del todo".

<ref.>P 4: Entrevista004X.docx.rtf - 4:4 [ (9:9)]]

"Mirá, el Tano era divino porque nos contenía mucho. Nos juntaba mucho. Hacía hincapié en la parte social. Terminamos siendo mucha gente".

<ref.>P 5: Entrevista005C.docx.rtf - 5:3 [ (10:10)]>

"Lo que me acuerdo, pero muy muy bien era que el pase había que hacerlo hacia atrás y al tacklear a alguien poner la cabeza en la cola del jugador, me acuerdo muy bien de eso. Dos cosas claras que jamás me voy a olvidar".

$<$ ref. $>$ P 2: Entrevista002P.docx.rtf - 2:3 [ (11:11)]>

No obstante lo expresado y su carácter general, es preciso señalar que el liderazgo ejercido y estimulado por sus entrenadores en el pasado en pos de fortalecer el compromiso grupal, tiene modalidades diferentes en la actualidad en los contextos en que cada uno de ellos se desenvuelve. Cada club ofrece situaciones distintas, con características, necesidades, deseos, expectativas y motivaciones que remiten tanto a la esfera de lo social como de lo estrictamente deportivo.

"Y... J. H., te juro que es un flaco puro, trabaja, estudia, el hijo que vos querés tener, empezó en pre intermedia, la peleó llegó intermedia, creciendo muy rápido, y ahora es casi indiscutido en plantel superior. Ese perfil de jugador quiero. A partir de él hay 
muchos más pero siempre con el mismo carácter: estudiosos, buenas personas, familieros, cabeza ovalada con el club; o sea de pertenecer: cuando se los convoca en el club, van; tienen que trabajar en el chulengo, van".

$\langle$ ref.>P 2: EntrevistaP.docx.rtf - 2:26 [ (51:51)]>

"Tendría 19 años más o menos, y cuando me acerqué me llamó la atención las personas con distintos grados (yo soy militar) que se trataban todos por igual y en la cancha todos se apoyaban, en los entrenamientos todos se aconsejaban y se hablaban, de cómo tenían que ubicarse y no bajar los brazos. Esa fue una experiencia muy importante para mí. Yo no había jugado al rugby, lo había visto por televisión".

$<$ ref.>P 3: Entrevista003A.docx.rtf - 3:4 [ (8:8)]]

\subsubsection{El entrenador, las exigencias y la hostilidad}

Los recuerdos se mantienen nítidos y los relatos ponen en evidencia las exigencias en las épocas de inicio y del rugby infantil. Se establecen claras diferencias entre lo que se hacía en ese momento y lo que en la actualidad podría llegar a ser aceptado: se evocan malos modos, emparentados con cuestiones militares, relacionados con motes, gritos y caracterizaciones que demostraban hostilidad.

"Era muy directo con lo que hacía, nos hacía correr. Hoy lo meterían preso por lo que nos hacía en ese momento, por los motes".

$<$ ref.>P 1: Entrevista001S.docx.rtf - 1:3 [ (5:5)]>

"Él, un ogro, una bestia. Muy gritón, y con una pedagogía que hoy no se puede ni practicar...".

<ref.>P 1: Entrevista001S.docx.rtf - 1:4 [ (5:5)]>

La mayoría de los entrevistados recuerda bien alguna característica personal, los nombres y los apodos de sus antiguos entrenadores. A medida que avanza cada entrevista, van apareciendo recuerdos ligados a las prácticas que ellos desplegaban, caracterizadas por una idea dominante: que los golpes eran buenos para formarse como jugadores; pero también se acuerdan de la 
estrategia que desarrollaron como jugadores para evitar tantos golpes: ir al piso (“...recuerdo hasta el olor al pasto de ese día...").

"De ese día me acuerdo hasta el olor del pasto casi, porque yo tenía miedo a golpearme, a caerme. $Y$ obviamente iba al piso cada 10 segundos [como una manera de protegerme]".

<ref.>P 7: Entrevista007M.docx.rtf - 7:2 [ (9:9)]>

"Yo tuve al cordobés, fue el cordobés siempre. Nadie lo conocía por otro nombre. Tuve a los mellis, que en ese momento uno no prestaba atención cómo se llamaba el entrenador. Mi entrenador era aquél: el grande, el gordo, el peludo, el pelado. Obviamente en ese momento la formación era todo a los golpes. Si bien se entrenaba, el entrenamiento era no llorar. Que los chicos no lloran. Y a matarse. Matarse, pasar la pelota y golpear al otro, pasar la pelota y golpear al otro, tacklear con uno, tacklear con otro hombro y si te dolía tenías que tacklear igual, porque había que hacer eso".

<ref.>P 7: Entrevista007M.docx.rtf - 7:6 [ (15:15)]>

La relación entre el entrenador de antaño y el jugador-actual entrenadorse describe como muy significativa. Los entrenadores asumen como meta hacer mejor a los otros, que sean mejores personas. Se entiende que con mayores cuidados o con mejor interacción, los entrenadores pueden exigir a sus jugadores mayor esfuerzo.

"...era bastante militar".

$<$ ref. $>$ P 1: Entrevista001S.docx.rtf - 1:6 [ (8:8)] >

"Yo estaba en el grupo elite, pero tenía amigos que estaban en el grupo "bazofia", él mismo lo decía. Muchachos: yo entreno con veinte".

$<$ ref. $>$ P 1: Entrevista001S.docx.rtf - 1:8 [ (8:8)]>

"Primero que confíen en sus destrezas y que sean líderes de su propia persona, no confiar en otro principalmente, después dentro de tu equipo".

$<$ ref.>P 2: Entrevista002P.docx.rtf - 2:7 [ (17:17)]>

Si bien, como se señaló, las entrevistas dan cuenta de que los actuales entrenadores reconocen que en el pasado existía una clara y directa relación directa entre mayor preocupación por parte del entrenador y mayor exigencia 
(y auto exigencia) por parte del jugador, habría que profundizar y complejizar ese vínculo. En primer lugar, la exigencia solicitada y esperada no se agotaba en lo deportivo sino, fundamentalmente, en lo emocional. Pero, conforme iba in crescendo este tándem preocupación y cuidados - exigencia y esfuerzo, también aumentaba la tolerancia a la hostilidad por parte del jugador. En segundo lugar, y aparentemente de manera paradojal con lo reconocido por los actuales entrenadores -que ponen de manifiesto una mirada crítica sobre la hostilidad de sus antiguos instructores- todos han continuado siendo jugadores y luego se integraron como entrenadores; aún más: han regresado con sus hijos al club. Se puede afirmar que, la fuerza de los mecanismos identificatorios es mayor que el peso de las críticas a las prácticas o las posibles bondades que el deporte trae consigo en materia de habilidades motoras, autoestima o hábitos saludables.

"Volví a entrenar con mis hijos. Con mi hijo más grande que ahora tiene 14, tenía 5. Lo empecé a llevar al club, no sé si ese año o al año siguiente, me obligaron a cruzar el alambrado, haciendo un poco de maestra jardinera".

<ref.>P 4: Entrevista004X.docx.rtf - 4:7 [ (11:11)] >

\subsubsection{El temor a empezar a jugar. Entender al jugador}

El temor a jugar, el temor al contacto físico, es un tema no siempre abordado de modo explícito; no obstante, conforme cada entrevista gana en profundidad, los entrenadores comienzan a hablar de este asunto como si estuvieran desafiando una suerte de tabú. En primer lugar, algunos de ellos admiten que llegaron de niños al club llevados por familiares que tenían una idea del rugby ligado a un juego brusco. Con lo cual se puede señalar una 
contradicción entre el mensaje familiar -que podría reforzar el temor aludidoy la práctica. Y a esta contradicción podría añadírsele otra: experimentar temor $y$, no obstante, querer jugar.

"Y según mi papá era un deporte muy brusco, mi familia no quería que juegue; pero cuando me abrí paso sólo en la vida, y pude hacerlo, lo hice".

$<$ ref.>P 3: Entrevista003A.docx.rtf - 3:3 [ (8:8)>

"Me acuerdo que me llevo mi papá, mi papá no jugaba a rugby, nada que ver con el tema rugby, me veía ahí siempre medio inquieto con la pelota y tenía a mi mejor amigo de toda la vida que vivía pegado a casa".

<ref.>P 6: Entrevista006D.rtf - 6:3 [ (6:6)]>

"Me acuerdo que no entendíamos nada, éramos dos...Fuimos un día martes y ya el día sábado estábamos jugando. No me lo olvido más, perdíamos con el club F. Pero muy lindo, lindo el ambiente, lindo el clima. Eso fue lo que nos atrapó y nos sedujo para continuar. La verdad no teníamos ni idea".

<ref.>P 5: Entrevista005C.docx.rtf - 5:2 [ (6:6)]>

Tal vez por esta misma situación, ponerse en el lugar del otro es una figura recurrente en los actuales entrenadores. Reconocen que es un verdadero conflicto interno el temor a empezar a jugar o a enfrentar las situaciones de contacto físico. Este reconocimiento enlaza su propia experiencia previa como jugadores con la experiencia de los jugadores que actualmente entrenan.

"Y recuerdo que me metieron en un partido, e hice lo que después vi muchas veces, que cuando venían a buscarme tiré la pelota. Entendí en esos pobres pibes el conflicto, el quilombo que tenían".

<ref.>P 1: Entrevista001S.docx.rtf - 1:5 [ (8:8)]] 


\subsubsection{Nadie hizo todo, todos hicieron algo}

En las entrevistas, los actuales entrenadores se acuerdan de cada entrenador de sus inicios de forma clara. Se destacan en los recuerdos dos elementos fundamentales: quién fue su primer entrenador y quiénes fueron aquellos que los hicieron sentir valiosos y los motivaron a seguir jugando. Entienden que sus entrenadores vieron alguna cosa buena o positiva en ellos y la fueron perfeccionando. Nombran aptitudes deportivas y de destrezas individuales, pero también la tan nombrada contención.

"Yo creo que B., el chicato R., ese grupo de gente me estabilizó en rugby, digamos. Pero no en lo deportivo. Yo no fui bueno hasta los 16, te diría. Mi cuerpo todavía no estaba preparado, era flacuchento, lento. No tenía puesto. Ellos me contuvieron en el grupo, en el grupo que había. Y recién en Menores de 16 me cambiaron de puesto, a tercera línea con otro carácter, con más confianza. En realidad de cada uno saco distintas cosas. $M$. $V ., D$. fueron tipos que indirectamente me fueron ordenando. Fueron marcando cosas, cuestiones de grupo, cuestiones de rugby. No puedo decir éste me hizo todo. Fueron distintas etapas y distintas necesidades. Creo que en determinados momentos resaltaba determinadas cosas, según la circunstancia personal".

$<$ ref. $>$ P 1: Entrevista001S.docx.rtf - 1:9 [ (11:11)] >

"A mí me formó de esa manera el turco que me llamaba todos los años para que siga entrenando, vio cosas que hacía bien y me las perfeccionó, y después vinieron otros entrenadores que siguieron con eso".

$<$ ref.>P 2: Entrevista002P.docx.rtf - 2:29 [ (55:55)]>

"Después hay varios que me marcaron".

$<$ ref.>P 4: Entrevista004X.docx.rtf - 4:5 [ (9:9)]>

Los entrenadores recuerdan e identifican los nombres de sus formadores, además de tener presente a cada uno. Esta situación es tomada como un valor en sí mismo. Por otro lado también refieren que esos instructores les fueron planteando distintas cuestiones, en distintas etapas y con diversas necesidades. Aceptan que algunos de sus antiguos entrenadores han hecho 
algún tipo de aporte y luego los siguientes formadores continuaron un posible hilo o al menos alguna idea en común. En sus reflexiones reconocen que han sido marcados por aquellos entrenadores, provocando en ellos aprendizajes "por goteo" (ver punto 2.8). Esta expresión repetida, en varias entrevistas, relaciona la situación de aprendizaje en situaciones puntuales que, en principio, no parecían significativas (ver punto 2.2.8.).

"De los entrenadores me acuerdo de todos, no tengo uno preferido porque siempre uno aprende lo bueno y lo malo también de cada uno".

<ref.>P 6: Entrevista006D.rtf - 6:4 [ (9:9)] >

"Me acuerdo de muchos, de casi todos. De M.V., el oso L., A.P. en juveniles. Después, el negro S., el cabezón, bueno un montón más. Mi primera experiencia como entrenador fue con la división de D.S., nosotros jugábamos en el estadio provincial. Un día un entrenador dijo si alguien le podía dar una mano un sábado a la mañana, yo era pibe, tenía 17 y fui a colaborar con los nenes. El otro día recordaba con D.S., uno de los referentes del club de 40 y pico de años, y esos fueron mis primeros pasos. Desde chiquito me gustaba el tema de la docencia. Fue una o dos veces, lindo, no me acuerdo mucho, pero me acuerdo de las pelotas número cuatro. Yo empecé a entrenar en el año 2000, 2001, 2002".

<ref.>P 5: Entrevista005C.docx.rtf - 5:4 [ (13:13)]>

\subsection{8. "Del resultado te das cuenta después"}

En distintos relatos se hace mención a la pasión de los entrevistados y cómo transcurría el día a día, demostrando que nunca habían perdido el entusiasmo. En sus palabras, de modo recurrente, se alude a los valores. Pero en torno a este término pueden distinguirse dos posturas: la de aquellos que los que los mencionan -sin decir cuáles, a pesar de su reiteración- como propios del rugby; y la de quienes hablan de los valores como "de la vida", "de las familias"

y sostienen que el rugby es el lugar y momento que permite aplicarlos, 
ponerlos en práctica. Los entrevistados cuentan los gestos, las acciones o los silencios de sus entrenadores como momentos importantes con el paso del tiempo. Lo interesante también es que no existe una charla inicial desde la cual se comienzan a desglosar los valores, sino que el mensaje -interpretan- es día a día, "por goteo" (expresión adelantada en el apartado anterior), un concepto que se practica y se va construyendo.

"Uno no se va dando cuenta como jugador de lo que se nutre todos los días. Hay pequeños mensajes que uno recibe y los asimila, no conscientemente. Vos vas a la Facultad y aprendes tal cosa. Pero el mensaje del entrenador es un mensaje por goteo. $Y$ tiene un proceso que el final lo ves al final. El resultado te das cuenta después. Yo estoy haciendo esto porque hacíamos tal cosa. No ves el programa antes".

<ref.>P 1: Entrevista001S.docx.rtf - 1:11 [ (12:12)]>

\subsubsection{El entrenador que jugó y el que no jugó}

En muchos momentos de varias entrevistas los entrenadores señalan una frontera entre quiénes han jugado al rugby y quiénes no han jugado. Los relatos evidencian un tema del que poco se habla "hacia afuera". Al presentarse esa tensión, todos los que han jugado conocen códigos, necesidades y saberes sobre los temas que están hablando.

"Si ha jugado es más fácil. Te lo digo asi".

<ref.>P 6: Entrevista006D.rtf - 6:13 [(25:25)]>

A su vez cuando comienzan a entrenar equipos, y con todas las actividades en marcha, se dan cuenta que necesitan más colaboradores en muchas posiciones, entrenadores incluidos; es entonces que aparecen mayoritariamente padres y madres que no han jugado al rugby a sumarse y colaborar. Los entrenadores admiten que los medios de comunicación han 
influido de manera positiva en la difusión del rugby, logrando que más personas se hayan acercado, aunque no todos han jugado previamente el deporte. La mayoría de los nuevos aficionados que se acercan a colaborar han tomado conocimiento del rugby gracias a la mayor difusión del deporte por la TV (más torneos internacionales o con más participación de argentinos) o a través de las redes sociales.

En otro orden, los entrenadores cuentan que en sus experiencias anteriores, un grupo de jugadores de la misma división o del mismo año de nacimiento -la "camada" es un término repetido que alude a la pertenencia dentro del club- puede hacer su desarrollo en los clubes y al llegar a edades de plantel superior (17-21 años), pero los que finalmente juegan o "llegan" y se mantienen son finalmente sólo unos pocos. Los clubes, a través de sus entrenadores, no parecen prestar atención a este desgranamiento que se produce a través de los años. Sí, en cambio, se considera a los jugadores que llegan a edades mayores y, comparado con los inicios, advierten que la cantidad es menor.

Es usual que quienes dejan de jugar en edades mayores, regresen al club acompañando a sus hijos. $Y$ entonces, algunos que han dejado de jugar se acercaron de otros modos: como managers, referís, dirigentes. Igualmente cuentan los entrenadores que la cantidad no es suficiente. Pertenencia e inclusión -asuntos que no forman parte de los debates de esta tesis- asoman como términos de interés para futuros abordajes del tema.

"Viste como es, dejás de jugar y decís hasta acá llegué, no jugás más. Y después cuando vas al club te sentís raro, viste. Los sábados [no sabés] qué hacer, los domingos... Los 
días de semana, martes y jueves en mi casa...".

$<$ ref. $>$ P 6: Entrevista006D.rtf - 6:7 [ (16:16)] >

\subsubsection{A la distancia, cambia}

Una vez más, el análisis de los entrenadores se vuelca sobre la propia práctica de manera autorreflexiva. En el presente, ellos entienden que las prácticas llevadas a cabo en los entrenamientos estaban automatizadas, como algo que obedecía a una especie de reproducción de aquello que venía de antes y que no era del todo pensado.

"Cuando me veo como jugador, he hecho cosas que estaban automatizadas. No pensando en la pelota, cómo sabía que la iba a agarrar, a quién se la pasaba. Estabas en cosas que se hacían automáticas. A qué cosas se le da prioridad, en qué foco se pone al ganar un partido. Yo no y hoy el foco no es en el partido, mirás más a largo plazo. Yo sólo veía mi división, no me importaba lo que hacían los pibes el año que viene; entonces por ahí le enseñaba jugadas, uno enseñaba táctica en $\mathrm{M} 12$, hoy ya sé que es una imbecilidad. Es una parte egocéntrica del entrenador, mira cómo le gano al club $C$, al club $D$. No se puede medir cómo enseñas en un año. Nadie ve eso, solamente ven los resultados de los partidos".

$<$ ref.>P 1: Entrevista001S.docx.rtf - 1:23 [ (31:31)]>

Nadie puede medir las enseñanzas ocurridas durante todo un año entero. Los entrenadores admiten que los demás (padres y dirigentes) sólo ven los resultados de los partidos. Comentan que cuando comenzaron en sus tareas como entrenadores sólo importaba su grupo, su división. Y ahora a la distancia, toman conciencia ellos mismos que el proceso de aprendizaje consta de muchas etapas y se enfocan en el largo plazo. Varios entienden que no alcanzaba con enseñar tácticas en edades tempranas, era un error pensar más en el gusto o interés del entrenador que en lo que el jugador necesita dentro de su proceso. 
"Empecé como entrenador mirando a un entrenador (J.) que había venido a darnos una mano al club. Observaba su forma de entrenar y la del G.G. que está en el club, y para mí fue muy bueno entrenar en el club. Que los chicos te devuelvan su afecto con un abrazo, con una sonrisa, lo que le estás tratando de decir".

$<$ ref.>P 3: Entrevista003A.docx.rtf - 3:5 [ (11:11)]>

Inclusive, reconocen, la forma de comunicarse ha cambiado, la forma de expresarse, es decir, cómo dicen lo que quieren que hagan sus jugadores. Notan que en el pasado la recepción al grupo era mayormente pasiva y que esa evolución expresa otra necesidad. El lenguaje emocionalmente estimulante lo identifican como positivo en virtud de cómo los jugadores reciben los mensajes.

"La forma de comunicarse, con los chicos es una. Antes se gritaba, se decía cualquier cosa, había que tenerlos cortos. Ahora no, se ofenden, se inhiben. Eso en lo comunicacional. Pero después yo enseñaba de un modo que no era progresivo. En el rugby, el tackle es un elemento muy importante. En ese momento se enseñaba como algo emocional. 'Tackleá, cagón'. 'Tackleá, porque hay que tener huevos'. 'Acá se juega al rugby y somos machos'. Después entró en otro proceso que tiene que ver con lo emocional, pero también hay un cambio de estructura mental, de pasos que hay que superar. Podés ser un macho bárbaro y no vas a tacklear. Porque no sabés hacer la técnica, para que sea más fácil. Era para cambiar el foco en vez de decirle que mariconeaste, ahora le decís "bien, estuviste casi cerca'".

$<$ ref.>P 1: Entrevista001S.docx.rtf - 1:22 [ (31:31)] >

\subsubsection{1. "Entrenás repitiendo como te entrenaban"}

Los inicios en la función de los entrenadores marcan pleno desconocimiento y una sensación de nuevo desafío. Como se adelantó en el apartado precedente, en las entrevistas dicen que comienzan su rol como entrenadores repitiendo cómo han vivido sus experiencias y haciendo las mismas prácticas y modos. Con muy poca información pueden observar e ingresar al rol de entrenador de forma progresiva pero dependiendo de la 
realidad de cada club estando a cargo de una división, de un grupo de niños y jóvenes como una alternativa concreta.

"Entrenas repitiendo lo que te entrenaban a vos, no era algo consciente". <ref.>P 1: Entrevista001S.docx.rtf - 1:12 [ (15:15)]>

"En ese momento ni sé lo que les decía a los chicos, repetís y debo haber dado conceptos fuera del foco para la edad. En esa época para los que no éramos profesores de educación física, pensar como si fuese un colegio la educación del rugby, para mí era impensable. Para mí con Cordero Biedma empezó a haber cierta estructura de niveles, de etapas".

<ref. >P 1: Entrevista001S.docx.rtf - 1:13 [ (16:16)]>

Describen en sus relatos que comenzaron a ser entrenadores casi sin darse cuenta y hasta dicen haber brindado conceptos que creían que eran correctos para la edad. El pensamiento en esos momentos de inicio como entrenadores era reproducir una práctica divertida y aprender, pero lejos de pensar una estructura de formación de jugadores.

"En ese momento nuestra Menores de 16 tenía bastante técnica individual, lo que le aportamos, lo que en ese momento se llamaba técnica individual, año 89... no había estructura de juego. ¿A qué jugamos? Era que los forwards conseguían la pelota y los backs eran bastante rápidos, de los cuales me acuerdo que salió un capitán M.G., el negro C. también jugó en superior, dos wingers que jugaron en superior".

$<$ ref. $>$ P 2: Entrevista002P.docx.rtf - 2:9 [ (23:23)]>

"Primero porque avanzó un montón el rugby sobre técnica individual y vos impones siempre las técnicas individuales, en ese momento había mucho menos estructura de juego mucho más entrenamiento de técnica individual, sobre todo aporte físico".

$<$ ref. $>$ P 2: Entrevista002P.docx.rtf - 2:10 [ (23:23)] > 
En las entrevistas repiten que además de intentar que los niños y jóvenes aprendieran el juego, también querían que incorporen técnicas individuales pero no estructuras de juego grupal. No nombran conceptos técnicos pero reiteran las formas y modos de entrenar que vivieron y cuentan que repitieron aquellas con las que se sintieron más reflejados. Refieren a la puntualidad, la vehemencia, la rigidez, la disciplina y los valores como un gran legado a transmitir. También la definición de estar hombro con hombro y espalda con espalda con el de al lado como concepto que, según ellos, los marcan "para toda la vida".

"A mí también me marcó mucho P.D., que también me entrenó. $Y$ con P. me tocó que él me entrene y ayudarlo a entrenar una división. Así que también, un tipo con mucha personalidad, con mucha vehemencia. Y con mucha (palabra que ahora está de moda en el rugby) mucha 'locura' para entrenar y para poder trasladar o transmitir lo que ellos saben. Eso me marcó y yo trato de ser analítico con mi forma de entrenar".

<ref.>P 4: Entrevista004X.docx.rtf - 4:10 [ (14:14)]]

"Entonces ese choque generacional provoca que a veces uno sea una barrera para poder transmitir. Si bien uno tiene la marca de los entrenadores, de $M$. tengo la parte de la rigidez en los horarios, en lo estricto, de que te metan en la cabeza que lo primero está el rugby. M. era un extremo, le decías a $M$. 'no vengo porque el martes tengo examen' y él te decía: 'hacé lo que quieras; si el martes no venís, el sábado no jugas.' Te ponía entre la espada y la pared. Hoy yo trato de aggiornarlo, y decirle que le den mucha bola al colegio en las horas que no entrenan, para que los padres no le prohíban venir a entrenar. Hay que darle una vuelta de rosca a eso, pero el espíritu es más o menos lo mismo".

$<$ ref. $>$ P 4: Entrevista004X.docx.rtf - 4:12 [(14:14)]>

"Lo que más me acuerdo que me ha marcado es la disciplina, por ahí no tanto, cuando uno empieza a estudiar, uno empieza a formarse y tomar su propia impronta. Pero sí rescato la disciplina, los valores, el grupo, el club, el no defraudar, estar hombro con hombro y espalda con espalda con el de al lado. Esas cosas fuertes que te marcan para toda la vida".

<ref.>P 5: Entrevista005C.docx.rtf - 5:6 [ (14:14)]] 
Incluso en ese transcurrir del rol de entrenador, se nombra un "rugby viejo" en contraste con uno más actual como modo de enseñanza. Cuentan que no se entrena más a los gritos, no se entrena más "se hace así porque se hace así". Antes no había fundamentos, había que hacerlo porque alguien dijo que había que hacerlo de esa forma.

"Yo cuando arranqué era un grupo de chicos que estaban formándose, la mayoría nunca había jugado al rugby y eran de multi edad. Infantil pero multi edad. Yo arranqué con un trabajo distinto al que me había tocado a mí. Arrancamos con juegos para perderle el miedo al golpe, perder el miedo al que es más grande, perder el miedo a caerme arriba de otro compañero, pero todo a partir de situaciones, (como) desde cuclillas, desde rodillas. No desde caer directamente, cosas que yo decía, bueno, esto tiene que ser distinto porque se van a ir todos. Y además eran cosas que habían cambiado de entrenar del rugby viejo. Ya se veía que no se entrenaba más a los gritos, no sé entrenaba más "se hace asi porque se hace asi". No había fundamentos antes. Había que hacerlo porque alguien dijo había que hacerlo de esa forma".

$\langle$ ref. $>$ P 7: Entrevista007M.docx.rtf - 7:9 [ (26:26)]>

"Claro, claro... cuando sos jugador lo que dice el entrenador, es lo que hay que hacer. Supuestamente él lo sabe, lo aprendió de alguien, y te lo transmite. Después cuando sos más grande te das cuenta que esa gente o esa persona que te forma a vos, no había tenido la formación pedagógica para ser entrenador. A él lo habían entrenado así, había aprendido de esa forma y él lo transmitía de la misma forma. Entonces se pasaba la pelota con una mano adelante, una mano atrás, no porque la aerodinámica de la pelota permitía que vaya más rápido, más lejos, sino porque era así. Y porque mundialmente era así, desde que se creó el rugby sería así...".

<ref.>P 7: Entrevista007M.docx.rtf - 7:10 [ (29:29)]]

Sin embargo los entrenadores ven que es muy bueno entrenar en sus clubes debido a que los niños y jóvenes les devuelven su afecto con un abrazo y con una sonrisa. 


\subsection{Del dato empírico a la elaboración teórica}

\subsubsection{El oficio del investigador: la construcción de biografías}

Como hemos adelantado en el punto 2.1., este capítulo recupera los datos más profundamente biográficos de los entrevistados; la utilización del término "profundamente" no es casual, ya que bajo este título se recuperan experiencias desde la infancia misma de los actuales entrenadores y se puede reconstruir con ellos una trayectoria vital y "profesional" (si asignamos a esta última expresión el sentido de la experticia en el oficio de enseñar rugby). Pero, ¿qué hay de valioso y significativo para esta tesis en la rememoración de la infancia y la juventud y en la reconstrucción de esas biografías? Trataremos de responder a esta pregunta.

Tal como dice Vargas (2000, citado por Cornejo, 2006), es posible construir una epistemología de los relatos de vida. Esa epistemología cuenta para la autora de cuatro dimensiones: constructivista (el sujeto entrevistado construye un relato a partir del entrevistador, con una determinada selección de experiencias), clínica (lo cual supone que, dado que el sujeto es fruto de una interacción o de una relación intersubjetiva, su carácter individual es expresión de lo universal), cualitativa (la recuperación de un retazo de experiencia lleva al sujeto a estructurar lo no estructurado) e interdisciplinaria (tiende a romper las fronteras entre campos disciplinares).

En este sentido, la asociación lejana entre infancia y juego (en este caso, el rugby) como así también familia y club es una genuina construcción de los entrenadores a partir de las preguntas de la entrevista. Que esos lazos estén 
presentes en todos ellos, permite confirmar el lugar que el rugby ocupa como experiencia vital y no sólo como una práctica anexa o aleatoria. Del mismo modo, la figura de los antiguos entrenadores, con sus luces (el compromiso grupal que generaban) y con sus sombras (los tratos hostiles) y el modo en que estas imágenes atraviesan a varios de los entrevistados, permite corroborar que ellos mismos son el efecto de interacciones sociales significativas y que hay algo en cada uno de ellos que pertenece al orden de lo universal. En esta línea de razonamiento, el reconocimiento del miedo como una experiencia clave que les permite articular su propio pasado con el presente de sus jugadores, habla de la capacidad de estructurar un dato presumiblemente "suelto" de su infancia e insertar este recuerdo en un rompecabezas que ellos mismos van armando, en un ejercicio tanto mayéutico como autoanalítico.

También de la mano de Cornejo nos llegan las ideas de Correa (1999), para quien el enfoque biográfico implica una triple opción: epistemológica (la realidad no es algo que esté por fuera del sujeto que la conoce), ética (la relación entre entrevistador y entrevistado debería percibirse como de mutua colaboración y no de oposición a partir de una escucha que genere confianza) y metodológica (consistente en romper el clásico límite entre la historia personal y la historia social de los sujetos).

Desde la posición señalada, no sólo aspiramos a una justificación epistemológica y metodológica de la estrategia adoptada para la recolección de datos, sino que entendemos que esa era la única vía razonable para que aparecieran ciertas imágenes tapadas por otras como una suerte de 
palimpsesto, o voces puestas en sordina. Nos referimos a la experiencia del temor que experimentan los jugadores y que lejos de poder reprimirse con facilidad, a partir de un discurso "del aguante" o de "largarlos" a la cancha prematuramente, se transforma en un aprendizaje a veces penoso por el carácter vergonzante que el miedo puede tener en un deporte como el rugby. Lo mismo sucede con la hostilidad, los motes descalificadores, las exigencias desmedidas de antiguos entrenadores: sólo el "cara a cara" y la complicidad implícita permitieron la emergencia del asunto. Pero a su vez, es esa confianza la que hace que se asome una relación contradictoria: pese a las críticas deslizadas sobre las prácticas de los entrenadores del pasado, ninguno de los actuales entrenadores comenzó en el "oficio" de entrenar de otro modo que no sea repetir lo mismo que vivieron. Con lo cual -sumado al hecho de llevar a sus propios hijos al club-, se confirma la idea de que los mecanismos de identificación (con el club, con el rugby, con los actores) son más fuertes que las razonables críticas al sistema de prácticas que se analizan.

\subsubsection{El oficio de entrenador: la construcción de una práctica}

Resulta evidente que es necesario plantear las relaciones y definiciones de las prácticas desde una perspectiva que no sea meramente instrumental sino crítica. Desde este punto de vista, es posible afirmar que se ha tendido a legitimar y reproducir la cultura dominante y las prácticas en el rugby definidas como un conjunto de saberes, valores, hábitos, esquemas y representaciones acerca de lo corporal que caracterizan a determinados grupos. Los relatos en 
las entrevistas de las distintas realidades en los clubes así lo muestran.

Dentro del rugby se ha colaborado con un proceso que naturaliza los usos, representaciones y construcciones que se identifican con las prácticas. Es decir que circulan como "naturales" dichos usos y representaciones y, por lo tanto, únicos posibles (o, al menos, "estándar").

Sin embargo, se ha extendido a lo largo de diferentes dominios de problemas vistos en los entrenamientos y partidos, el uso del concepto de práctica. Poder definirlo como medida a pesar de su extendida utilidad, podría atentar contra el alcance teórico y metodológico (Pinedo y luliano, 2015: 375). A pesar de ello, incorporar el concepto de práctica social en el nuevo entorno del rugby se sugiere como un aporte.

Tomamos como orden a Giddens (1991), quien expone que el dominio primario del estudio en las ciencias sociales no es ni la vivencia del actor individual (claramente los entrenadores en nuestro estudio), ni la existencia de alguna totalitaria societaria (más difícil de identificar en nuestro caso; aunque podría asociarse a esta totalidad la fusión de "vida de club", experiencia de juego y normas institucionales), sino las prácticas sociales ordenadas en un espacio-tiempo. Además Bourdieu (1991) sostiene que lo propio de la lógica de lo social se identifica con la lógica práctica: con la capacidad que tienen los agentes de participar del juego social sin seguir de manera consciente ninguna regla, sino incorporando (como habitus) "el sentido de juego" a lo largo de su proceso de socialización.

Dentro de lo que entendemos como oficio del entrenador, se brindan 
algunas pistas en la construcción de lo entendido como práctica. Bajo esta mirada, las prácticas se desarrollarán según la formación de los entrenadores, estableciéndose un papel fundamental en las enseñanzas y los acompañamientos técnicos, tácticos y afectivos dirigidos a los jugadores, como así también los sistemas de prestigio y reconocimiento que se desean obtener como contraparte.

En la sociedad occidental actual, el rugby forma parte de las actividades y los consumos culturales que cada vez más personas practican y consumen en su tiempo libre. Estas prácticas asumen características diversas de acuerdo a la posición en el espacio social de los entrenadores, variando el tiempo que se le dedica, el sentido y la relevancia que se les atribuye en el marco de cada biografía, entre otros aspectos. A su vez, estas prácticas -en tanto "actividades físicas"- implican la realización de acciones que involucran fuerza o habilidad, llevadas a cabo en forma de juego o competencia, en el marco de ciertas normas o reglas de juego que deben respetarse y que reducen al mínimo el riesgo de daño físico de los competidores (Elías y Dunning, 1992). 


\subsubsection{El oficio de entrenador: la adquisición de un capital}

Sin lugar a dudas la adquisición de un capital dentro del rugby, se entiende como punto importante en el presente trabajo. El campo comenzaremos a definirlo como un espacio conformado por un conjunto de relaciones objetivas impuestas e irreductibles respecto de la voluntad de los agentes. Agregamos que para Bourdieu (1990:282-283) el campo es un espacio social organizado en torno a posiciones e interacciones objetivas; esto puede observarse con relativa facilidad en el rugby: diversos agentes pugnan por la producción, distribución o apropiación de un capital, en este caso tanto cultural como social o simbólico (este aspecto se desarrollará en mayor profundidad en el capítulo 3. Formación).

Se puede visualizar que aquí también los agentes se distribuyen en los distintos clubes de rugby en primer lugar por el capital global que detentan (o creen detentar) y en segundo lugar por la composición del capital específico que se pone en juego en ese campo. Se distribuyen por el volumen y el peso relativo de distintas especies de capital (experiencia, conocimiento) en el conjunto de las posiciones, determinando posición en un campo. La distinción, entre los propios entrenadores, respecto de aquellos que jugaron rugby y aquellos que no, resulta una invocación explícita a ese capital. Del mismo modo, opera el prestigio de ciertos clubes respecto de otros: tradiciones, identificaciones y pertenencia forman también parte del capital aquilatado.

Siguiendo la propuesta de Bourdieu, los entrenadores en ese campo poseen intereses, creencias y valores jugando un juego a partir de una imagen 
que poseen de ese campo y de las relaciones dentro de ese campo. El sentido práctico de Bourdieu (1996: 65-66; 79-80) es la posibilidad concreta de jugar ese juego, de hablar una lengua que lo incluye y lo transforma en un productor de estrategias dentro de ese campo.

Dentro del espacio social determinado, el habitus es un principio, una disposición que hace percibir, valorar y accionar en un campo: un cierto tipo de capital y no de otro y una cierta posición en ese campo. Ciertas experiencias que se incorporan tienen como resultado visualizar como inversión el acopio de una forma de capital y no de otras (Uro, 2015: 274). Por esta razón es necesaria una reconstrucción de las biografías de los entrenadores que incorpore otros aspectos -en principio, aparentemente insignificantes- pero que actúan como "depósitos" en la "cuenta" del propio capital disponible: haber organizado viajes, haber participado en giras como jugador o entrenador (tanto más valiosas cuanto más "rugbísticos" fueran los destinos), tener un "directorio" de contactos amplio de otros entrenadores (de la ciudad y del país), tener mucho "vestuario", etc.

Si se acepta que en el rugby se debería permitir la producción y la circulación de la idea de distintos capitales y habitus, cabe también la posibilidad de preguntar(se) por ciertos mitos más o menos instituidos: para ser buen entrenador, ¿̇es más importante haber jugado o haber estudiado? El nivel de competencia alcanzado como jugador, ¿garantiza la forma de ser entrenador? ¿En qué debería consistir la actualización permanente del entrenador si evitamos soslayar el capital que detenta? Inclusive, a partir del 
encuadre producido por los anteriores interrogantes, podemos formular nuevas y específicas preguntas sobre aquello que forma parte de la cotidianeidad de las prácticas: ¿Qué tipo de objetivos se persigue con las distintas prácticas? ¿Qué se busca con las prácticas cuando los cuerpos experimentan exigencia? Las prácticas vividas como jugador, ¿̇son una guía útil para sus nuevas prácticas como entrenador? ¿Existen prácticas para la toma de decisiones por parte de los jugadores? ¿De qué manera se expresan?

\subsection{Bibliografía del capítulo}

- Bourdieu, P. (1996). Cosas dichas. Barcelona: Gedisa.

- Bourdieu, P. (1996). El sentido práctico. Buenos Aires: Siglo XXI Editores.

- Cornejo, M. (2006). “El Enfoque Biográfico: Trayectorias, Desarrollos Teóricos y Perspectivas". En PSYKHE, Vol.15, N. 1, 95-106. Disponible en: http://dx.doi.org/10.4067/S0718-22282006000100008

- Elías, N. y Dunning, E. (1992). Deporte y ocio en el proceso de la civilización. Madrid: FCE.

- Giddens, A. (1991). La constitución de la sociedad. Bases para una teoría de la estructuración. Buenos Aires: Amorrortu.

- Pinedo, J. y luliano, R. (2015). "Prácticas sociales". En Carballo, C. (coord.) Diccionario Crítico de la Educación Física Académica: rastreo y 
análisis de los debates y tensiones del campo académico de la educación física en Argentina. Buenos Aires: Prometeo Libros.

- Uro, L. (2015). "Habitus, capital”. En Carballo, C. (coord.) Diccionario Crítico de la Educación Física Académica: rastreo y análisis de los debates y tensiones del campo académico de la educación física en Argentina. Buenos Aires: Prometeo Libros. 


\section{FORMACION}

\subsection{Sobre el contenido de este capítulo}

Tal como se adelantara en el punto 2.1., en este capítulo persiste la estructura del anterior: en primer lugar, el relevamiento de las categorías nativas agrupadas en torno al eje "formación", de manera tal que se facilite el análisis de esas expresiones; como en el capítulo precedente, se sigue el doble curso de analizar pormenorizadamente los dichos de los informantes evitando que se disgregue su discurso y mantener la teoría en estado latente para no cargar prematuramente de significados forzados a los fragmentos seleccionados. En segundo lugar, se contrastan los fragmentos de discurso con las fuentes bibliográficas que remiten a desarrollos teóricos relativos al tema. Nuevamente, se pone a prueba el recorte efectuado en el análisis empírico y se dota de mayor generalidad a los enunciados de los actores para ofrecerles un horizonte que los conecte con problemáticas de similar tenor.

Si el capítulo anterior aludía de manera directa a la biografía de los entrenadores de M14, en especial, a su infancia, su juventud y sus primeros pasos como formadores de niños y jóvenes, en el presente apartado destinamos nuestro esfuerzo a reflexionar sobre la formación de los entrenadores para el ejercicio de esa función. En este marco, resulta visible la presencia de una matriz de formación que, aunque matizada, revela elementos en común. Esa matriz está constituida por un sinfín de elementos, desde el reconocimiento por los antiguos entrenadores -cargado de una cuota 
de emoción adicional-, hasta el reconocimiento de la necesidad de formación y capacitación complementaria y continua, pasando por la asunción de una actitud crítica que creemos honesta.

Este complejo de situaciones, escenas y actores abre paso a la comprensión de una subjetividad en acto en la que se identifican valiosas cristalizaciones: la convicción -a pesar de los errores cometidos y lo que resta por aprender- de "ser entrenadores"; la importancia otorgada a la transmisión de valores que, aunque considerados constitutivos del rugby, adquieren la forma de un "plus" educativo; la necesidad de adoptar una actitud apasionada. A simple vista, estos elementos parecen suplementarios, pero forman parte del programa de formación no escrito, pero seguido a pie juntillas por los instructores.

Lo expresado anteriormente encontrará eco en los estudios de Pampliega de Quiroga, quien pondrá énfasis en los vínculos como situación social en la que el sujeto emerge y se reconoce como tal. Esta dimensión social inscripta en la condición de los entrenadores no sólo permite recorrer su formación no formalizada y fragmentaria- como un conjunto, sino que ofrece también justificativo epistémico a este trabajo de naturaleza cualitativa. Desde esta plataforma, -y con la ayuda que nos ofrecen Turner et al. y también de Devís Devís y Wein, entre otros- no resulta extraño que los entrenadores se muestren permeables a una formación -la cual, a su vez, desborda en las formas de enseñanza- inclinada a modelos basados en la resolución de problemas.

\subsection{Análisis de las entrevistas a los entrenadores}




\subsubsection{Matriz de formación}

Siguiendo la línea de haber recibido una formación y similares vivencias previas, la opinión de los entrenadores nombra una "estructura". Hay varias opiniones al respecto. Algunos no la identifican como tal, como una matriz que estampa la formación; otros opinan que debería corresponder a los propios clubes establecer las líneas rectoras del tipo de juego y jugadores que se espera formar; están quienes entienden que los clubes con más organización podrían colaboran con aquellos menos organizados; y hasta existe la opinión de que la bajada de línea debería corresponder a la unión de rugby regional (URBA).

"Creo que tengo la formación de los entrenadores de Neuquén. Los entrenadores de La Plata, cuando yo llegué a jugar, ya tenían una estructura."

$<$ ref. $>$ P 1: Entrevista001S.docx.rtf - 1:7 [ (8:8)] >

"Esa estructura debería ser de esa manera. La URBA entrenar entrenadores que entren a [otros] entrenadores".

<ref.>P 4: Entrevista004X.docx.rtf - 4:30 [ (39:39)]>

En las opiniones de los entrevistados se encuentra presente la intención -y la necesidad- de formar formadores y que los entrenadores puedan disponer de más información y herramientas para aportar a los jugadores en los clubes. Incluso la incorporación necesaria de recursos humanos de ambos sexos, con el concepto de pareja pedagógica, proveniente de programas de cooperación con la Universidad Nacional de La Plata (UNLP), ha marcado una experiencia que se destaca en algún caso. No obstante, no identifican una guía clara con la cual continuar o a la cual replicar, ni qué aspectos puntuales deberían ser tenidos en cuenta. Sin embargo, coinciden 
en asegurar el correcto proceso del aprendizaje por encima de resultado inmediato.

"En el año 99 cuando yo estaba en la facultad, yo estaba en segundo año, había un plan que estaba haciendo (el club) D. que era llevar profesores o estudiantes de educación física y profesoras para trabajar en las categorías, o sea un hombre y una mujer como pareja pedagógica. Una compañera mía había entrado a trabajar y cómo sabía que yo había jugado, en ese momento había dejado, me dijo si quería. Mandé un currículum y la profe que coordinaba eso era profe nuestra en la facultad (era M.B.). Ahí arrancamos. Me tocó con una chica que se llamaba L. que era de Tapalqué y entrenamos a la M10, hacíamos una parte física, de juegos y después tenían sus entrenadores que daban la parte de rugby. Esa fue la primera experiencia, vamos a poner "como entrenador".

$\langle$ ref. $>$ P 7: Entrevista007M.docx.rtf - 7:7 [ (18:20)]>

"Al año siguiente volví a quedar con el mismo grupo de entrenadores y con la misma chica y pasamos a M9. Y ya al año siguiente que ya se pasaba a Octava, cambiaba con 12 jugadores, con más reglas y [era] otra cosa, quedé con uno de los entrenadores como entrenador. Igual el plan siguió con las profesoras y los estudiantes, con mucho recambio de profesores y estudiantes. Pero bueno, yo ahi seguí, estuve dos años con Octava y después pasé a lo que ahora es M15". $<$ ref. $>$ P 7: Entrevista007M.docx.rtf - 7:7 [ (18:20)]>

"En Octava había chicos que ahora están jugando en primera en el club, y yo los veo [hoy] y son enormes, pero en ese momento eran nenes. Te estoy hablando del año 2000, cuando me tocó en ese año Octava". $\langle$ ref. $>$ P 7: Entrevista007M.docx.rtf - 7:7 [ (18:20)]>

Se alude a una matriz de formación, representada por el paso por diferentes divisiones infantiles y juveniles como jugador y por "la mano" de los entrenadores que los tuvieron a cargo, a lo cual se agrega "el sello" (real o supuesto) del tipo de rugby que se practica en cada club. Pero, aunque los entrenadores denominen "estructura" a este complejo de marcas, debe reconocerse que la misma está confeccionada de manera fragmentaria, en base a experiencias puntuales y muchas veces carente de un horizonte 0 plan de acciones a futuro. 


\subsection{2. "Me siento entrenador de rugby"}

"Cuando yo dejé de jugar, la forma principal de seguir ligado al juego es la de ser entrenador. No había otra opción. Era dejar de jugar y entrenar cualquier categoría. Obviamente, el sueño de todos es entrenar un Plantel Superior pero tenés que estar preparado para eso. Arrancamos con infantiles tipo castigo, y después te va gustando eso y vas subiendo, cada vez más con el mismo grupo o en un momento te llega el famoso 'bueno, tenemos una M19 para vos'. Para mí entrenar es continuar tu formación como jugador, porque el jugador en algún momento se acaba. Por la vida misma, por alguna lesión, porque no hay tiempo para seguir jugando, el mismo juego te superó. Lo que tenés para seguir es o ser dirigente, o ser entrenador. Yo lo primero que me planteé es ser entrenador". $<$ ref.>P 7: Entrevista007M.docx.rtf - 7:15 [ (38:38)]>

Las entrevistas ponen en evidencia que los informantes disfrutan de su condición de entrenador de rugby. Y el sueño de muchos de ellos es entrenar un plantel superior o una primera división. ${ }^{12}$ Como vimos con el fragmento de entrevista anterior y como se podrá apreciar con el que sigue a este párrafo, se conjugan en ese placer por entrenar elementos muy variados, sino directamente opuestos. Por una parte, el afán por "marcar" al jugador joven con la enseñanza, para lo cual -plantean- eso sólo ocurrirá si existe una base de confianza (tienen que creer en lo que les dice): cuando eso se logra, manifiestan que sienten plenamente "ser entrenadores de rugby". Por otro, cierta devaluación de la figura del entrenador de divisiones infantiles -que son las consideradas tradicionalmente "formativas"- ("castigo") y mayor reconocimiento del entrenador de las divisiones mayores (premio).

"Pero en el concepto mío, en lo que a mí me gusta es algo que algunos entrenadores lograron hacer conmigo. Es dejar una marquita, una mella, al pibe, que entendió algo que vos le dijiste. O que le sale algo. La base es la confianza que te tiene a vos y cree en los que le decís. Cuando lográs eso, yo me siento entrenador de rugby". $<$ ref. $>$ P 1: Entrevista001S.docx.rtf - 1:20 [ (28:28)] >

12 Plantel Superior: Grupo de jugadores de rugby de 20 años de edad o más. 
Es curioso, pero de ninguna manera raro, que los entrenadores hablen de formar cabezas ovaladas. Un término que circula por el rugby y que se expresa en identificarse con el club, con los compañeros, asumir actitudes de respeto; en suma, pensar en términos de rugby todo el tiempo.

"A mí me gustaría que sea formador de cabezas ovaladas, que al chico le guste mucho el rugby y ser cabeza ovalada, además de ser buen chico y buena persona, es que tenga una pertenencia muy profunda con el club, con sus compañeros, con el grupo, con el equipo. Ser cabeza ovalada es el que va a todos lados junto con su equipo, con su grupo y siempre quiera seguir aprendiendo; que no sea el cancherito que te tire una y te la muestre. Que la haga si quiere, sin faltar el respeto a nadie. Pero que sea formador de cabezas ovaladas".

$<$ ref. $>$ P 2: Entrevista002P.docx.rtf - 2:28 [ (55:55)]]

Otros describen que en las edades formativas deben trabajar con todos los niños y jóvenes con el objetivo de hacerlos mejores jugadores. Que los jugadores crean en los entrenadores y poder sacarles un "plus" dentro de la cancha para seguir mejorando. Entienden también que cuando aumenta el número de practicantes es un indicador positivo, ya que esto se debería a la contención realizada y que desborda en una mejora del juego.

"Poder hacer un análisis del grupo, no todos los grupos son iguales, hacer un primer análisis, ver en qué condiciones están, tanto de grupo como deportivamente están, y planificar a partir de ahí. Y no llevar adelante un plan sin ver lo que uno, de los jugadores que me parece, que es la clave del entrenador. Laburar el material con el cual cuenta para y poder hacerlos mejores".

$<$ ref. $>$ P 4: Entrevista004X.docx.rtf - 4:17 [ (17:17)] >

"Laburo mucho en la semana, apuntar para corregir o lo que uno quiere el sábado, o el domingo, trabajamos bastante, me gusta, como te dije hoy, trabajar mucho en lo que es la cabeza del jugador, de poder convencerlo, y saber [que]lo que uno hace está bien. A medida que van pasando las divisiones, los resultados, por ahí, es lo que manda. El sábado o el domingo el día del juego soy un buen entrenador, un buen convencedor, 
para que la gente crea en cada uno de ellos. Siempre trato de sacarles ese "plus", que buscamos que el jugador deje dentro de la cancha".

<ref.>P 5: Entrevista005C.docx.rtf - 5:14 [ (29:29)]>

De todas maneras, no sólo evalúan su propio desempeño como entrenadores a partir de los resultados deportivos o de la formación del carácter de sus jugadores. También sostienen que retener jugadores y ofrecerles contención es señal de una buena tarea realizada. En este sentido, es posible afirmar que en este plano vuelve a reflejarse el compromiso de dejarle al club no sólo mejores jugadores sino más jugadores para las divisiones siguientes.

"Para nosotros es fundamental en infantiles crecer en gente, si creciste en gente, hiciste un buen laburo de contención, y la contención también llega al juego".

$<$ ref.>P 5: Entrevista005C.docx.rtf - 5:18 [ (37:37)] >

\subsubsection{El entrenador se ve desde afuera}

Cualquier análisis externo, como si el entrenador fuese ajeno a su propia práctica, les resulta complejo; y más aún cuando la pasión es tan intensa que no permite intercambiar roles y limita la posibilidad de ponerse en el lugar del otro. Mencionan que ser quien conduce un grupo de niños y jóvenes que juega al rugby y transmite saberes y valores los hace sentir dueños, pudiendo decidir sobre todo. Entonces reiteran que como el entrenador ya aprendió y ya lo hizo, está en condiciones de poder mostrar "cómo es la cosa".

"En general el entrenador de rugby eras como el dueño de la división, y medio el kapanga. Yo ya lo sé, yo ya lo hice y se lo explico a los pibes. Una cosa asi".

$<$ ref. $>$ P 1: Entrevista001S.docx.rtf - 1:18 [ (25:25)> 
"Nunca entrené divisiones grandes porque no me interesa a mí salir campeón, decir qué bueno que soy... cómo sé de rugby..."

<ref.>P 1: Entrevista001S.docx.rtf - 1:21 [ (28:28)]>

No parece importar mucho cuánto se sabe al inicio. La responsabilidad al frente de un grupo de rugby ha sido asumida y entonces, aún sin entender demasiado sobre enseñanza, como ya manifiestan que "conocen todo del rugby", los entrenadores sólo hacen que los niños y jóvenes practicantes hagan lo necesario para llegar al try. Admiten que como ya han adquirido el conocimiento sólo queda transmitirlo. No saben si llegarán en su carrera de entrenadores a poder hacerse cargo de algunas divisiones juveniles y hasta divisiones mayores.

"Lo que nosotros hicimos [no tiene] nada que ver [con] lo que ahora tienen que hacer los chicos. Te ponen 40 chicos, no entendés nada y hacés lo que ya conocés. Vas a que los pibes hagan try...".

$<$ ref.>P 1: Entrevista001S.docx.rtf - 1:19 [ (25:25)]>

Los entrevistados admiten que la seguridad en aquellos tiempos no era lo primordial. El prisma propio permite ver con el tiempo que algunos hacían "barbaridades" en la enseñanza del rugby, como enfrentar niños en distancias no muy cercanas para que se realicen un tackle. ${ }^{13}$ Recuerdan algunos golpes debido a esta situación.

13 El tackle es el elemento usado por el equipo defensor para detener el avance del equipo atacante y le brinda una oportunidad al equipo defensor de disputar la posesión de la pelota. "Un tackle ocurre cuando el portador de la pelota es agarrado por uno o más oponentes y derribado al suelo." (Ley 14. Leyes del Juego de Rugby. World Rugby, 2018). 
También admiten errores en la enseñanza y práctica del scrum, ${ }^{14}$ sobre todo con riesgo en la salud y el cuerpo de los niños.

"Ante nos ponían en una línea a 5 metros y uno contra uno aprendíamos a tacklear. Una barbaridad, y lo hice mil veces... más o menos parejos en peso, pero yo lo hacía mal. En el scrum hice miles de errores. Cosas que ponían en riesgo el físico de los chicos. No se valorizaban".

<ref.>P 1: Entrevista001S.docx.rtf - 1:38 [(50:50)]>

En los relatos recogidos los entrenadores admiten que han cambiado durante su propio proceso del aprendizaje. Muchos les piden a los chicos que realicen tackles "positivos", 15 pero comienzan a pensar si ellos mismos los hacían y cuántos tackles positivos llegaron a hacer los propios entrenadores en su época activa. Ese análisis permite bajar las expectativas y exigencias a los actuales jugadores.

"Los entrenadores de mi división empezaron a entrenar: gritar 'itackle positivo!' A reclamarlo. En un momento, los junté y le dije, sin ofender y poniéndome yo de ejemplo: '¿Saben cuántos tackles positivos hice yo en mi vida?' Tres, cuatro... ¿Quién hizo tackles positivos más que yo?' Entonces ojo con la teoría para otros; porque desde la tribuna somos todos Maradona, pero hay que ponerse en la realidad... ¿Cuántos tackles positivos podemos hacer...? Y el contexto era M14... el entrenador se focaliza en los objetivos y en lo que hay que hacer y lo quiere repetir, lo exige. Esperá... es muy difícil hacerlo. Requiere de un proceso que lleva tiempo, no es sólo para ahora".

14 Un scrum se forma en el campo de juego cuando ocho jugadores de cada equipo, asidos en tres líneas por cada equipo, se juntan con sus oponentes de modo que las cabezas de las primeras líneas quedan intercaladas. Así se forma un túnel en el cual el medio scrum (posición de un jugador que enlaza a los delanteros o forwards con los backs o tres cuartos) introduce la pelota para que los jugadores de las primeras líneas puedan disputar la posesión hookeando (trayendo con el pie) la pelota hacia atrás. (Ley 19. Leyes del Juego de Rugby. World Rugby, 2018).

15 El tackle positivo es el gesto realizado según el reglamento donde el objetivo es, además de recuperar la pelota, tacklear más allá de la línea de ventaja, lo que en la práctica sería equivalente a hacer retroceder al rival portador de la pelota. (Manual de Rugby Ready. World Rugby, 2018). 
<ref.>P 1: Entrevista001S.docx.rtf - 1:40 [ (50:50)]>

Cuando decimos que el entrenador "se ve desde afuera" nos referimos a esta capacidad autocrítica que fluye con bastante facilidad cuando se produce la escucha y se valoran sus saberes. Llamativamente, no sólo se juzgan severamente por lo que han enseñado y cómo lo hicieron, sino que reconocen que hablan más para escuchar su propia voz que por la necesidad de transmitir un determinado saber.

"Lo otro que hemos mejorado con el tiempo es, cada vez que parábamos a explicar, te repito que [soy] crítico conmigo como entrenador, pero nosotros como entrenadores, sentía que... hay muchos entrenadores que siento que nos gusta escucharnos hablar. Nos gusta nuestro tono de voz. Entonces pasamos mucho tiempo hablando. Y hay [que] modernizarse y entender que los chicos quieren todo ya, si le hablas más de 5 minutos, el minuto 6 ya no te escucharon. Entonces esa atención se logra, me parece, corrigiendo con el ejercicio andando. Y eso hace que los chicos no paren entrenar".

<ref. $>$ P 4: Entrevista004X.docx.rtf - 4:22 [ (30:30)]>

A pesar de la apertura a la crítica, los entrenadores también exhiben repliegues, por ejemplo al admitir que "ya están formados" y que todo lo que tienen que hacer es transmitir lo que saben. Pero, al continuar la conversación, reconocen que la época en que se formaron como jugadores es distinta a la de sus jugadores actuales. Es decir, que el ejercicio de la propia charla los va enfrentando a las propias contradicciones.

"Porque por más que entrene chicos chiquitos le doy mucha bola a cómo entreno, y parte de la evolución fue que en algún momento somos entrenadores formados o marcados, ya que uno se trae la imagen de quién a uno lo entrenó, para entrenar. Es eso, se transmite y trato de evolucionar, porque me he dado cuenta que muchas veces somos entrenadores formados en los 80, o en los 90, entrenando chicos del 2020". $<$ ref. $>$ P 4: Entrevista004X.docx.rtf - 4:11 [ (14:14)>

Describen que cada vez hay más niños y jóvenes jugando en los clubes, tomando esto como una afirmación de que las cosas "se están haciendo bien". 
Aun admitiendo que no tienen suficiente formación como entrenadores, disfrutan ver crecer a los niños y jóvenes. Finalmente los entrenadores entrevistados relatan que al dejar de jugar, para mantenerse unidos siguen entrenando a otros "para mantenerse vivos..."

"Ya cuando uno deja de jugar, para mantenerse unido, para mantenerse vivo, sigue con esto de lo que es entrenar".

<ref.>P 5: Entrevista005C.docx.rtf - 5:5 [ (14:14)]>

"Con respecto a nuestras evaluaciones, creemos que fue un buen año, un muy buen año, después de que el entrenador que colaboró con nosotros (J.) dejó de acompañarnos, teníamos menos de 15 jugadores y llegamos a tener cerca de 32 chicos. Se empezaron a sumar, incluso fuimos a clubes de fútbol, que en primer lugar nos miraron sorprendidos, y cómo que nosotros le íbamos a sacar los chicos, yo les aclaré que no, pero fue muy bueno porque hubo chicos de clubes de fútbol que vinieron a entrenar con nosotros un par de veces. $Y$ muchos chicos vinieron a entrenar. También fue muy bueno por los padres que vinieron, no tengo nada de qué quejarme. Sino al contrario siempre sumar". $<$ ref.>P 3: Entrevista003A.docx.rtf - 3:17 [ (35:35)]>

"Es según el carácter de cada uno, yo por el mío, y por mi forma de ver el rugby, los veo a los entrenadores que entrenan escuelita, M6 y M7 y pienso que hay que cuidarlos mucho porque, no hay mucha gente que se pueda dedicar, más que nada los varones en general de nuestra edad, no tenemos formación para atender a 30, 40, 50 chicos". $<$ ref. $>$ P 4: Entrevista004X.docx.rtf - 4:8 [ (11:11)]>

En este ejercicio de mirarse desde afuera, reconocen que es indispensable cuidar a los entrenadores que se dedican a los más pequeños, porque aún sin los conocimientos necesarios cubren una función indispensable.

\subsubsection{La formación de un entrenador de rugby}

"Lo que hoy pasa es que vas tomando aprendizaje por error, por práctica. Yo creo y estoy convencido que debería haber un proceso de formación de entrenadores, en los clubes. Debería estar como un ítem que no se hace. Lo que vos estás proponiendo, cada vez que hay un curso de algo van 100 tipos. Porque la parte teórica es importante, en los clubes 
tendría que hacerse mesas de charlas, mesas de cambio de experiencias. Porque a veces uno está convencido que ve una cosa porque nadie le mostró la otra cosa. Descubro algo nuevo y me doy cuenta, es cierto. Entonces ese proceso de aprendizaje primero es práctico".

$<$ ref. $>$ P 1: Entrevista001S.docx.rtf - 1:28 [ (37:37)]>

Los entrevistados expresan su necesidad de formarse para poder dar respuestas y sentirse seguros como entrenadores, responsables de un grupo de niños y adolescentes. En varios casos, reclaman poder complementar la formación del entrenador relacionándolo con una gran cantidad de capacitaciones existentes. Entienden que esa formación, además de ser un proceso continuo, podría incorporar mesas de charlas e intercambio de experiencias. Si bien admiten la importancia de la práctica y de un proceso de aprendizaje, también dicen que sus repetidas prácticas fueron llevadas a cabo como respuesta a no haber vivenciado otra opción. "Nadie nos mostró otra cosa". Se vislumbra, entonces, que las virtudes del entrenador son la percepción, el manejo de grupo, la comunicación, pero todo eso ha sido incorporado sólo a través de la propia práctica.

"El entrenador tiene algo que es percepción, cosas de percepción que se ganan con el tiempo. De manejos de grupo, de comunicación, es más complejo, para mí... Y requiere de algo que sólo te dan las batallas, en la trinchera. Entonces creo que tiene una etapa de práctica y el club tiene que preocuparse de darle contenido a esa parte práctica". <ref.>P 1: Entrevista001S.docx.rtf - 1:29 [ (37:37)]>

Refieren que la sola lectura de un texto de una personalidad reconocida legitima el contenido en cuestión y la práctica como entrenador. Además lo reafirman con haber jugado en esos puestos de la cancha, dándole un valor agregado. Con este complejo de experiencias, dan por descontado que aquello que enseñan está bien hecho; de este modo, la legitimidad se condensa en la 
fórmula: palabra autorizada + experiencia como jugador (en especial, si se trata del mismo puesto) $=$ conocimiento legítimo .

"Recién en el 2011, primero empecé como entrenador de pateadores, yo fui pateador, y empecé a seguir al entrenador de Wilkinson que se llama Dave Alred, tipo que además de entrenar hace clínicas, sacó un libro muy importante de presión, con Wilkinson en la tapa, entrenó a Carter también y entrenó golfistas con respecto a la parte de cómo entrenar la cabeza y la postura; porque un pateador y un golfista o un tenista tienen situaciones similares, en la postura, en la biomecánica. Entonces me adentré en ese aspecto con respecto a los pateadores, individuales". $<$ ref.>P 2: Entrevista002P.docx.rtf - 2:14 [ (26:26)]]

Otro elemento que se destaca es la impronta personal de los entrenadores, su propio gusto o paladar rugbístico, pues se nombran las preferencias por el rugby del hemisferio norte o del hemisferio sur, destacando las formas de juego más ordenadas o más desestructuradas, respectivamente. A partir de esas preferencias de estilo, se inclinan a incorporar conocimientos de uno u otro "rugby".

"Yo saco muchas cosas del juego australiano, me gusta más que el neozelandés. El neozelandés hace todo perfecto, pero es muy estructurado. El australiano es más desestructurado, he visto a Genia y Cooper y no sabés que van a hacer en ningún momento, y venía de antes con Gregan y Larham que tampoco sabías para dónde van a salir, y me encantaba eso".

$<$ ref. $>$ P 2: Entrevista002P.docx.rtf - 2:22 [(46:46)]]

"Entreno en general al equipo, pero hago más los tres cuartos. Me llegó mucho una capacitación que hicimos hace dos o tres años, en el club L., dónde vinieron dos entrenadores de tres cuartos (ex All Blacks y ex Auckland Blues), a hacer todo un entrenamiento de dinámica de pase y de tres cuartos. Donde la seguí muy de lleno, la verdad es excelente, con trabajos sencillos, como es el juego de los All Blacks. Es muy difícil, lo sencillo hacerlo bien, lo fácil hacerlo bien es lo más difícil que hay". $<$ ref.>P 2: Entrevista002P.docx.rtf - 2:23 [ (47:47)]>

Con al menos tener una estructura de entrenamientos por división, con análisis propios y de los contrarios, observación de errores y propuestas 
nuevas, parecerían asegurar que el proceso de formación de jugadores marcha de forma correcta. La organización que aporta un coordinador que distribuye información, hasta incluso de forma despersonalizada a través de redes sociales, permite observar o entender que todo anda bien. Los entrenadores reproducen en varias ocasiones el mensaje de intentar "lo fácil hacerlo bien". También manifiestan tener convivencia con muchos entrenadores autodidactas que sin llegar a hacer cursos, miran TV y muchos videos para poner en prácticas esos ejercicios.

"La formación mía la vamos armando a medida que va pasando el tiempo en el club. Por los tiempos que yo manejo no he llegado a hacer cursos, pero si veo mucha TV, muchos videos, entonces muchas veces ponemos en práctica eso. Escribimos mucho, porque mi hijo está con nosotros, escribimos mucho planificando las cosas que les queremos hacer hacer a los jugadores. Eso lo vamos archivando, pero cursos hasta ahora no hice, solamente ver este entrenador, J., el que me ha enseñado un montón a pesar del poco tiempo juntos. Me queda mucho por aprender, cómo llegarles a los chicos y enseñarles". $<$ ref. $>$ P 3: Entrevista003A.docx.rtf - 3:8 [ (17:17)]>

En parte del relato proponen la construcción de un entrenador ideal como alguien concreto. Una persona que colabore en el club haciéndole sentir a los jugadores que mejoran sus habilidades y que también el club exprese su interés hacia el entrenador.

"Un entrenador ideal y su formación para mí sería...hacer cursos, pero esos cursos los debe seguir alguien que realmente la tenga clara, porque como humanos todos cometemos errores a veces. Y tenemos que tener el apoyo de la Unión de Rugby y también del Club. Pero en nuestro caso que somos un club en crecimiento, tendríamos que tener apoyo de otros clubes que ya están formados, que tienen mucha más estructura, para poder enseñar".

$<$ ref.>P 3: Entrevista003A.docx.rtf - 3:12 [ (25:25)]>

Los entrenadores manifiestan la necesidad de formación al reconocer lo mucho que les queda por aprender. Sin embargo, estos aprendizajes 
pendientes no siempre son relativos al juego del rugby, sino a los modos de enseñanza. De forma simultánea los entrenadores consideran de suma importancia y viable, el apoyo de la unión de rugby local, del propio club, y también de otros clubes que cuentan con más estructura.

Entre las estrategias posibles, los entrevistados sugieren que debería haber un departamento de Coaching que se dedique a formar entrenadores dentro de cada club. ${ }^{16}$ Se trata de una solución que de algún modo les simplifique la vida, pues los entrenadores tienen trabajo y familia y su función de entrenador -insistimos- es ad honorem después de sus compromisos laborales. Esta fortaleza del rugby de respaldarse en el trabajo voluntario es, a su vez, una debilidad: resulta complicada tanto la formación inicial como la formación continua de entrenadores que no hacen de ese oficio una profesión rentada. Incluso sugieren que tanto la Unión de Rugby de Buenos Aires (URBA) como la Unión Argentina de Rugby (UAR) puedan entrenar departamentos de coaching, para entrenadores y éstos a su vez ir a los clubes y entrenar a los entrenadores.

"Debería haber un departamento de Coaching que se dedique a formar entrenadores dentro de cada club. Digo por las distancias... el entrenador de rugby tiene un perfil particular, que es un tipo que labura, tiene su casa, su todo y aparte tiene que dedicarle tiempo a venir a entrenar. Me parece que seguir sumándole tiempo a eso que ya le dedica, es un poco complicado. Si uno quiere captar ¿no?".

<ref.>P 4: Entrevista004X.docx.rtf - 4:25 [ (39:39)]>

16 El coaching se entiende como un método que consiste en acompañar, instruir o entrenar a entrenadores de rugby, con el objetivo de cumplir metas o desarrollar habilidades específicas. Anglicismo que procede del verbo inglés to coach, entrenar. 
Otros entrevistados manifiestan que quien debería formar al entrenador de rugby es principalmente el club. Identifican que el primer lugar adonde llega la gente es al club, ya sea como jugador, como padre, como manager. Entonces el club debería tener un plan de formación para eso. A partir de los relatos entienden que la unión de rugby tendría que "bajar" información a los clubes. Es decir, no existe una resistencia respecto de la membralidad entre la unión y los clubes, pero se pone en foco la responsabilidad y la potestad de los clubes.

"Yo considero qué quién debería formar al entrenador es principalmente el club. El primer lugar donde llega a la gente es el club. Ya sea como jugador, como padre, como manager, como lo que sea la gente llega al club. Entonces considero que el club debería tener un plan de contingencia para eso. Después obviamente que la Unión o las uniones tendrían que bajar más información a los clubes, para estar más mucho más capacitados con el rugby general en la ciudad, en la provincia, en el país. Creo que ese sería el ideal. El club debería tener tres o cuatro personas que se dediquen a formar gente. Específicamente. Esa formación incluiría todo; ya sea desde el inicio de rugby infantil, al juvenil y después superior. El club debe tener abocadas tres o cuatro personas, o tener un máster plan, para que se continúe, pero siempre haciendo docencia. Lo que nos pasa en particular a nosotros en el club F, pasa en todos los clubes, es que la gente deja de entrenar y cuando la gente vuelve, vuelve con otra historia. Nunca tenés una línea. Eso creo que es lo fundamental para poder mantener y más que nada para poder contener". $<$ ref.>P 5: Entrevista005C.docx.rtf - 5:15 [(32:32)]>

Es posible reconocer una tercera posición: el club debería tener especialistas que se dediquen a formar gente de forma específica. Para los entrenadores, esa formación incluiría todo, ya sea desde el inicio en el rugby infantil, el pasaje al rugby juvenil y hasta el rugby superior. A su entender los clubes deberían tener un plan a mediano y largo plazo donde la docencia sea uno de los pilares y atender a quienes se van incorporando luego de sus propias circunstancias vividas (trabajo, paternidad, ex jugadores, 
alejamientos). Este plan demandado permitiría mantener una línea de formación y crecimiento a través de los años. Ese trabajo estudiado y extendido en el tiempo debería estar por sobre ideas personales con permanentes cambios.

Los entrenadores quieren conocer a las personas que manifiestan intención de colaborar con ellos antes de comenzar y que se adapten a las normativas y formas del club. Luego de ello brindarle objetivos, herramientas y estilos de entrenamiento que utilizan. Los entrevistados transmiten en sus palabras que la formación de los recursos humanos es prioritaria y determinante en el crecimiento del club.

"Si viene una persona al club que quiere entrenar lo primero que haría es formarlo, charlar con él, cuáles son los objetivos que tiene él, porque quiere venir al club, y una vez que conoces a la persona empezar a diagramar un estilo de entrenamiento que se adapte a las normativas del club que te conté. Es importante que sumemos gente, no se nos puede ir un chico del club de una división".

<ref.>P 6: Entrevista006D.rtf - 6:19 [ (44:44)]>

\subsubsection{Los entrenadores apasionados y los valores}

Se repite el punto en común donde los recuerdos de todos los entrenadores siguen bien claros. Los entrenadores se muestran fanáticos -y muy ocupadosen su desempeño y relatan la total entrega en lo que hacen.

"En general en mi ciudad [de origen] eran bastante fanáticos. Lo estoy viendo ahora, tipos totalmente entregados. Y fanáticos de la filosofía del rugby, en los valores del rugby".

<ref. $>$ P 1: Entrevista001S.docx.rtf - 1:10 [ (12:12)]>

En las descripciones nombran los valores del rugby y evocan las muestras 
de afecto y de confianza por parte de sus entrenadores. Identifican a la transmisión de esos valores incluso como algo más importante que la planificación de las actividades y que la transferencia de conceptos técnicos a sus jugadores. En el papel y el trabajo de los entrenadores, se sugiere que la "satisfacción" y el "disfrute" también serían características centrales de su filosofía de entrenamiento y ciertamente de su propia práctica del oficio de entrenador.

"Que los chicos te devuelvan su afecto con un abrazo, con una sonrisa, lo que le estás tratando de decir. Así ellos aceptan un montón de cosas que vos le decís y te lo agradecen de distintas formas. Cuando me refiero a cosas, quiero decir cómo explicarles a los chicos, que los chicos entiendan lo que vos le querés decir, lo que vos le estás explicando. Porque todos los chicos no son iguales, algunos entienden mejor y otros no. Y otros están en su mundo y quieren hacerlo. Con gestos, con la forma de hablarles, en el momento que le estás enseñando, vos le haces una pequeña broma para que se desenchufe y se vuelva a enchufar. De esa forma puede captar lo que vos le estás enseñando".

<ref.>P 3: Entrevista003A.docx.rtf - 3:6 [ (11:11)]>

Destacan como muy positivo haberse sentido contenidos en sus etapas infantiles sobre todo ante los inquietos momentos en los cuales no dejaban de correr y saltar tornándose incómodos para sus hogares. Cuentan que en el seno familiar y en la escuela no dejaban de moverse pudiendo representar un inconveniente o algo molesto. Así pues, poder hacerlo con total libertad en el club, indica un lugar donde los entrenadores cuando eran niños se sentían comprendidos.

"A mí me encantaba, me gustaba jugar, correr, me gustaba sobre todo ganar, siempre fui muy competitivo en eso, yo escuchaba muy bien al entrenador qué cosa teníamos que hacer y después confiaba mucho en perfiles míos de lo que tenía que hacer dentro de la cancha".

$<$ ref. $>$ P 2: Entrevista002P.docx.rtf - 2:5 [ (14:14)]> 
Asimismo, describen que como jugadores les devolvieron a sus entrenadores muchas cuestiones afectivas (abrazos, sonrisas, agradecimientos) y refieren que sus entrenadores le enseñaron rugby "en esencia" y poco del rugby en la práctica.

"Así que creo que cada uno de los entrenadores que tuve me marcó, me enseñó me enseñaron mucho lo que es del rugby, sobre todo el compromiso, todo lo que es el equipo pero si me preguntas por uno diría que todos me enseñaron algo, todos".

<ref.>P 6: Entrevista006D.rtf - 6:5 [ (9:9)]>

\subsection{6. "Los entrenadores necesitamos capacitarnos"}

Ante distintas dificultades cotidianas en el rol del entrenador, los entrevistados manifiestan la necesidad de capacitarse. Existen distintas propuestas en reclamos hacia los clubes de rugby y hacia las uniones locales de rugby. Proponen que los clubes más desarrollados incluso, puedan colaborar con quienes se están iniciando, pero, más allá de las demandas específicas, también son creativos a la hora de proveerse experiencias formativas o estrategias de comunicación. Resulta indispensable entender la necesidad de formación en este doble juego: demandas y reclamos, por un lado; genuino interés por actualizarse, por otro (dentro del mencionado contexto de restricciones que imponen la vida laboral y familiar y el carácter ad honorem de su tarea).

"Entonces, ¿de dónde sacamos? Tenemos un coordinador de rugby de donde sacamos muchas cosas, esa información se da por WhatsApp a principio de semana. Los más grandes se da, no recuerdo si una planificación mensual, donde está calibrado la estructura de entrenamientos por división y cada vez más grandes, los hace el entrenador y depende de cada entrenador, depende del partido de la semana siguiente 
donde hay análisis de video, análisis del contrario, de los tuyos, de lo que hiciste mal y a partir de eso, dónde ajustar tuercas".

<ref.>P 2: Entrevista002P.docx.rtf - 2:21 [ (45:45)]>

"Miro muchos videos. Yo trabajo en Buenos Aires, en transporte, informática, y me tomo mi hora de almuerzo todos los santos días, a buscar videos de rugby, de lo que sea, tanto lo que es técnico como pedacitos de partidos, o lo que pueda mirar en esa hora. Trato de meterle todos los días realmente me gusta entonces, le dedico tiempo. La posibilidad estar en Buenos Aires me ha dado... ahora se está abriendo, pero hasta hace un par de años había más muchos más cursos o charlas o cosas para ir a ver en Buenos Aires que acá, en La Plata o lo que llegaba. Me daba la posibilidad mayor ya que estaba en Buenos Aires. Recuerdo unas charlas con este hombre que hacía análisis de video de Jaguares, video de Pumas y después fue Head Coach, A.P. es excelente y me gusta la forma qué tiene de ver el juego y de transmitir. Con el negro G. también fui a ver un par de charlas, y también fui a varias con el mono $M$. En este año no pudimos pero otros años, cuando fuimos de gira a Uruguay y arreglamos, toda una clínica con la m14 con el mono allá, nos recibió en el estadio de ellos. Todo un lujo. Nos dio una charla muy buena no sólo para jugadores sino también para los entrenadores. Cursos completos de varios días no he hecho, he participado en un montón de charlas. Soy un desastre con los nombres, pero fui a una charla con un argentino que está haciendo un trabajo con juveniles en Inglaterra, J.M., me pareció muy interesante es otra forma de concepción del rugby". <ref.>P 4: Entrevista004X.docx.rtf - 4:18 [ (20:20)]>

"Para eso necesitamos formarnos."

<ref.>P 4: Entrevista004X.docx.rtf - 4:26 [ (39:39)]>

Al mismo tiempo, admiten una falta de sistematización y formación permanente y presencial como una posibilidad de incorporación de herramientas que les permita poder enfrentar de forma actualizada la enseñanza del rugby. En el marco de este debate, se actualiza la discusión respecto a cuál debe ser la relación entre clubes y uniones de rugby.

"Después obviamente que la Unión o las uniones tendrían que bajar más información a los clubes, para estar más mucho más capacitados con el rugby general en la ciudad, en la provincia, en el país. Creo que ese sería el ideal".

<ref.>P 5: Entrevista005C.docx.rtf - 5:16 [ (32:32)]> 
Ser entrenador es una gran responsabilidad y desean hacer los mejores entrenamientos posibles. Entienden que tienen la obligación de mejorar y poder estudiar, perfeccionarse y conocer sus virtudes y sus defectos. La consecuencia de la superación en estas acciones los hace sentir competentes.

\subsubsection{Las actividades de formación complementarias}

Ha habido un cambio importante y favorable en materia de accesibilidad al material y al conocimiento en las fuentes complementarias desde el punto de vista de los entrenadores, quienes manifiestan que era muy distinto cinco años atrás. Existía muy poca información de manera escrita, era todo espontáneo y debido a las escasas charlas existentes todo se reducía a la práctica y al error. Anteriormente -sostienen- no existía la posibilidad de realizar cursos presenciales y recién en los últimos años aparecieron los cursos de la Unión de Rugby de Buenos Aires (URBA), de la Unión Argentina de Rugby (UAR) y de la International Rugby Board (IRB), actual World Rugby (WR). ${ }^{17}$

"Ahora es accesible. De acá a tres, cinco años atrás es accesible la información. Pero antes era inaccesible. Y no había mucha gente que hablara para enseñar. El único libro con el que yo me formé fue el de Cordero Biedma, que después me dijeron que no era muy bueno. Yo no vi otro. Y después fue todo práctica y error. Nada de cursos, recién hace poco hice los de la URBA, los de la UAR, los de la IRB, pero hace 5 años no había nada. Todo espontáneo y por charlas".

17 Existen niveles de incardinación en el rugby respecto a las instituciones. En la actualidad los clubes de rugby de Argentina se dividen en uniones provinciales o regionales. La URBA es la entidad que nuclea a los noventa y un clubes de rugby de la ciudad de Buenos Aires y un amplio anillo circundante, entre ellos, los estudiados en el marco de esta tesis correspondiente al área urbana del Gran La Plata. Los organismos provinciales/regionales forman la UAR como organismo nacional; los organismos nacionales integran la WR. 
<ref.>P 1: Entrevista001S.docx.rtf - 1:17 [ (25:25)]>

Varios supieron sumarse a internet desde donde pudieron bajar y estudiar algunos videos. Incluso han sido editados libros que desde la Educación Física y el entrenamiento de otros deportes (como el fútbol y el básquet) mostraban unas primeras y breves apreciaciones sobre el rugby.

Los entrenadores cuentan que los primeros cursos de rugby se orientaban a jugadores juveniles y sólo algunos entrenadores, que eran docentes, podían adecuar las intensidades para los más pequeños. Admiten que en la actualidad la información es muy amplia, incluso por demás, ya que llega por distintos canales reales y virtuales y además es una preocupación latente. "Mucha información y poca formación", sintetiza uno de ellos.

"Yo empecé agarrar el auge de internet y de videos. Y empezás a mirar pedacitos de entrenamiento, o lo poco que hay de rugby, y de grandes porque de chicos no había mucha información. Empezás a preguntar, conseguís algún libro. Algún libro que viene de la educación física que toca entrenamiento de fútbol, básquet y dos hojas de rugby porque tampoco teníamos mucha bibliografía y empezás a preguntarle a entrenadores que están hace mucho tiempo con chiquitos y que vos sabes que hicieron cursos en la URBA, te vas metiendo, vas preguntando le haces algún curso de coaching. Yo lo hice en el año 2001 en la URBA, pero era más orientado hacia jugadores juveniles, pero vas bajando la intensidad de la sesión de entrenamiento y la vas acomodando a lo que vos tenés que hacer con los nenes. Qué es más repetido, más charlado, más caminado. Y después cuando empezó a ver más información y más entrenadores que se preocupaban por los chiquitos, te va llegando más material".

<ref.>P 7: Entrevista007M.docx.rtf - 7:13 [ (35:35)]>

\subsection{8. "Los entrenadores también jugamos como árbitros"}


Ya hemos presentado al rugby como juego $y$, de sus principales características, es fácil concluir que se trata de un deporte difícil de ser autoarbitrado, es decir, que el referato lo administren los propios jugadores. Por eso, no resulta llamativo que los entrenadores hablen recurrentemente de la necesidad de la presencia de una persona que conduzca la instancia de los partidos, personificada en el árbitro. Esta es la razón por la que cuentan que también quieren ser capacitados en ese aspecto y si bien la primera mirada es hacia afuera buscando quien pueda colaborar, la realidad es que terminan haciéndolo los mismos entrenadores.

"Me parece que lo de los referís también es otro tema. Se ponen los mismos días a la misma hora que hay entrenamiento. Yo quisiera que todos hagan el curso de entrenadores, de referís. Pero no para entrenar, sino para que sepa las reglas. Hay muchos entrenadores que no saben las reglas actuales. Hay mucho ex jugador que no sea aggiornado".

<ref.>P 4: Entrevista004X.docx.rtf - 4:28 [(39:39)]>

Admiten disconformidad en el caso de haber una formación para el rol del árbitro debido a que la misma se dicta siempre los mismos días y a la misma hora de los entrenamientos. En realidad, la queja se relaciona con el tiempo que insume incorporar nuevas actividades en el club y con los pocos recursos que cuentan con ellos. Si se juntan ambas cuestiones (la necesidad de formarse también como árbitros con la de contar con más colaboradores) es posible inferir que, desde el punto de vista de los entrenadores, si hubiese más padres o ex jugadores disponibles para hacer el curso de referato, podría contarse con ellos no sólo para los partidos sino también para los entrenamientos. 
"El curso de referee estaría buenísimo que lo pueden hacer todos. Aparte por si en algún momento no hay nadie que referee, podés referear de manera idónea y consciente que vas a hacer las cosas bien".

<ref.>P 4: Entrevista004X.docx.rtf - 4:29 [(39:39)]>

Finalmente aceptan que la modificación y actualización permanente del reglamento de rugby infantil debería ser un tema que movilice a todos y de forma didáctica para tener en cuenta el juego y el modo de los niños. ${ }^{18}$

\subsection{9. “¿Qué cambié?": la actitud autocrítica}

"Tengo 54 años, soy el viejo y los chicos me dicen el abuelo y todo eso, y he desempolvado muchas cosas de cuando yo entrenaba, de cosas viejas y por ahí hay jugadas de tres cuartos, simples, sencillas, como salteos, redobles, que no se hacen mucho ahora y a los chicos les sirvió un montón".

$<$ ref. $>$ P 2: Encuesta002P.docx.rtf - 2:18 [(35:35)]>

Hay entrenadores que recuperan experiencias del pasado, sobre todo, jugadas sencillas. Pero queda claro que muchas acciones de los entrenadores han cambiado. También el juego ha cambiado. Los entrenadores admiten que les queda mucho por aprender, quieren aprender cómo llegarles a los niños y jóvenes y además quieren saber cómo enseñarles. Entre los cambios que reconocen, admiten que en la actualidad, al no cumplirse alguna consigna, se sientan y reúnen con los jugadores intentando buscar el diálogo. Si bien los jugadores están ansiosos por tocar la pelota y jugar, manifiestan que si no

18 Al momento de la realización de esta tesis aparece una nueva actualización del reglamento de rugby infantil de la Unión Argentina de Rugby (UAR, 2019). La misma es informada por el organismo rector y ocurren dificultades de aplicación e información de las modificaciones, debido a la extensión de nuestro país y a la falta de formación previa al respecto en todos los entrenadores. Fundamentalmente, la dificultad estriba en la metodología de la enseñanza del contacto. 
cumplen con las exigencias manifestadas por el entrenador no pueden jugar.

Entienden que hay una jerarquía de pasos previos a jugar.

"Las cuestiones en las que más hice hincapié junto a los tres entrenadores que estaban conmigo en infantiles, lo que hicimos era por más que les cueste, el cumplir con los horarios, en cumplir con la comunicación, y en el compañerismo hice mucho hincapié. Cuando esto no salía, lo ajustábamos en lugar de entrenarlo, nos sentábamos, lo hablábamos. Cuando yo estoy, cuando yo estoy con la pelota en la mano el chico está ansioso por jugar con la pelota. Y le hicimos que si no cumplimos con lo que el entrenador exige, hay cosas que se tienen que sacrificar. Una es agarrar la pelota".

$<$ ref.>P 3: Entrevista003A.docx.rtf - 3:16 [ (34:34)]>

"Si algo evolucioné en este tiempo como en entrenador es en calmar mi ansiedad y poder volcarles a los chicos, lo que los chicos necesitan. Poder hacer un análisis del grupo, no todos los grupos son iguales, hacer un primer análisis, ver en qué condiciones están, tanto de grupo como deportivamente están, y planificar a partir de ahi".

$<$ ref.>P 4: Entrevista004X.docx.rtf - 4:16 [ (17:17)]>

En el contexto de reconocer las cosas en que han ido cambiando, cuentan además, que debido al método de prueba y error les ha pasado de querer saltear objetivos o etapas, o dar por hecho que esos objetivos y esas etapas deberían estar cumplidas; y al constatar que eso no era así, verse obligados a desandar el camino. Es importante destacar el carácter reflexivo de este reconocimiento, pues ubica la necesidad de análisis en todo el proceso de formación de jugadores.

"A prueba y error me ha pasado de querer saltear cosas, o dar por hecho cosas que, deberían estar y no están, y por no analizarlas previamente después tener que volver, retroceder y hacerle perder el tiempo a otros, a los chicos".

$<$ ref.>P 4: Entrevista004X.docx.rtf - 4:15 [(17:17)]>

Los entrenadores entienden como una evolución el hecho de calmar algunas ansiedades y poder volcarles a los niños y jóvenes lo que creen que los niños y jóvenes necesitan. Al no ser todos los grupos iguales, hacen un análisis 
y luego ven en qué condiciones están, tanto de grupo como deportivamente, y planifican a partir de ahí.

Creen que se debería poder copiar una forma "europea", según la cual los "mejores entrenadores" -y aquí conviene interpretar: los que más saben de rugby y están más formados- deberían estar con los más pequeños; pero reconocen que muchos clubes designan a los mejores entrenadores en primera división. Suponen que al jugador hay que formarlo a partir de fundamentos básicos, y si bien el jugador mayor -el jugador del plantel superior- se considera que ya está formado, puede seguir aprendiendo. Enfatizan que son distintas las necesidades de los niños y de los jóvenes.

"Me queda mucho por aprender, cómo llegarles a los chicos y enseñarles". <ref.>P 3: Entrevista003A.docx.rtf - 3:9 [ (17:17)]>

"Yo considero que entrenamos de la forma que no se debe entrenar. Los mejores entrenadores están con los más grandes, cuando deberían estar con los más chicos. Porque el jugador hay que formarlo desde cero, y si bien el jugador grande, del jugador del plantel superior se considera que ya está formado, puede seguir aprendiendo, pero es distinto lo que necesita a lo que necesita un chico. Esa forma europea de entrenar deberíamos copiarla nosotros".

$<$ ref. $>$ P 7: Entrevista007M.docx.rtf - 7:14 [ (35:35)]>

\subsection{Del dato empírico a la elaboración teórica}

\subsubsection{La formación del entrenador y su matriz de aprendizaje}

Una matriz permite representar de forma visual y sencilla el nivel de cumplimiento que tenemos sobre un plan de formación y capacitación. El objetivo de una matriz es delinear los conocimientos de los entrenadores con 
las necesidades de los jugadores y clubes, demanda que hoy en día tiene un grado de variabilidad muy alto.

Para introducir algunas notas es importante situar un terreno común, definir matrices de aprendizaje, qué se entiende por configuración de los entrenadores (sujetos) y cómo pueden operar los grupos operativos sobre las subjetividades.

Al trabajar la configuración de los sujetos en el proceso de conocimiento, Pampliega de Quiroga (1994) advierte que la posibilidad de existencia del sujeto como tal, está determinada por su capacidad de emerger de los aprendizajes que se tejen en sus vínculos y relaciones sociales a partir de necesidades manifiestas propias. En otras palabras y para nuestro caso, los entrenadores necesitan de otros (entrenadores, jugadores) para devenir sujetos: "el sujeto entrenador"; es decir, es social su constitución y existencia como tales. Es más, en tanto sujeto, no sólo son una síntesis de sus trayectorias vinculares y sociales, sino también de sus aprendizajes.

La relación que las matrices de aprendizaje cumplen en la configuración del sujeto en el proceso de conocimiento (o aprendizaje) está dada desde el momento en el que se construyen modelos internos o matrices de encuentro con lo real. Esos modelos internos son personales y sociales, están en movimiento y son susceptibles de modificación: esto se verifica en el constante pasaje de pasado a presente y viceversa de sus reflexiones. El aprendizaje que los entrenadores puedan hacer los configura como sujetos en un proceso que tiene continuidades y discontinuidades en el tiempo. 
Cabe resaltar entonces que todos los aprendizajes tienen su historia. Cada quien ha aprendido a aprender, organizar y significar experiencias, sensaciones, emociones, pensamientos; ha construido hábitos de aprendizajes y configurado una actitud hacia el aprendizaje. Es decir han construido sus matrices de aprendizaje, que si bien tiene sus singularidades no dejan de estar determinadas socialmente. La matriz de aprendizaje es compleja y contradictoria. Esta paráfrasis reconstruida a partir de las afirmaciones de Pampliega de Quiroga se refleja plenamente en nuestros casos, particularmente en lo que hace a la valoración de la formación y la relación con el "éxito" como entrenadores: nuestros entrevistados suelen ponderar el trabajo en rugby infantil y la necesidad de estar mejor formados para el trabajo con los niños; pero no dejan de percibir como una tarea más gratificante en cuanto al reconocimiento la de entrenar a jóvenes y adultos en edades más competitivas.

Como ya se expuso en los capítulos anteriores, y a través de las entrevistas, los entrenadores de rugby "sienten" el rol de entrenadores de rugby. Desde una observación externa, y si bien les cuesta en una primera aproximación ser autocríticos, entienden que la pasión y la transmisión de los valores es su objetivo primordial en cada práctica.

Los entrenadores enmarcan el concepto de aprendizaje del rugby necesariamente como un proceso pedagógico, progresivo y sistemático de enseñanza y de aprendizaje, de habilidades y competencias motrices que puedan ayudar a la formación integral, utilizando la práctica deportiva y el 
juego como un medio y un fin de estos logros, permeado en muchos casos por momentos de goce y disfrute durante la práctica. Exaltan continuamente el incremento de las diferentes capacidades humanas, ya que estas ayudan a aumentar el interés por aprender.

\subsubsection{Los entrenadores frente al desafío de la formación}

En sus propuestas de formación, y entendiendo que su rol es voluntario, relatan que las distintas instancias de recepción de información para sus entrenados, es de suma importancia. Manifiestan interés en su formación, particularmente a través de los cursos online, como instancia prioritaria en estos tiempos; no obstante, valoran de manera especial el vínculo personal, el "cara a cara" con quienes pueden ayudar en su formación. Algunos manifiestan que hay mucha información y poca formación.

Los actuales enfoques en la comprensión del juego, les permite a los entrenadores acceder a situaciones problemas semejantes a los del juego real. Incluso en sus entrevistas, relatan que utilizan distintos métodos. Proponen en sus prácticas, además poner el foco en los valores, plantear situaciones de partido con reglas básicas y utilización de variables en el reglamento, técnica, espacio, tiempo, comunicación y estrategia. Este método tiene estricta relación con métodos de enseñanza de resolución de problemas y descubrimiento guiado (Turner et al., 2002). 
Los entrenadores manifiestan una necesidad de formarse. No encuentran situaciones presenciales y tanto los libros como los textos técnicos parecerían no satisfacer su demanda. Sin embargo, a lo largo del presente estudio, se plantean actitudes autocríticas permitiendo un cambio que consideran positivo en ellos y que redunda en mayores instrumentos para las prácticas con sus jugadores. Entienden que pueden plantear ejercicios relacionados con el juego y los jugadores podrán aplicar las habilidades. Buscan soluciones a los distintos aspectos y que los jugadores sean conscientes del por qué y para qué se necesita (Devís Devís, 1992).

Los educadores de rugby buscan herramientas nuevas para poder enseñar el rugby, conociendo con mayor profundidad no solo el deporte sino una gran cantidad de aspectos que intervienen en la creación de situaciones de aprendizaje del deporte, sobre todo de diferentes edades. Consideran que la responsabilidad recae sobre el entrenador pues él tiene la función de educar en las diferentes esferas del ser humano.

Los entrenadores se mueven en un entorno donde todo evoluciona muy rápido; por tanto, además de reclamar formación continua, entienden que deben reciclarse de forma constante. En ocasiones, entienden que desde los clubes no se valora las ansias de ponerse al día del entrenador innovador y no se favorecen estas iniciativas. Alientan a incitar a los entrenadores menos motivados a ponerse al día, siendo los entrevistados los primeros interesados para seguir recibiendo formación de calidad. 
En la actualidad no se puede entrenar correctamente si se ha perdido el interés por seguir aprendiendo. El entrenador que deja de aprender, se convierte en un inconveniente para la experiencia de sus jugadores. Hay entrenadores de rugby que, con sus prácticas, no sólo no estimulan las ganas de entrenar, sino que hasta las frenan.

Los entrenadores de rugby alzan su voz con la convicción de que son necesarios nuevos estudios, incluso enfrentándose a la oposición en los cambios de modelos. Son conscientes de sus carencias pero entienden que se deben plantear nuevos aprendizajes, nuevas formas de enseñar, y para eso es necesario formarse de manera continua. Relatan que para enseñar a niños y jóvenes determinados modos de vivir el deporte, primero deben formarse y aprender.

Los entrenadores de rugby se transforman en meros operadores, reduciéndose su saber sólo a la cuestión empírica, tal como lo ha considerado Wein (1995: 78), “para trabajar con este 'modelo' el monitor/entrenador no necesita tener muchos conocimientos y gran experiencia antes de iniciar un proceso de enseñanza-aprendizaje, sólo entusiasmo y voluntad de hacer las cosas lo mejor posible". La tarea profesional se reduce a la coordinación y monitoreo de las conductas naturales del jugador, lo que refuerza la idea de una disciplina empírica, al considerar que la sola experiencia alcanza para justificar la intervención en la enseñanza. Pero estos planteos que pretenden orientar la enseñanza concentrándose únicamente en el método, desvinculándola de las implicancias sociales no son nuevos. 
Se propone continuar indagando cómo se enseña el rugby, con el objeto de aportar elementos para nuevos análisis. En función de la importancia capital que el estudio asigna a las condiciones y a la significación subjetiva que tuvieron para cada uno de los entrenadores de rugby, la investigación se basa en la reconstrucción del discurso, las trayectorias, la forma de conducción y los modos de formación tal como los entrenadores de M14 puedan evocarlos.

Ahora bien, toda biografía admite dos dimensiones: una, en la que importa determinar cómo fueron realmente los hechos; y otra, en la que interesa cómo fueron vividos y significados por quien los vivió. Es evidente que la verdad de los hechos incluye al sujeto que enseña, aunque esto no suela ocurrir en algunas investigaciones.

Sin embargo, registrar los hechos en el nivel en el que los entrenadores de rugby pueden evocarlos implica el riesgo de dejar fuera del análisis aquellos datos cuya significación, aun habiendo sido decisiva, permanezca ignorada por el propio sujeto; riesgo que se asume desde el principio, de todos modos, dado el límite ético que impone a la indagatoria la privacidad de los entrevistados.

\subsection{Bibliografía del capítulo}

- Devís Devís, J. (1992). "Bases para la propuesta de cambio en la enseñanza de los juegos deportivos". En J. Devís Devís y Peiró Velert, C. Nuevas perspectivas curriculares en Educación Física: la salud y los juegos modificados. Barcelona: Inde. 
- Pampliega de Quiroga, A. (1994). Matrices de aprendizaje. Constitución del sujeto en el proceso del conocimiento. Buenos Aires: Ediciones Cinco.

- Turner, A., Crespo, M., Reid, M. y Miley, D. (2002). "The games for understanding (GFU). Teaching approach in tennis". En ITF Coaching \& Sportscience Review, 26, 2-3.

- Wein, H. (1995). Fútbol a la medida del niño. Madrid: RFEF. 


\section{CONTENIDOS Y MODOS DE ENSEÑANZA}

\subsection{Sobre el contenido de este capítulo}

Continuando con el mismo ejercicio realizado en los dos capítulos anteriores (en primer lugar, la selección y organización del material empírico; en segundo lugar, la confrontación de ese material con las fuentes teóricas), en este apartado el eje vira hacia los contenidos y las formas de enseñanza. Como en los casos anteriores, este recorte agrupa una serie de categorías que surgen de las expresiones de los entrenadores devenidos en expertos informantes.

Al principio, dispersos, los datos reunidos en este apartado forman un collage que sólo alcanza una suerte de gestalt al final de la sección. En torno al contenido -denominación que no siempre está presente de este modo entre los instructores-, se preguntan nuestros expertos qué es importante al enseñar en el rugby lo cual vinculan al perfil del jugador que sale de la categoría M14; en este punto, el señalamiento respecto de que los niños dejan de ser niños para pasar a ser jugadores resulta recurrente. Dentro de estas reflexiones se cuela un tema que adquiere la dimensión de ser un "secreto a voces" en el rugby: el temor de los jugadores a golpearse, el temor a que se golpeen por parte de los entrenadores; lo cual, como se verá, afecta aquello que se enseña y la manera en que se enseña.

Pasando a la enseñanza, los entrenadores harán foco en la modalidad propia de cada entrenador, en la necesidad de dejar un legado y en que, 
finalmente, es el club el que marca un estilo, una identidad rugbística que afecta a la enseñanza y al tipo de rugby a enseñar. Por último, veremos que los entrenadores no separan contenidos y enseñanza de la contención que ellos le ofrecen a niños y jóvenes y cómo eso se vincula al reconocimiento de otros $\mathrm{y}$ al disfrute personal.

Para finalizar, se conectan los dichos de los educadores con el material propio del acervo académico. Así, los aportes de Viciana, Díaz Lucea, Coll y Candreva y Susacasa son concurrentes a la hora de dar tratamiento al contenido como un saber que encuentra su origen y su destino en la cultura y no en la mera acumulación de información. Pensar en un contenido como saber implica dimensionarlo como concepto, procedimiento y actitud, lo cual ensambla sin dificultad con la opinión de los entrenadores que más allá de las cuestiones tácticas, técnicas y reglamentarias, aluden a los valores y a lo grupal como pilares de su trabajo.

Al pasar a los asuntos propios de la enseñanza vamos a ver una divergencia inicial, dado que los entrenadores, a pesar de su apego a una visión tan amplia como intuitiva del contenido, se recuestan al principio de sus prácticas en modelos tradicionales basados en la imitación y repetición; este modelo, no obstante, va a sufrir modificaciones a fuerza de errores y de nuevas convicciones. Por eso recurrimos a visiones clásicas de la pedagogía y la didáctica en su versión crítica, como lo representan Freire y Gimeno Sacristán, respectivamente. 


\subsection{Análisis de las entrevistas a los entrenadores}

\subsection{1. ¿Qué es importante al enseñar en el rugby?}

Los entrenadores definen y entienden que los grupos son distintos y que cada grupo tienen sus necesidades y objetivos. Ponen énfasis y repiten el concepto de grupo, de "armar grupo", vínculos y lazos en las edades formativas. El buen trato y la diversión cobran una dimensión significativa en su discurso.

"Simplemente es, yo te cuento lo que hago, lo que yo hice, lo que hacemos con la barra mía es, si bien haces hincapié en lo que es el rugby, para mí muy importante es el grupo. De armar un buen grupo, que los chicos traten de tomar un compromiso con el entrenador, y después enseñar las cosas básicas, y sin gritarles, hablarles, que sepan que los chicos vienen acá a divertirse. No es el colegio, vienen a pasar un buen rato. Nosotros estamos para que ellos lo hagan. Uno se pone contento cuando les enseña las cosas a ellos, porque disfrutás ver a los chicos jugar, le ponés cariño, le ponés entusiasmo. Yo les diría que si ha jugado rugby y quiere entrenar que venga a divertirse con los chicos". $<$ ref. $>$ P 6: Entrevista006D.rtf - 6:18 [(41:41)]>

Describen que la base es pasarla bien y que, una vez logrado el efecto de lugar amable y seguro, los niños y los jóvenes saben que pueden regresar al club en cada entrenamiento, en cada semana. Entonces, una vez que se aseguran que van a jugar, comienzan a sumar aprendizajes y conocimientos del deporte. Surge la premisa de que deben lograr primero un ambiente divertido para luego lograr captar su atención.

"Todo depende de qué división es que te toquen. Nunca puse el foco en ganar, no sé por qué. Un ex jugador ya grande, me dijo que conmigo no iban a salir campeones, pero el grupo iba a salir fortalecido. No sé porque siempre me ocupé más de los equipos $B$. De armar gente, el grupo, siempre pienso en eso. Yo creo que la base es divertirse. Lo importante en esa etapa es el grupo. Para mí la base está sobre el divertimento". $<$ ref.>P 1: Entrevista001S.docx.rtf - 1:14 [ (19:19)] > 
"Nuestro foco en M14, este año más allá de los objetivos del club, el primer objetivo que pusimos fue con una división que percibíamos desunida, con conflictos internos, y el objetivo número uno fue que se diviertan. Llamar la atención del grupo porque es divertido. Que se diviertan haciendo cosas de rugby. Que se diviertan, cuando logramos la atención, la idea es ahí sí, darles más cuestiones técnicas. Incluso hicimos carrera de caballitos, manchas, cosas que los chicos se desestructuren, cosas que los chicos se diviertan. Que tengan ganas de venir. Si logras que el chico está divertido, tenés la atención".

$<$ ref. $>$ P 1: Entrevista001S.docx.rtf - 1:15 [(19:19)]>

Los entrenadores más fanáticos intentan que los niños y jóvenes tengan una "cabeza ovalada" -toman como referencia la pelota ovalada característica con la que se juega al rugby- y hasta entienden como una obligación la de "devolver" mejores hijos a sus padres.

"La pregunta es cómo llegan a ser ovalados de la cabeza. Además de ser muy buenos chicos, no hacer quilombo, ser sanos y todo eso. Además, casi todos estudian, todos pasaron a la universidad, y vos fijate que todos los que están jugando en Superior están en la Universidad, ya no sólo primer año sino a segundo año, y que no sean revoltosos, que tengan todo el tiempo ganas de aprender. Pasaron por pocos grupos de entrenadores, los formó al principio F.H., el padre de J. Yo no soy muy amigo de que el padre sea entrenador de su propio hijo, pero la verdad que F. era profesor de educación física, era formador de grupo, formador de buenas personas. La verdad que me dejó un plantel exquisito y me pidió por favor, cuídamelo".

$<$ ref. $>$ P 2: Entrevista002P.docx.rtf - 2:25 [ (50:50)] >

"Que sientan el rugby las 24 horas. Sentir el rugby las 24 horas no significa estar pensando solamente en jugar, sino pensar en todo el resto de las cosas que hacen a la vida para que puedan jugar al rugby libremente, sin que nadie les ponga trabas". $<$ ref. $>$ P 4: Entrevista004X.docx.rtf - 4:13 [ (14:14)]>

A pesar de algunas dificultades con los elementos y el espacio disponible, entienden que debe imperar el sentido lúdico de las actividades y el interés para que el aprendizaje les llegue a todos, independientemente de la cantidad de jugadores que tenga cada club. Los entrevistados manifiestan que una de las acciones del entrenador del rugby formativo sería simplificar algo que es 
difícil. No hablan de simplificarle la resolución de una actividad al niño o al joven, sino simplificarle alguna situación difícil de hacer. Entonces reiteran que deben hacer $\mathrm{y}$ proponer que todos los entrenamientos sean simples y divertidos.

"Primero debería ser muy lúdico cuando es el inicio, pero yo creo que en Menores de 14 a como viene la Menores de 15 después posterior, en el club se está implementando... a veces llega la Menores de 14 es demasiado lúdico. Si bien la técnica individual tenía que estar, no le daban la base para estar bien afirmados en la M15. Creo que ahora hace un par de años en el club, se empezó a entrenar en cancha mucho más abierta. Viste que antes entrenaban como veinte equipos en una sola cancha por problemas de espacio, pero por lo menos tener una vez a la semana en cancha completa, hacer recepción de salida de cancha, una estructura mucha más abierta en $M 14$, por lo menos en el segundo semestre".

$<$ ref.>P 2: Entrevista002P.docx.rtf - 2:27 [(55:55)]>

"Cuando vos no le prestas atención al chico, al jugador número 38, que siempre es el suplente del [equipos] B o juega en el [equipo] C, siempre lo vas a necesitar, siempre le tenés que dar bola y formar cabeza ovalada como todos los demás. Nosotros en el club sufrimos eternamente la salida de jugadores que no le daban bola, lo tildaban de traidor por irse, pero no vimos cuál era el problema interno de por qué se iban, porque había entrenadores que no le dan bola o le decían siempre pocas cosas. O sea como le digo yo, no eran formadores de cabeza ovalada. Se iban al club A, al club B o al club C. Todavía sigo viendo jugadores de primera división [de otros clubes] que han sido formados en nuestro club".

$<$ ref. $>$ P 2: Entrevista002P.docx.rtf - 2:30 [ (55:55)]>

"Hacerlo simple y hacerlo divertido. Y después trasladarlo a la cancha y a que el jugador que está en movimiento me va a tratar de esquivar. Me va a tratar de pasar por otro lado. Voy a tratar de lo que aprendí de forma estática trasladarlo a forma dinámica. Eso es lo principal, lo estamos trabajando desde los chiquitos hasta los grandes, porque tenemos jugadores grandes que nunca han aprendido a tacklear de la forma que no es peligrosa para ellos. Lo trasladamos desde los chicos para arriba, usando los mismos materiales con ejercicios más fáciles y otras veces más complejos. Mucho visto con los coaching que hace Jaguares y lo ponen en Internet, y equipos de Europa que ponen sus entrenamientos. Te sirve mucho para mostrarles diciendo, bueno esto era una pavada, y nunca los habíamos hecho...".

$<$ ref.>P 7: Entrevista007M.docx.rtf - 7:22 [(51:51)]> 


\subsubsection{La forma propia de entrenar}

Otra categoría que hemos construido a partir de las narraciones de los entrenadores es la que llamamos "forma propia de entrenar". Se trata de un complejo conjunto en el cual se articulan fragmentos sencillos como ejercicios y formas de evaluación, hasta objetivos y valores puestos en juego. Si bien esos elementos son de calibre bien distinto, todos confluyen en la autopercepción que los entrenadores tienen de su propio perfil.

En primer lugar, el conocimiento global del rugby como juego está asociado a la experiencia (de jugador y entrenador); sin embargo, reconocen que para "pulir" este saber práctico es necesaria la teoría.

"Creo que estoy capacitado con conocimientos rugbísticos, en la visión global del juego. Creo que tengo una gran experiencia práctica, me falta mucha teoría, pero práctica que no hay muchos entrenadores que tengan, me falta pulirla y confrontar con alguien para poder teorizarla; para tener más concientización técnica, para completar la técnica. Creo que tengo mucho campo, me falta variantes, porque me falta la teoría, pero me falta pulir la teoría. Aprendí a detectar las pequeñas luces que se prenden en los grupos, no soy un gran manejador de grupo, me focalizo demasiado en lo global y no en los individuos, entonces pierdo la detección de algunos problemas individuales. Me cuesta, siempre estuve a cargo de grupo, a mi cuesta delegar. Yo era el que hacía todo".

$<$ ref. $>$ P 1: Entrevista001S.docx.rtf - 1:16 [ (22:22)>

"Yo tuve dos partes como entrenador, una parte como entrenador formativo que me fue muy bien, y una en plantel superior que no me fue para nada bien. Hablemos de formadores que yo quería darle... El club siempre se destacó por tener forwards pesados que van para adelante, batalladores, que no está mal. A mí me gusta conservar eso y darle más vuelo a los [jugadores] tres cuartos. Darle más velocidad, darle dinámica tanto forwards como tres cuartos; que lo pudimos conseguir el año pasado con M.D., donde laburamos durante tres años, con ese estilo de juego. Forwards batalladores, rápidos y darle mucha velocidad a los tres cuartos. Que no sean los [jugadores] tres cuartos la última fase cuando no puedan avanzar más los gordos, cuando no dan más, sino hacer un grupo dinámico tanto de forwards como de tres cuartos".

<ref.>P 2: Entrevista002P.docx.rtf - 2:17 [ (32:32)]]

"Y ahora vos necesitas una estructura de juego, y qué hacer, dividir la cancha casi en 9 
secciones y decir por lo menos donde tenés que hacer las cosas, en cada momento, qué hacemos con pelota y sin pelota".

$<$ ref.>P 2: Entrevista002P.docx.rtf - 2:11 [(23:23)]>

La autocrítica de los entrenadores no se detiene en la relación teoríapráctica: también admiten que, a pesar de ser sensibles a la globalidad del juego, pueden perder de vista los aspectos individuales de cada jugador. Es necesario poner de relieve este aspecto del propio examen de los entrenadores, pues como se dijo en apartados anteriores, ellos aprecian su condición de líderes que aconsejan y guían. Como contrapunto de lo expresado, reconocen dos méritos propios: la capacidad de situar a los jugadores en distintos puestos y la creatividad para organizar actividades que generen algún tipo de transferencia al juego.

"El ejercicio es dos líneas enfrentadas que no pueden pasar una línea imaginaria, o la línea de 22, y los jugadores van pasando la pelota. Con eso vos corregís pase, postura, comunicación, carreras, todo. $Y$ tenés 14 jugadores en 10 metros y que podés verlos tranquilamente. A mí eso me identifica, a mí, en la parte de cómo querés entrenar. La forma que vos querés al jugador, en el pase y todo eso. Después formaciones fijas es otra historia. Este es el ejercicio que me gusta hacer".

<ref.>P 5: Entrevista005C.docx.rtf - 5:10 [ (23:23)]>

Regular la ansiedad aparece como otro elemento determinante de la "forma de enseñar": el objetivo es formar a mediano y largo plazo y se debe evitar saturar de indicaciones el entrenamiento. En ese sentido, describen que con sus prácticas buscan desestructurar los ejercicios, simplificando sus entrenamientos al utilizar espacios de juego más pequeños o más amplios.

"Intento evolucionar permanentemente. Yo tuve la oportunidad de hablar algunas veces con C.P. Y realmente es un tipo para hablar mucho, porque sabe mucho de rugby y tienen muy claro como es la metodología y por eso no es casual que ahora esté en Pumas M20, un poco seleccionador y un poco de formación también, que es la edad del golpe final de formación para pegar el salto. Me parece que lo que traté de evolucionar es tratar de 
calmar la ansiedad de los entrenadores para que las cosas sucedan".

<ref.>P 4: Entrevista004X.docx.rtf - 4:14 [ (17:17)]]

Por supuesto, no se limitan a aspectos generales del entrenamiento y por eso, la adquisición de destrezas ("todas" las destrezas, enfatizan) y la incorporación de sistemas tácticos ocupan un lugar relevante. De otro modo, entrarían en contradicción con la importancia que le asignan al saber rugbístico específico que les confiere autoridad.

"En los ejercicios que me siento más cómodo cuando se hace actividades como saltar los aros, hacer escaleritas, o con los pases, en eso me siento más cómodo. En cómo enseñarles las posiciones, cómo ponerse para recibir la pelota, o cómo pasarla. En eso me siento más cómodo que en enseñar a limpiar un ruck y todo eso. ${ }^{19}$ En mi pensamiento ellos tienen que saber que tiene que adquirir todas esas destrezas". $<$ ref.>P 3: Encuesta003A.docx.rtf - 3:7 [(14:14)]>

Conviene destacar que la observación de la "propia forma de entrenar" grupos de rugby aparece como un análisis inaugural o novedoso para ellos, incluso ante las preguntas de la presente investigación, ya que manifiestan que nunca han sido ni entrevistados ni consultados desde los ámbitos de los clubes, de las uniones de rugby y mucho menos desde ámbitos académicos.

En algunos casos, los entrenadores explican que dividen el año de rugby en dos objetivos que desean principalmente cumplir. Uno de esos objetivos es la parte grupal y la parte humana: erradicar toda forma de maltrato o falta de respeto entre todos los actores (jugadores, entrenadores, rivales, etc.) no sólo

19 Ruck: El objetivo del ruck es permitir que los jugadores compitan por la pelota que está en el suelo. Un ruck puede tener lugar solamente en el campo de juego. Un ruck se forma cuando por lo menos un jugador de cada equipo está en contacto, sobre sus pies y sobre la pelota que está en el suelo. (Ley 15. Leyes del Juego de Rugby. World Rugby, 2018). 
es básico desde una moral convencional, sino que le otorga valor agregado en el juego.

"Yo divido lo que es rugby en dos. Cuando empiezo el año con un grupo lo divido en dos items que quiero cumplir. Uno es la parte grupal y humana; no permito el maltrato, ni el destrato ni ninguna locura que se le parezca a ese tipo, a ninguno de los jugadores, ni a ninguno de los entrenadores, ni entre ellos, ni entre pares, ni para los otros. Eso para mí es determinante y es la base, el respeto y pensar en el otro, nos va a dar un valor agregado en el juego. Estoy seguro de eso. La parte humana nos va a dar el salto de calidad que el juego necesita. Sí, después es pasarnos la pelota, tacklear, más o menos todos después hacemos lo mismo; un ejercicio más, un ejercicio menos, todos hacemos lo mismo. Creo que el valor agregado es que tener un grupo fuerte. Y me parece también, como hablamos al principio de la conversación, de apuntar a los entrenadores; yo siento que soy muy crítico con los entrenadores, y siento que nos falta mostrarnos o ser más equipo de entrenadores para entrenar un equipo. Es muy difícil transmitir equipo cuando uno desde el lado que tiene que dar el ejemplo no es equipo. Es un grupo, no es lo mismo. Nos formamos, nos juntamos, planificamos pero no somos equipo. Se nota. Si somos equipo también se nota. Todo eso se transmite y el jugador lo absorbe".

$<$ ref. $>$ P 4: Entrevista004X.docx.rtf - 4:20 [ (28:28)]]

La distinción entre grupo y equipo es retomada más adelante en otro plano: se reconocen como parte de un grupo (de entrenadores); pero sostienen que si ellos mismos fueran un equipo, eso incidiría de modo más decisivo en sus jugadores, por la eficacia que tiene el ejemplo. Por esa razón, relatan que en varias ocasiones el trabajo es dentro del grupo en forma individual y que les gustaría mostrarse con objetivos en común. Entienden que ellos serían el primer equipo dentro del equipo. Eso no constituye en sí mismo una garantía de que las cosas funcionen; pero si contribuye a la formación dado que los niños y los jóvenes observan permanente sus acciones y actitudes.

"En cuanto a lo rugbístico. La hora y media de lunes y miércoles que me toca entrenar, es sagrada. Está planificado, nada queda a la deriva. Hemos tenido una metodología de trabajo, que se va desarrollando durante el año. No llegamos y vemos qué onda. Si no está de todo está planificado, yo se los envío a los entrenadores por WhatsApp, le transmito los ejercicios del día, los sabe también el profe". 
<ref.>P 4: Entrevista004X.docx.rtf - 4:21 [ (29:29)]>

No resulta un dato menor que algunos hayan decidido acortar los tiempos de los entrenamientos, reconociendo que el cumplimiento de los objetivos no queda asegurado en la extensión de las prácticas sino en la calidad de los aprendizajes. Esta pequeña pero significativa ruptura con las tradiciones puede considerarse un gesto de audacia.

\footnotetext{
"Bueno, creo que ahora en comparación con un tiempo atrás, no muchos años, uno ha incorporado a través del conocimiento mucha dinámica. Mis entrenamientos en la actualidad tienen que ser dinámicos, efusivos con 45-50 minutos, y se termina el entrenamiento. Antes uno se tomaba dos horas para entrenar, una hora y media. No lo cortaba nunca. Hoy creo que con 45 minutos te sobra, te alcanza. Eso fue mucho lo que uno cambia. En lo que es la dinámica y en el aula (sic) hacia el jugador. Hoy no hace falta hablar tanto. Simplemente con tres o cuatro cosas puntuales creo que se marca y se define muy bien lo que uno quiere".

$<$ ref.>P 5: Entrevista005C.docx.rtf - 5:8 [ (20:20)]>
}

Los relatos manifiestan que las instrucciones son cada vez más puntuales y que en la actualidad prestan mucha más atención al respecto. También que las planificaciones han cambiado con el tiempo, aunque muchos ejercicios se mantienen parecidos. Planificar les permite prever toda una secuencia de actividades beneficiando que los niños y jóvenes estén en actividad todo el tiempo. También admiten que los jugadores más grandes de estas edades formativas están familiarizados con un volumen de información proveniente de entrenamientos de equipo de primera división que los torna críticos de sus entrenadores en las formas y los modos de entrenar.

"En realidad lo hago relativamente igual. Lo que cambió es un poco el conocimiento de ellos. Hoy con todo el tema de redes sociales, celulares, computadoras, están actualizados. De repente ves pibes de 13, 14 años que ya quieren hacer el off load, y lo ven. Bajan entrenamientos, te observan para ver como entrenás".

$<$ ref.>P 6: Entrevista006D.rtf - 6:10 [ (19:19)]> 
Los entrenadores admiten que les ha costado salir de la postura inicial de reproducir entrenamientos porque era la forma predeterminada. Los jugadores nuevos, los participantes nuevos que van al club, los cuestionan y les exigen tener que dar siempre una respuesta. Dicen que para dar una respuesta correcta ahora tienen que perfeccionarse y actualizarse. Les resulta sintomático el comportamiento de los jugadores al final de la práctica: si se acercan o no para hacer consultas y comentarios sobre la misma. Los entrenadores utilizan esas preguntas para saber si el entrenamiento estuvo divertido o aburrido.

"Y creo que el resultado te lo da cuando vos ves que termina el entrenamiento y los jugadores te dicen '¿ya terminamos?' Eso es una frase que te determina, si el entrenamiento estuvo divertido o fue un embole. $Y$ me parece que ese es un punto donde captás al entrenador si vos sentís que el jugador está entretenido". <ref.>P 4: Entrevista004M.docx.rtf - 4:23 [ (30:30)] >

\subsubsection{Lo que necesita un jugador al finalizar M14}

Este es un punto importante y central de este trabajo, quizás determinante, ya que es el objetivo final de todo el proceso de enseñanza de rugby formativo infantil. Han transcurrido varios años desde escuelita de rugby y este es el objetivo final. $\mathrm{O}$ al menos parte del mismo.

Según la opinión de los entrenadores, los jugadores al finalizar la etapa de rugby infantil y en el ingreso a las categorías juveniles deberían:

a) Lograr tener volumen de juego y tener una visión global del mismo. A grandes rasgos: poder jugar agrupados y desplegados, entender el 
concepto de pelota rápida y pelota lenta, pero básicamente tienen que estar muy convencidos de poder tacklear. La referencia al volumen de juego se puede transmitir en la continuidad del juego con conexiones entre los portadores de la pelota y quienes juegan como apoyos. Eso requiere una combinación de actores.

"Para mí tiene que tener volumen de juego, haber superado la pérdida de miedo al contacto, y tiene que tener una visión global de juego. A grandes rasgos: agrupados, desplegados, pelota rápida, pelota lenta, pero básicamente tiene que estar muy convencido, en un $80 \%$ del tackle. Siempre se trabaja, pero no debe ser la prioridad en M15".

<ref.>P 1: Entrevista001S.docx.rtf - 1:24 [ (34:34)]>

"En referencia al volumen de juego tiene que ver con la continuidad, tiene que ver que se conecten los portadores y los apoyos. Eso requiere una combinación de actores. Tiene que haber un apoyo que haga determinadas cosas, tiene que haber uno que levante la pelota si se hace un ruck, tiene que haber otro corriendo de determinada manera según la defensa. Son cosas que van abriendo abanicos y decisiones. Ahora se habla de la toma de decisión".

<ref.>P 1: Entrevista001S.docx.rtf - 1:25 [ (34:34)]>

b) Aprender a ser parte de un grupo a partir actividades divertidas y sin necesidad de generarles presión. El jugador tiene que salir divertido de cada situación de entrenamiento y partido. Dependerá de cada grupo dónde se pone el acento y en qué medida. Hay grupos que ya están constituidos, están unidos, y requieren nada más que juego; mientras otros necesitan más trabajo grupal.

"Nosotros le pusimos como prioridad no jugar al rugby sino divertirse, por un grupo que estaba desarmado".

<ref.>P 1: Entrevista001S.docx.rtf - 1:26 [ (34:34)] >

"Pero todavía hay que macerarlos, pero no con presión. El jugador tiene que salir divertido y con estas características técnicas. Depende de cada grupo en qué medida presionas una u otra. Hay grupos que ya son muy buenos, están unidos, y quieren técnica 
nada más. Los quince jugadores van a todos lados, etcétera. A esos sí hay que meter ese fuego, que es lo que están haciendo los entrenadores".

$<$ ref. $>$ P 1: Entrevista001S.docx.rtf - 1:27 [ (34:34)]>

c) Poder jugar en todos los puestos (o al menos tener cierta versatilidad). Los entrenadores renuncian de este modo a una definición prematura y final de puestos o posición final en el campo de juego, ya que consideran que los jugadores están atravesando una edad de grandes modificaciones.

"El jugador a esa edad debería saber jugar en todos los puestos. No podemos hacer como hacíamos antes, que el gordo iba de forward y el flaco y rápido iba de wing y de tres cuartos. Porque encasillábamos a un jugador que por ahí pegaba el estirón, bajaba 20 kilos y medía dos metros y lo habíamos tenido de primera línea toda su vida porque era gordo y fuerte. Los jugadores deberían hasta los 14 [años], jugar en todas las posiciones, bien o mal, pero probar todas las posiciones. Aprender las destrezas de todas las posiciones, mirar la cancha desde esas posiciones. El jugador tiene que saber usar todo el cuerpo y ocupar todas las posiciones dentro de la cancha porque si no lo estamos limitando a que ocupe un puesto dentro de quince". $\langle$ ref. $>$ P 7: Entrevista007M.docx.rtf - 7:16 [(41:41)]>

d) Tener incorporadas y desarrolladas en el mejor nivel posible las destrezas individuales básicas. A pesar de que no puntualizan a estas destrezas, entendemos que se refieren a un conjunto de acciones entre las cuales se destacan: pasar, recibir, correr, tomar contacto y patear.

“¿Qué tenía que tener? Para mí, sobre todo, las destrezas manuales a la perfección, uno nunca termina de aprender, pero debería tener las técnicas individuales a flor de piel, bien preparadas, o en un desarrollo bastante avanzado. Que se terminan de amoldar hasta que terminas de jugar supongo...".

<ref.>P 2: Entrevista002P.docx.rtf - 2:16 [ (29:29)]>

e) Conocer y practicar los valores del rugby. Más allá de las consignas destacadas por la WR, los relatos de los entrenadores reiteran los conceptos de "sacrificio" y "compañerismo". 
"Ellos ya tienen muy incorporado, por lo menos en el club, ya tiene incorporado el sentido de grupo, el sentido del equipo, el sentido de la pertenencia lo tienen muy incorporado muy a flor. Hay momentos donde vos sabés que un hooker después se puede poner de ala porque adelgazó un año, son todos chicos que no se desarrollaron completamente los físicos. No tienen una determinada posición en el campo de juego, que después puede variar".

$<$ ref. $>$ P 2: Entrevista002P.docx.rtf - 2:15 [ (29:29)] >

"Un chico al terminar M14 y que ya sube como la categoría que ahora, que por primera vez, lo está haciendo el club, tiene que tener los valores del rugby bastantes definidos y que sepa que el rugby es sacrificio. Porque el rugby es mucho sacrificio. Que el chico sepa que cuando el entrenador que tome esa división diga lo que tenga que hacer, sepa hacerlo. Pero lo más importante es ser buen compañero. Ser buen compañero, asumir también los riesgos e ir siempre para adelante. Después las destrezas y todo eso, se va viendo con el tiempo".

$<$ ref.>P 3: Entrevista003A.docx.rtf - 3:11 [ (23:23)]>

\subsubsection{De niños a jugadores: cambio de categoría}

El paso de la categoría M14 a M15 es un tema importante en la formación del jugador de rugby. ${ }^{20}$ Los entrenadores reconocen que los grupos son distintos pero que podrían encontrarse puntos en común en la enseñanza de los aspectos técnicos (tackle, scrum y line out) ${ }^{21}$, en los cuales se debería tener en cuenta la evolución de los jugadores y el reglamento de rugby infantil para el abordaje de la enseñanza. Entre esos cambios resaltan la modificación y ampliación del terreno de juego (no mencionan el pasaje de un rugby de 13 a 15 jugadores que se operó entre M13 y M14). Los entrenadores dicen que

\footnotetext{
20 Según el reglamento de rugby infantil UAR, la categoría Menores de 14 años (M14) es la última categoría de rugby infantil. La categoría Menores de 15 años (M15) es la primera categoría del rugby juvenil.

21 El line out es una forma de reiniciar el juego después que la pelota, o un jugador que la porta, cruza la línea de touch. (Ley 18. Leyes del Juego de Rugby. World Rugby, 2018).
} 
reciben "nenes" y tienen que sacar "jugadores" porque al año siguiente entrenan "en serio". Y juzgan ese salto y cambio de categoría como muy grande.

"El salto de M14 a M15 es un tema que habría que tocar. Tanto en M13 -M14 como en M14 y M15. Los grupos son todos distintos los que yo recibo, hay cosas que tienen en común. En mi experiencia M14 recibí nenes, y los tenías que sacar jugador. Porque el otro año entrenan. Entonces ese salto es muy alto".

<ref.>P 4: Entrevista004X.docx.rtf - 4:24 [ (33:33)]]

Incluso mencionan que podría haber una etapa intermedia de transición entre infantiles y juveniles. Según su juicio, la segunda mitad de M13 debería incluir adecuaciones que preparasen para el año siguiente, para que lleguen a M14 un poco más maduros, desarrollados como jugadores, para poder aprovechar más los aprendizajes del año transcurrido en M14.

"Por más que es el primer año que juegan en cancha entera, estoy pensando mientras hablo, pero debería ser una transición entre infantiles y prejuveniles. La segunda mitad de M13 debería tener una transformación y no seguir todo el año como si el año que viene fuese todo lo mismo".

$<$ ref. $>$ P 4: Entrevista004X.docx.rtf - 4:24 [ (33:33)]]

El perfil del jugador de M14 debería ser un jugador formado física y rugbísticamente para afrontar un campeonato. Los entrenadores manifiestan sus dudas respecto de ese logro. Este debate incluye aspectos no exentos de polémica. Un ejemplo es el que se da con el line out: el reglamento no permitía que en esta formación (en el momento en que las entrevistas fueron realizadas) el jugador de la hilera que actúa de receptor fuera levantado ("alzado") por sus compañeros. Esta medida tenía que ver con la protección de los jugadores. Sin embargo, al año siguiente esto sí estaría permitido. Se da una suerte de contrasentido, para los entrenadores, que opinan que ese 
cambio será muy brusco y que, por esa razón, convendría comenzar a enseñar en forma anticipada esa acción aunque no se pueda implementar en el partido.

"Por ejemplo, yo la segunda mitad del año pierdo tiempo, no pierdo tiempo, gano pero se podría ver como una pérdida de tiempo de entrenamiento. Los hago tirar el line y les enseñamos toda la técnica de levantar. No lo pueden usar en el M14, por regla no lo pueden usar. Si no llegan a M15 sin saber saltar. El entrenador de M15, con un año competitivo por decirlo de alguna manera, ya competitivo, en vez de dedicarse a planificar ese año tiene que estar enseñándole cosas que hasta hoy no vieron, que es por ejemplo saltar en el line out. Eso no se hace porque asi no se juega. Me parece que negamos cosas que van a suceder. Por eso M14 y en M15 deberían ser transitivos. La segunda mitad del año deberían mutar a algo que es lo que se le viene. Se les viene saltar en el line, bueno que salten en line".

<ref.>P 4: Entrevista004X.docx.rtf - 4:24 [ (33:33)]>

De esa manera los entrenadores de M15, en una categoría que ya es competitiva, se dedican a planificar y trabajar con destrezas ya aprendidas, por ejemplo saltar en el line out. Algunos de los entrenadores manifiestan que en el juego niegan o no quieren enseñar cosas que ya van a suceder igualmente.

Los entrenadores expresan que fundamentalmente deben lograr que los jugadores pierdan el miedo al contacto, una de las cosas más difíciles de lograr en la etapa del rugby formativo infantil. Hasta incluso en el caso de no lograrlo, los jugadores se pueden golpear evitando que regresen a la práctica.

"Fundamentalmente que pierda el miedo al contacto, en lo personal creo que es una de las cosas más difíciles que tiene el rugby infantil. Que los chicos pierdan el miedo al contacto, porque a veces uno se acostumbra, pero se golpea feo, que vuelva a retomar es medio complicado. Principalmente eso y además que maneje las técnicas y también algunas de las tácticas fundamentales como formaciones físicas como el line, el scrum que no lo maneje simplemente que tenga un buen conocimiento general para que después las puede limar en el rugby juvenil".

<ref.>P 5: Entrevista005C.docx.rtf - 5:11 [ (26:26)] >

\subsubsection{El legado: la marca de cada club}


Los entrenadores hacen referencia a un propósito colectivo que puede denominarse un legado. Nombran el esfuerzo y el sacrificio como íconos de esa transmisión en los niños y jóvenes. Y no es casual: se trata de una suerte de marca a fuego en el rugby. Justamente, en Legado (2013), así lo dice James Kerr: "El desafío es siempre mejorar, aun si eres el mejor. Especialmente si eres el mejor".

A cada paso constatamos que existen rasgos identificatorios y distintivos en cada club y habría modos implícitos que colaborarían en la transmisión del mismo. Podrían tomar una determinación propia en cada club, es decir, claramente no es para todos de la misma forma. Frente a nuestras preguntas, los entrenadores se interrogan sobre qué concepto de juego, de valores, de modos de relacionarse, quiere cada club. Sin embargo, relatan que ellos pueden transmitirlo a las nuevas generaciones.

"Educás al entrenador para que tenga los conceptos del club. Un ex jugador de A está entrenando una división en un club de otra ciudad y no sé si es el mismo concepto. Un ex jugador de $B$ que está en $A$ y está entrenando, ¿tiene el concepto del club que quiere el club? Por eso para mi en ese proceso hay parte técnica y parte conceptual, pautas del club".

$<$ ref. $>$ P 1: Entrevista001S.docx.rtf - 1:30 [ (37:37)]>

Esas pautas tendrían parte técnica, pero diferencialmente estaría conformado por una parte conceptual y axiológica. Intentan traducir acciones cotidianas, simples y comunes. Inclusive esa demostración de valores definiría el propósito a trasmitir a los demás colegas y a los más jóvenes. Cada individuo asume responsabilidad y comparte sentido de pertenencia. 


\subsubsection{La identidad del club de rugby}

Los entrenadores entienden que, además del legado, de la herencia, existe otro rasgo que los define y se traduce en una forma de jugar rugby o identidad de juego. Esa identidad puede ser el uso de más o menos espacio de juego, momentos de juego espontáneo y hasta desestructurados, como contrapartida de juego estático, estructurado y preestablecido.

"El club tiene una identidad de juego y es bastante...".

<ref.>P 1: Entrevista001S.docx.rtf - 1:31 [ (45:45)]>

"Y el juego nuestro es así. Ahora el rugby no puede ser como lo pensamos en su momento, pero era un juego de más riesgo, de más ataque. Con más espacio a la espontaneidad. Es cierto que teníamos individualidades en el juego y nosotros corríamos detrás de ellos. Bien, mal, es lo que hay. Te agarra el club $X$ y hacen todo estructurado, el divertimento no existe en $M 14$, y ¿le funciona? y no sé. Después tenés al club $Z$, que juega de otra manera, nosotros somos 45, no abren el club. Son modos".

$<$ ref. $>$ P 1: Entrevista001S.docx.rtf - 1:33 [ (45:45)]>

Los entrenadores, llegados a este punto, redoblan la apuesta: identidad y pertenencia son a su vez causa y efecto recíprocos, se retroalimentan. Ese tándem de valores podría extenderse a otros que mantienen esa relación consistente en coadyuvarse como si fuera de manera natural: juego y actitud, camaradería y compromiso, etc. Y eso no puede suceder en otro ámbito que no sea el del club, al cual no se representa como mera institución sino como espacio de amigos, extensión de la familia. Todo se resuelve en el club, donde parece ofrecerse el mejor plan, el mejor lugar para estar. La función de los entrenadores sería estar permanentemente fomentando que el niño esté en el club y brindarle contención, ánimo, una palabra, una corrección. Dicen que siempre tienen que estar predispuestos. 
"La identidad del club tiene que ver con la pertenencia, no sólo con un estilo de juego. El estilo de juego también hace a la pertenencia, al modelo que tenemos. Tiene que ver también con las cosas que creemos ser, con lo que nos parece que queremos ser. Todavía no estamos convencidos que somos un equipo de primera, y eso es parte de nuestro mediopelismo, me incluyo. Los jugadores de las camadas que ahora están en plantel superior tienen eso metido. Hoy un jugador de primera es profesional sin cobrar. Le dedica el $70 \%$ de su tiempo a entrenarse y jugar. En algunos clubes de Buenos Aires se lo piden, y chau. Pero acá ¿cómo le pedís más tiempo? Yo no sé cómo pedirle eso. Y nosotros lo flexibilizamos. El capitán de primera viene y da una mano en el M12, ayudan. Eso es parte de nuestra identidad... En Buenos Aires, van, dan una charla, saludan y se va a entrenar. Hay un paladar para cada tipo de rugby, sin lugar a dudas".

$<$ ref.>P 1: Entrevista001S.docx.rtf - 1:34 [ (46:47)] >

"Principalmente es eso, tener mucha paciencia con los chicos. Lo ideal es darle cariño. Es la base de todo. Tratarlos bien, darle cariño. Llamarlos por teléfono, juntarnos a hacer actividades extra rugby. Yo los juntaba mucho, por ejemplo una vez por mes hacíamos un asado en el club con toda la división. Ese mismo asado le festejamos los cumpleaños que hubo ese mes. Si cumplieron 4, los padres llevan 4 tortas, le festejamos el cumpleaños, los saludamos. Un poco que los chicos sientan que tengan ganas de vernos, querer ir al club, querer ir al club a jugar tocata. Estar permanentemente fomentando que el chico esté en el club y si uno puede estar para darle una contención, un ánimo, una palabra, corregirlo, que ese tipo esté dispuesto siempre a hacerlo".

$<$ ref.>P 6: Entrevista006D.rtf - 6:20 [ (44:44)]>

Existen entrenadores que no dudan de esa identidad propia e incluso hasta la denominan "mística", y la llegan a definir como "algo intangible". Y apelan a esa expresión no solo por el carácter inefable de esa "mística", sino también para tomar distancia de los remanidos "valores", a los que tantas veces se echa mano pero en pocas ocasiones se los definen con un grado mínimo de precisión.

"No tengas dudas. Viste eso que se llama mística, es intangible. Son cosas que vas aprendiendo, maneras y formas de manejarse, que no tiene que ver con los valores en sí. Yo estoy en contra de la frase "los valores del rugby", no me parece. Me parece que el rugby copia valores de la sociedad, pero no tiene valores propios. No el valor propio. Son valores que se toman de la sociedad, son buenos valores, para poder transmitirlos y ponerlos adelante de otras cosas, darles prioridad a esos valores por encima de ganar. Ganar cueste lo que cueste, no. Hay valores. Trampa no tenemos que hacer. Esos valores se transmiten. Se han tomado como propios pero no son propios. Son de la sociedad y 
yo creo que nosotros desde el club ayudamos, lo reforzamos, pero si no hay una base desde casa es muy difícil transformar una persona con 2, 3, 5, 7 horas que lo tengamos en el club, conteniéndolo".

<ref.>P 4: Entrevista004X.docx.rtf - 4:19 [(24:24)]>

Al complejo conformado por "mística", "valores", "identidad" y "pertenencia" algunos no dudan en sumarle "garra", "corazón": el valioso e insustituible recurso de los que menos tienen.

\begin{abstract}
"A ver... para identidad es un club joven todavía, y con pocos chicos en el Plantel Superior que fueron formados desde juveniles. Hemos llegado a tener 5 o 6 que eso estuvo muy bueno, pero lo que caracteriza al club es la garra que le ponen todos los que vienen a jugar, porque saben que están en un club nuevo. Que es chico, que tiene un montón de déficits. Pero lo bueno es que aprenden a querer lo poco que hay, y juegan con mucha garra. Eso es lo que nos han dicho también entrenadores de otros clubes. Que es impresionante la garra que le ponen los chicos. Garra la transformamos en compromiso, en decir bueno te duele hasta el alma pero sigo tackleando. Sigo yendo para adelante y sigo apoyando a mis compañeros. Nosotros es lo que tratamos de hacer, porque también trabajamos con chicos que están con situación social muy difícil y muy violenta. Tratamos que no respondan con violencia a una situación de juego, sino que las solucionen a través de una solución mental, no corporal. Entonces trabajamos para que eso lo apliquen en su vida cotidiana, porque la verdad es que vienen de una situación habitacional difícil, donde todo se soluciona a los golpes. Entonces nosotros tratamos que la identidad sea ésa, respeto sobre todo y nunca bajar los brazos...".

$<$ ref. $>$ P 7: Entrevista007M.docx.rtf - 7:18 [ (47:47)]>
\end{abstract}

\title{
4.2.7. El temor en la enseñanza
}

En el gesto de la destreza del tackle y su enseñanza aparece el temor de forma recurrente. Los entrenadores admiten que existe y está presente, entonces abordaje para su realización es de extrema atención. Según su opinión, anteriormente los niños probaban y exigían a sus cuerpos en las actividades del barrio, de la calle y de la escuela. Pero entienden que el "paradigma social" cambió y admiten también que el tackle es un gesto 
antinatural. Relatan que al tackle se le destina un porcentaje alto del tiempo de entrenamiento.

"En lo que respecta al tackle no es que sean más temerosos antes o ahora. Antes estábamos más probados con nuestros físicos y nuestras cosas. Habías saltado una zanja, un techo. Esto lo puedo hacer, decías. Hoy no. Hoy tienen el problema ahí. Entonces, entran las dudas. Ahora razonan, ¿por qué voy a hacer eso? Entonces el paradigma social cambió. Este año y el año pasado metí casi el $60 \%$ de ejercicios de tackle, porque el tackle justamente es algo antinatural".

$\langle$ ref. $>$ P 1: Enrtevista001S. docx.rtf - 1:36 [ (50:50)]>

Los entrevistados cuentan que cuando los jugadores entienden que con los ejercicios de la técnica pueden trabajar la pérdida de miedo, el cambio en el juego individual es sustancial. Los entrenadores reconocen que a partir de un lenguaje que premia los pequeños logros, los jugadores comienzan a ganar confianza y ello se traduce en la mejora de la ejecución de la técnica del tackle. Incluso debido a ello, los jugadores son estimulados de forma especial en cada uno de los entrenamientos.

"No le podés decir a una persona temerosa, porque cuando viene con la pata levantada, lo natural es poner las manos adelante, sacar la cabeza. Y vos le decís: Tírate con la cabeza. Ese proceso es un abismo. El cuerpo te está diciendo que no lo hagas. Lo empezás a cubrir con un proceso de técnica y evolución de esa técnica. Yo lo he visto, lo vi. El pibe que ve con los ejercicios de la técnica que puede cambiar eso, es un cambio sustancial. Nosotros estos dos últimos años, dábamos premios al final de los encuentros para los tackleadores. Le dimos una medalla para los tackleadores, es decir le pusimos el valor. Y nunca criticamos al que no lo hace, siempre por lo positivo. iQué bien te salió! Los chicos empiezan a ver y a ser consciente de sus defectos, te dicen me acerqué y le contesto: bien ya estabas agachado... ya estás en posición. Pero todavía no se animaba a hacer el golpe. Bien, estás más cerca".

<ref.>P 1: Entrevista001S.docx.rtf - 1:37 [ (50:50)]>

Como se pudo observar, los relatos mencionan que una forma de incentivar el tackle era premiarlos al final de cada uno de los encuentros. Querían valorar 
esos gestos y les daban un premio. Además describen que no criticaban a los que no los realizaban sino que proponían conductas y comentarios positivos.

El abordaje de la pérdida de miedo al contacto se realiza de forma progresiva. Es un trabajo que se va haciendo de menor a mayor. Cuentan los entrenadores que encontraron mucho resultado cuando jugaban junto a sus jugadores. Esa evolución es planificada y permite que los principiantes puedan hacer de manera más personalizada las vivencias de esas experiencias desembarazadas de la presión del juego.

"La pérdida de miedo al contacto lo trabajamos de a poco. Primero con los rhinos," después con bolsas y después jugando, jugando a que lo agarren estilo mancha. Pero esta vez con agarre, que no tiene que pasar, que se tiene que caer. Tenía un nene de 4 años que tenía mucho miedo, lo fuimos trabajando de a poquito, y le decíamos que no se escape, que no se escape, y lo fuimos agarrando de a poco, así fue perdiendo el miedo al contacto. Hoy por hoy no tienen el miedo con el que iniciaron. Es un trabajo que se va haciendo de menor a mayor. Da mucho resultado cuando uno también juega con ellos. Más allá de que uno es entrenador y juegan con ellos, es distinto. Esa evolución es planificada y a veces la vamos viendo. Lo fuimos separando y mientras unos hacían una actividad, nosotros hacíamos otras con ellos. Sacándole el miedo. Y después lo volvíamos a poner a jugar con todo y era uno más. Con la misma tenacidad y todo, y sin la pérdida al contacto".

$<$ ref.>P 3: Entrevista003A.docx.rtf - 3:19 [ (38:38)]>

Aseguran que la enseñanza del rugby hoy cambió, y el rugby hoy cambió. Es una "cuestión cultural". Expresan que "antes los niños tenían otra autoconfianza, que hoy no la manejan". Incluso se lo adjudican a la sociedad y en varias opiniones nombran las tabletas electrónicas, en todas sus variantes, como los primeros responsables.

22 La denominación de rhinos hace referencia a elementos de protección de la marca Rhino. Se ha naturalizado su uso en el ambiente del rugby. 
"La enseñanza del rugby hoy cambió, y el rugby hoy cambió. Es una cuestión cultural. Antes los chicos tenían otra autoconfianza, que hoy no la manejan. Por eso digo que son los chicos de la Play, por culpa de la sociedad. El rugby que los chicos hoy ven en la televisión lo toman como algo normal. Espero que no vean mis filmaciones, yo jugaba...era un asco. Es otro rugby totalmente distinto. Yo era un buen jugador, era vehemente. En el tackle positivo el jugador gana ese metro, avanzar sin la pelota". $<$ ref.>P 1: Entrevista001S.docx.rtf - 1:39 [ (50:50)]>

Reconocen que la pérdida del miedo al contacto y el temor en la enseñanza son puntos que hay que abordarlos apenas comienzan los jugadores principiantes a participar en el club. Resaltan que si es desde la etapa de la escuela de rugby (M6 o inferiores) es mejor y que cuanto más crezcan se dificulta su enseñanza. Sin embargo, existe la opinión de que el miedo está siempre presente y el tema es cómo manejar ese miedo. El riesgo de no pasarse de etapa, con la premisa de la seguridad, es también tenido en cuenta.

"Me parece que hay que empezar desde la escuelita con la pérdida del miedo al contacto. Hay un punto donde si hay miedo al contacto no se puede jugar. Es determinante. O sea si llegas a M14 aunque parezcan chiquitos, ya es una edad donde hay mucha diferencia física. Esa brecha se hizo tan grande que es muy difícil de salvar. Se puede en algunos casos trabajar para que los chicos pierdan el miedo. Me parece que el miedo existe siempre. Poder manejar esos miedos. Está bien que no te quieras partir la cabeza contra el poste de la $\mathrm{H}$. No tener miedo te transforma en un ser no pensante, pero poder manejar ese miedo, tiene mucho que ver con trabajarlo desde mucho más chico y no que lleguen a M14. Cuando llegan a M14 es muy complicado trabajar la pérdida de miedo, a mí me ha pasado de todo. En estas edades me ha pasado hasta con chicos que le hemos metido ficha y dado herramientas para que pierda el miedo al contacto los hemos lastimado".

$<$ ref. $>$ P 4: Entrevista004X.docx.rtf - 4:31 [ (42:42)]]

Los entrevistados admiten que el temor y la pérdida de miedo al contacto deben haber sido trabajados de la manera más consciente posible al finalizar la etapa de rugby infantil. Manifiestan que debe entrenarse lo máximo y mejor posible, especialmente para salvar las diferencias de tamaño y peso. 
"Porque esta pérdida de miedo sin tener toda la técnica necesaria, sin tener el desarrollo físico, el venir golpeándose desde muchos años, hay chicos que pesan 90 y pico de kilos a los 14 años y otros que pesan 40. Entonces esa diferencia física sino fue sanada entre técnica y acostumbramiento al golpe, desde hace varios años, en M14 ya aunque parezca que tiene un montón por delante, en ese punto en particular es tarde. Para mí es tarde".

$<$ ref. $>$ P 4: Entrevista004X.docx.rtf - 4:32 [(43:43)]>

Los trabajos con escudos o colchones, bolsa de tackle y el contacto con el piso, de menor a mayor exigencia y con el uso de las partes duras del cuerpo (rodilla, cadera, hombro y mentón cerca del pecho) les permite a los entrenadores darles confianza a los jugadores y de forma escalonada darles indicios de que el aprendizaje está siendo exitoso. También proponen juegos o situaciones para que se acostumbren estar en contacto con un compañero.

"Entonces lo vamos trabajando de esa forma, que el chico le vaya perdiendo el miedo. Hacemos muchos juegos donde los chicos tienen que empujar, traccionar, mucho juego de abrazo, de entrar en una ronda, de salir de una ronda, donde están todos abrazados, para que pierdan la vergüenza de estar abrazados a un compañero."

<ref.>P 7: Entrevista007M.docx.rtf - 7:19 [ (50:50)]> 


\subsubsection{La contención y el reconocimiento: "iY lo que disfruto!"}

En todos los momentos de lo escrito en el presente trabajo se percibe la necesidad de los entrenadores de contener a los niños y jóvenes que llegan a una actividad que es puramente amateur en su origen. Los entrenadores se proponen ofrecerles a los niños un espacio y un tiempo para que la pasen bien y que puedan disfrutar. Entienden que pueden ofrecerles experiencias positivas en las dos o tres veces por semana que asisten al club. $Y$ eso los estimula a volver al club día tras día.

Poder disfrutar de la formación de niños y adolescentes y que tengan un lugar de contención en cada club, los hace sentir a los entrenadores valiosos y necesarios a la sociedad. En palabras de los entrenadores poder disfrutar hasta las lágrimas esos momentos los hace distintos. Los entrenadores reconocen que dentro de todos los momentos de sus vidas, disfrutar y poder darles un espacio de alegría y juego a muchos niños y jóvenes los hace sentir felices.

Los entrevistados manifiestan que lograr que los niños y jóvenes expresen sus sentimientos en todos esos momentos que están en los clubes, los llena de orgullo. Y de risas.

"Entonces lo vamos trabajando de esa forma, que el chico le vaya perdiendo el miedo. (...) Con los chicos que yo trabajo les cuesta mucho expresar sentimientos. Hasta que lo lográs...es lo más lindo que hay (lágrimas)".

$<$ ref.>P 7: Entrevista007M.docx.rtf - 7:19 [ (50:50)]> 


\subsection{Del dato empírico a la elaboración teórica}

\subsubsection{Acerca del contenido}

El capítulo que nos ocupa pretende analizar algunos de los contenidos y los modos de enseñanza que utilizan los entrenadores de rugby en edades formativas. Procuramos tener en claro qué entienden ellos por contenidos. También deducimos que los modos de llevarlos a cabo repercuten de modo directo en cómo los niños y los jóvenes aprenden a jugar y por ende permanecen en la práctica del rugby.

Inicialmente los contenidos aluden a todo aquello que se enseña. Esa amplitud genera grandes riesgos de interpretación y conviven múltiples posicionamientos y perspectivas tanto en las bibliografías como en las prácticas propiamente dichas.

En forma general, el Diccionario de la Real Academia Española de la Lengua (2016) recoge el concepto de contenido como "reglas, requisitos o exigencias esenciales".

Desde el punto de vista de Viciana (2001), se define al contenido como un subconjunto de la realidad cultural total, seleccionado por las áreas curriculares y sus docentes para contribuir al desarrollo y consecución de los fines educativos y objetivos generales de cada etapa y área, a través de conceptos, procedimientos y actitudes desarrolladas en el medio escolar. Tenemos otras definiciones como las que realiza Díaz Lucea (1994), el cual dice 
que son "el conjunto de formas culturales y de saberes seleccionados para formar parte del área en función de los objetivos generales de área".

En el campo de la enseñanza, ha tenido bastante aceptación la idea de que el contenido se despliega en tres grandes dimensiones: conceptual, procedimental y actitudinal. De modo tal que se produce un cambio de perspectiva: hablar de contenidos implica la selección de conocimientos pertenecientes a diversos ámbitos del saber formalizado, pero, sobre todo, la construcción de un conjunto de saberes o formas culturales cuya asimilación y apropiación por los jugadores se considera esencial para su desarrollo y socialización (Coll, 1994). Esta reposición del "saber" alude a algo más que "conocer", ya que saber se traduce en acciones transformadoras para el sujeto.

En la educación, en general, y en el rugby, en particular, el papel del educador-entrenador es el de un guía en este proceso. Desde la perspectiva manifestada en los párrafos precedentes, se pone en foco que los aprendizajes de las destrezas del rugby resultan o pueden resultar significativos si se atiende el proceso de enseñanza en términos de transmisión, de recepción, de acumulación de conocimientos y, sobre todo, de articulación de saberes transformadores. Sólo en principio, los jugadores juegan un papel receptivo y el rol de los entrenadores es el del transmitir un saber constituido; sin embargo, como valor agregado, se incorporan hábitos, valores, actitudes y hasta forma de relacionarse, cuya construcción -si se pretende formativa- es colaborativa, participativa. 
Aun cuando los entrenadores desconozcan la literatura específica sobre aquello que es un contenido, destacan, en principio, una importancia excesiva en los contenidos como conceptos; pero luego pasan a admitir la importancia de saber seleccionar la información apropiada, estrategias y habilidades para resolver problemas del juego y disponer de conocimientos adecuados para saber trabajar en equipo, mostrarse respetuosos y solidarios.

Aunque de manera intuitiva, los entrenadores entren en consonancia con ciertos aportes de la didáctica, si se acepta que el desafío para que el contenido se transforme en educativo requiere que: a) su selección sea una construcción social de los actores; b) sus dimensiones conceptuales, actitudinales y procedimentales se entramen y resulten el sostén de la interacción educandoeducador; c) estén en función de la misión, social e individual, que cada contexto cultural demande (Candreva, 2015: 105).

Las distintas posiciones se ponen a prueba en cada práctica educativa dentro del rugby. Si el contenido opera de tal suerte que el sujeto se transforme y que él transforme su entorno, habrá sido educativo.

\subsubsection{Acerca de la enseñanza}

Si la posición (intuitiva) de los entrenadores frente al contenido avanza hacia una concepción dinámica del saber, la posición relativa a la enseñanza, en cambio, queda anclada -según puede inferirse de sus distintos relatos- a normas más bien fijas, a entornos estables y previsibles, a logros observables 
en los jugadores, sobre todo, al comienzo de su desempeño como entrenadores. Coincide con un enfoque instrumental (Gimeno Sacristán, 1981), en el cual se concibe al jugador como integrante de un grupo homogéneo caracterizado por edad/nivel evolutivo y que adquiere el aprendizaje por sucesión de estímulos. Por otra parte, desde el punto de vista metodológico, las distintas explicaciones que realizan los entrenadores y la formas de mostrar en cancha afianzan la presencia de un aprendizaje como copia de un modelo, que deriva en la reproducción del conocimiento (Freire, 1970).

Los principios de la carrera como entrenadores muestran que orientan los contenidos para llevar las prácticas sin improvisaciones mediante clases armadas, planificadas y ordenadas. A medida que comienzan a evolucionar y a ganar experiencias en las prácticas, los entrenadores comienzan a focalizar sus aportes en el sujeto de aprendizaje, considerando sus gustos, intereses y la participación activa al momento de aprender. La visualización acerca de los contenidos y la enseñanza, resignifican variables e incluyen nuevas categorías de análisis e interpretación como la actualización y "modernización" de los ejecutantes. Los nuevos contextos en la enseñanza del rugby son poco predecibles y sensibles a los tiempos en los que transcurren.

A los contenidos nombrados como determinantes al finalizar la etapa del rugby infantil, se identifican otros (como legado e identidad de cada club) importantes por compromisos morales que contribuyen en la educación de los jugadores. Esas prácticas "de campo" trascienden preocupaciones e intereses 
individuales y están incluidas en climas y directivas institucionales. Los entrenadores reconocen lo complejo de la tarea si lo realizan en soledad, y también si no se mantienen los compromisos abordados en el mediano y largo plazo.

Los entrenadores, idóneos y de forma amateur, desean enseñar. Quieren que sus jugadores sean mejores. Primero mejores personas y luego mejores jugadores. Cada uno de los entrenadores relatan que quieren colaborar, algunos porque el deporte que jugaron los apasiona y desean estar cerca del campo de juego. Otros porque acompañan a sus hijos y buscan estar en el club siendo un lugar que les ofrece contención.

\subsection{Bibliografía del capítulo}

- Candreva, A. y Susacasa, S. (2015). “Contenido”. En Carballo, C. (coord.) Diccionario Crítico de la Educación Física Académica: rastreo y análisis de los debates y tensiones del campo académico de la educación física en Argentina. Buenos Aires: Prometeo Libros.

- Coll, C., Pozo, J., Sarabia, B. y Valls, E. (1995). Los contenidos en la Reforma. Enseñanza y aprendizaje de conceptos, procedimientos y actitudes. Buenos Aires: Aula XXI.

- Díaz Lucea, J. (1994). El currículum de la Educación Física en la reforma. Zaragoza: Inde. 
- Freire, P. (2012). Pedagogía del Oprimido. Madrid: Biblioteca Clásica Siglo XXI.

- Gimeno Sacristán, J. (1981). Teoría de la enseñanza y desarrollo del curriculum. Madrid: Anaya.

- Real Academia Española. (2001). Diccionario de la lengua española (22da. ed.). Madrid: Espasa.

- Viciana, J. (2001). Planificar en Educación Física. Granada: Reprografía Digital Granada S.L. 


\section{CONCLUSIONES}

Según los datos encontrados en las entrevistas $-y$ contrastados con el material bibliográfico- se han identificado distintos elementos que forman parte de la formación inicial de los entrenadores. Desde los discursos de los entrenadores de rugby formativo se pueden identificar dos categorías iniciales importantes: experiencias (en tanto suma de acciones acumuladas desde sus épocas como jugadores) y trayectorias (es decir, recorridos en sus distintas etapas como deportistas); a su vez, resulta significativo reconocer cómo se ponen en juego esas herramientas al momento de las prácticas como entrenadores.

El rugby, distinto a los deportes que tradicionalmente piensan exclusivamente en la búsqueda del triunfo y la obtención de resultados, plantea desde sus etapas formativas, orientaciones hacia la importancia de los vínculos, la contención y la enseñanza de situaciones de contacto físico junto con acciones conducentes a la pérdida del miedo al contacto. No se trata de una apreciación subjetiva o parcial: tal como se señaló en el apartado 4.2.4., el rugby posterga la competencia oficial hasta la categoría M15, privilegiando hasta ese momento la formación (y el cuidado) de sus jugadores-aprendices.

Los relatos de los entrenadores plantean a la enseñanza como una necesidad de conocer estrategias actuales y eficientes para que los jugadores (niños y jóvenes) puedan desarrollar sus capacidades. Esto supone 
entrenadores de rugby ávidos de aprender y reproducir conocimientos que incluyan tópicos de índole técnico.

Uno de los aspectos más destacables que la investigación permitió observar es el peso determinante que tienen las vivencias de los entrenadores, además de las situaciones de compromiso y exigencias que han experimentado. En este sentido, el espectro de trabajos de campo e investigaciones para poder contrastarlos son mínimos, por no decir escasos. Como se puede ver en el capítulo 2, predominan las experiencias y trayectorias, destacando que muchos de sus propios entrenadores los han marcado en sus inicios; no adjudicándole a un sólo formador la responsabilidad de los conocimientos sino a un proceso extendido durante varios años.

Llegados a este punto, es necesario recuperar el primero de los objetivos específicos planteado en el proyecto de investigación que da origen a esta tesis: determinar el peso que tiene la experiencia como jugador y como entrenador en la toma de decisiones de los entrenadores sobre la enseñanza. Podemos afirmar que este objetivo fue ampliamente cubierto a lo largo de estas páginas y que la hipótesis que lo acompañaba como respuesta tentativa no era equívoca. Afirmábamos entonces que "los entrenadores enseñan otorgándole una importancia capital a su propia experiencia -subjetiva e individual- como jugadores. Eso no significa que copien y trasladen mecánicamente lo recibido; pero sí que esa experiencia constituye 'la' referencia -para imitar o rechazar- de sus prácticas." 
El análisis de las entrevistas demuestra que los distintos criterios, conceptos y prácticas que los entrenadores ponen en juego en la enseñanza del rugby hunden sus raíces en un largo proceso de formación. Si bien no se vislumbra una matriz de formación de entrenadores de manera muy clara u homogénea, la argamasa de "pasión" y "valores" que circula en los clubes y que se reproduce en entrenamientos y partidos colabora en la unificación de criterios, generalizando otros conceptos y prácticas tendientes a maximizar las posibilidades de las acciones que contribuyan al aprendizaje del juego. La trasmisión de práctica en práctica en un ambiente determinado cohesiona y da "estructura" (palabra que los propios entrenadores prefieren a matriz) a la formación de nuestros actores.

En el curso de lo planteado en el párrafo anterior, es posible pensar al entrenador de rugby como alguien que ha sido formado en un cursus honorum tendiente a afianzar la pertenencia a una suerte a una "especie", es decir, un grupo en el cual las características de sus pares son similares -dentro de los parámetros que cada club define- y en donde particularmente se destacan aquellos con mayor y mejor capacidad de comprender a los niños y a los jóvenes en el entorno en el que se encuentran. Vale decir, que pertenecer es un aspecto clave del proceso de la formación.

La forma de transmisión del conocimiento, al comienzo de su trayectoria como entrenador (como se desarrolla en el capítulo 3), no implica de ninguna manera la criticidad, ya que el saber transmitido-heredado, por definición, se torna incuestionable, dado que supone verdad y legitimidad, y tiene como 
objetivo la formación de alguien que aún no ha sido formado. De esta manera, en esa fase de su trayectoria, la construcción del saber por parte del jugador queda obstruida por un mandato impartido, material y simbólicamente, por el encargado de transmitir los conocimientos. La enseñanza se reduce a la mera transmisión. Los relatos de los entrenadores sobre sus prácticas revelan que se instala la idea de que los entrenamientos deben automatizarse y para ello es necesaria la repetición continua y sistemática. Esta perspectiva tradicionalista- acepta la estructura tal como está, dedicándose a comparar los comportamientos o conductas que resulten de la aplicación de distintos juegos o ejercicios sobre los jugadores. Aquí también destacamos que en las formas de entrenar (organización, tareas, fundamentos), el lenguaje empleado y los recursos teóricos disponibles se realzan como primordiales para realizar las tareas que se consideran exitosas. Marcadamente influida por una concepción mecanicista, se extiende la idea de la simplificación de actividades.

No obstante, al menos en la actualidad, y a través de las entrevistas con los entrenadores de M14, aparecen en escena entrenamientos y preparaciones de partidos con rasgos más cercanos a la teoría de la iniciación deportiva española (Blázquez Sánchez, 1986). Es decir, se produce un viraje hacia una idea de enseñanza ligada a problemas a ser resueltos por los jugadores. Aunque esto se retomará más adelante, cuando hablemos de contenidos y formas de enseñanza, es necesario destacar que los entrenadores comienzan a ejercer la función con un cierto apego por las formas tradicionales y con cierto desconocimiento de los jugadores y que su principal cambio tiene que ver con una apertura que se va realizando a nuevos saberes deportivos y 
nuevas percepciones sobre sus jugadores -como generaciones culturalmente diferentes-.

En cuanto al material de estudio y la manera en que reciben ese material los entrenadores, nuestros informantes relatan que los mismos son escasos e incluso los disponibles desde las uniones de rugby son orientados sobre todo a quienes se inician en el rol de entrenadores. Luego, a medida que prosperan las experiencias, la necesidad de poder conseguir material de estudio y consulta se vuelca hacia lugares más cercanos -el propio club y su sistema de coaching, si lo hubiere- y se remarca la necesidad de realizar una formación de manera continua y presencial.

Una vez más, es conveniente confrontar estas afirmaciones con otros objetivos específicos de la investigación. En este caso, fueron dos los objetivos plantados que resultan concurrentes: por un lado, enumerar las distintas herramientas con las que cuentan los entrenadores para entrenar y a cuáles les asignan más importancia y por qué; por otro, establecer el lugar que ocupan los discursos de las uniones (...) en los actos de enseñanza de los entrenadores. Creemos que ambos propósitos fueron abordados y alcanzados en el capítulo 3, aunque estimábamos entonces que el peso de los discursos de las uniones de rugby era mayor al que efectivamente le otorgaron en las entrevistas nuestros informantes. También se refleja en estas conclusiones dos hipótesis oportunamente planteadas en el proyecto, cuando sosteníamos, por una parte, que "es probable que la apertura a la incorporación de herramientas o recursos técnicos sea mayor a la flexibilidad para cambiar de 
criterios y fundamentos [y que los] valores -tácitos o explícitos-, por su parte, parecen no modificarse sustancialmente." Dicha hipótesis es complementaria de otra que expresaba que "Ios mensajes de compañeros de tareas del propio club y las orientaciones emanadas de la unión de rugby no carecerán de sentido, pero serán incorporados en la medida que no contradigan esas creencias arraigadas."

Cuando comenzó esta investigación, suponíamos que, en materia de contenidos y modos de enseñanza, los entrenadores no se basaban en teorías e, incluso, existían pensamientos y acciones contradictorios entre sí. Sin embargo, a medida que se profundizaba en el tema durante el capítulo 4, se podía ver que esto no era exactamente así. Las formas de enseñar, las prácticas y la importancia dada al niño y al joven tienen claras orientaciones, que no son expresadas en términos de teorías académicas, pero sí en términos de preocupaciones que no dudamos en calificar de pedagógicas -toda vez que mencionan valores a transmitir- y didácticas -cuando ponen en discusión formas de transmisión-.

Los entrenadores construyen una idea de formador y le agrega el componente de contenidos, a los cuales distinguen, según la importancia, como correspondientes a la etapa de finalización de infantiles o de inicio de juveniles. Probablemente, no generan saberes nuevos o revolucionarios en el campo de la práctica que desemboquen en un posible modelo de enseñanza alternativo; pero tienden a cubrir todos los problemas que la enseñanza del rugby en etapas formativas supone. 
Entre las consideraciones pedagógicas más interesantes podemos señalar que los entrenadores reconocen la importancia de que todos los jugadores de rugby a la edad de 14 años jueguen siempre, indistintamente de su nivel de juego, no determinados por un puesto fijo en la cancha; y que las actividades sean divertidas y que no se les transmita presión.

Los educadores también distinguen estilos didácticos, al reconocer que las formas de enseñanza implementadas son "propias", es decir el resultado de una síntesis de subjetividad, saber y experiencia; y ponen especial énfasis en el paso de la etapa infantil a juvenil, determinado por los cambios corporales, los intereses de los jugadores e incluso los espacios de juego en cancha. A su vez, no olvidan nombrar los modos con que abordan importantes acciones de propósitos colectivos con pautas que incluyen legado e identidad de juego. El entusiasmo en la tarea de los entrenadores durante cada día, permite entender que priorizan la contención de los niños y jóvenes en los distintos clubes a fin de que ellos permanezcan haciendo amigos y jugando al rugby.

Continuando el ejercicio que iniciamos en los ítems anteriores, al contrastar estas últimas conclusiones con los objetivos específicos propuestos, observamos que los dos restantes también han tenido un adecuado tratamiento: caracterizar los criterios, conceptos y prácticas puestos en juego en la enseñanza por los entrenadores; e identificar los modos en que los entrenadores se vinculan con sus jugadores durante los entrenamientos, durante los partidos y en otras circunstancias. Asimismo, este último núcleo de conclusiones en torno a los contenidos y la enseñanza encuentran eco en 
la hipótesis original restante, dado que "es difícil pensar que los actuales entrenadores tengan incorporado en su menú de recursos y en su horizonte de posibilidades las nuevas expectativas que traen los jóvenes jugadores". Quizás convenga explorar el afianzamiento de un modelo ambivalente: responder con profesionalismo (...) a las demandas técnicas (para las cuales no carecerían de la información actualizada) y con una mirada más ligada al sentido común y la intuición ante los desafíos que se plantean los jóvenes en cuanto a sus propios sueños deportivos (para lo cual sus experiencias y las orientaciones que reciben resultan insuficientes).

Finalmente, creemos que esta tesis propone un debate que posibilite a los entrenadores de rugby formativo transformarse en especialistas a la hora de planificar y ejecutar actividades, de manera ascendente en cuanto a su complejidad. La formación continua y con material de estudio actualizado pretende ofrecer los elementos para que los entrenadores faciliten la transición del niño a la práctica del deporte juvenil. 


\section{BIBLIOGRAFÍA GENERAL}

- Alabarces, P. (1998). “¿De qué hablamos cuando hablamos de deporte?”. En Nueva Sociedad. Nro. 154, Marzo-Abril 1998.

- Alabarces, P. (2000). "Los estudios sobre deporte y sociedad: objetos, miradas, agendas". En Alabarces, P. (coord.), Peligro de gol. Estudios sobre deporte y sociedad en América Latina. Buenos Aires: CLACSO.

- Alred, D. (2016). El principio de la presión. Buenos Aires: Club House.

- Anderson, W. y Davidson, J. (1991). Nueva Imagen del Rugby. Madrid: Federación Española de Rugby.

- Archetti, E. (2001). El potrero, la pista y el ring. Las patrias del deporte argentino. Buenos Aires: Fondo de Cultura Económica.

- Arthur, J. (1998). Play the Game. Dublin: International Rugby Board.

- Astrand, P. y Rodal, K. (1992). Fisiología del trabajo físico. Buenos Aires: Editorial Médica Panamericana.

- Bartholomew, B. (2017). Conscious coaching. The art and science of building buy-in. Omaha: Bartholomew Strength LLC.

- Bayer, C. (1992). La enseñanza de los deportes colectivos. Madrid: Hispano Europea.

- Biscombe, T. (1998). Rugby. Steps to success. Champaign: Human Kinetics. 
- Blackburn, M. (2013). Coaching rugby sevens. London: Bloomsbury Publishing Plc.

- Blázquez Sánchez, D. (1998). La iniciación deportiva y el deporte escolar. Madrid: INDE.

- Bourdieu, P. (1996). Cosas dichas. Barcelona: Gedisa.

- Bourdieu, P. y Passeron, J-C. (1981). La reproducción: elementos para una teoría del sistema de enseñanza. Barcelona: Laia.

- Bourdieu, P., Chamboredon, J-C. Y Passeron, J-C. (2008). “Segunda Parte: La construcción del objeto". En El oficio del sociólogo. Presupuestos epistemológicos. Buenos Aires: Siglo XXI Editores.

- Bourdieu, P. (2010). El sentido práctico. Buenos Aires: Siglo XXI Editores.

- Branz, J. (2009). “El rugby, sus cuerpos, y las identidades construidas entre los sectores hegemónicos de la ciudad de La Plata". En XXVII Congreso de la Asociación Latinoamericana de Sociología. Buenos Aires: Asociación Latinoamericana de Sociología.

- Búsico, J. (2015). El rugido. Buenos Aires: Club House.

- Candreva, A. y Susacasa, S. (2015). “Contenido". En Carballo, C. (coord.), Diccionario Crítico de la Educación Física Académica: rastreo y análisis de los debates y tensiones del campo académico de la educación física en Argentina. Buenos Aires: Prometeo Libros. 
- Carballo, C. (2009). “La investigación en Educación Física: Algunas notas sobre el estado de su desarrollo en Argentina". En Crisorio, R. y Giles, M. (coord.), Educación Física. Estudios críticos de Educación Física. La Plata: Ediciones Al Margen, Colección Textos Básicos.

- Carballo, C. (2014). “La formación de formadores en Educación Física: Tradición e innovación, viejos y nuevos escenarios". En Cachorro, G. y Camblor, E. (coord.), Educación Física y Ciencias. Abordajes desde la pluralidad. Buenos Aires: Biblos.

- Carlin, J. (2009). El factor humano. Buenos Aires: Editorial Seix Barral.

- Coll, C., Pozo, J., Sarabia, B. y Valls, E. (1995). Los contenidos en la Reforma. Enseñanza y aprendizaje de conceptos, procedimientos y actitudes. Buenos Aires: Aula XXI.

- Collinet, S. (2006). Rugby. ¿Cómo enseñar el deporte hoy? Buenos Aires: Stadium.

- Corless, B. (1988). El Rugby. Barcelona: Editorial Hispano Europea.

- Cornejo, M. (2006). “El Enfoque Biográfico: Trayectorias, Desarrollos Teóricos y Perspectivas". En PSYKHE, Vol.15, N. 1. Disponible en: http://dx.doi.org/10.4067/S0718-22282006000100008

- De Marziani, F. A. (2014). Fútbol infantil: Conflictos, tensiones e intereses de una práctica institucionalizada. El caso de la liga LISFI de la ciudad de La Plata [en línea]. Tesis de posgrado. Universidad Nacional de La Plata. 
Facultad de Humanidades y Ciencias de la Educación. En Memoria Académica. Recuperado de:

http://www.memoria.fahce.unlp.edu.ar/tesis/te.1052/te.1052.pdf

- Devís Devís, J. (1992). "Bases para la propuesta de cambio en la enseñanza de los juegos deportivos". En Devís Devís, J. y Peiró Velert, C. Nuevas perspectivas curriculares en Educación Física: la salud y los juegos modificados. Barcelona: Inde.

- Díaz Lucea, J. (1994). El currículum de la Educación Física en la reforma. Zaragoza: Inde.

- Elías, N. y Dunning, E. (1992). Deporte y ocio en el proceso de la civilización. Madrid: FCE.

- Erickson, F. (1989). "Métodos cualitativos de investigación sobre la enseñanza". En: Wittrock, M. La investigación de la enseñanza. Buenos Aires: Paidós.

- Freire, P. (2012). Pedagogía del Oprimido. Madrid: Biblioteca Clásica Siglo XXI.

- Galán, N. (2015). El rugby, un juego de valores. La Plata: Artes Gráficas.

- Giddens, A. (1991). La constitución de la sociedad. Bases para una teoría de la estructuración. Buenos Aires: Amorrortu.

- Giménez, J., Abad, M. y Robles, J. (2009). “La enseñanza del deporte desde la perspectiva educativa". En Revista Waceulen. E.F. Digital. 
- Gimeno Sacristán, J. (1981). Teoría de la enseñanza y desarrollo del curriculum. Madrid: Anaya.

- Gimeno Sacristán, J. (1986). La pedagogía por objetivos: obsesión por la eficiencia. Madrid: Ediciones Morata.

- Gómez, C. (2015). Maten al rugbier. Buenos Aires: Sudamericana.

- Greenwood, J. (1993). Rugby total. Madrid: Ediciones Tutor.

- Grosser, M., Strischkai, S. y Zimmermann, E. (1988). Principios del entrenamiento deportivo. Barcelona: Martínez Roca.

- Hammersley, M. y Atkinson, P. (1994). Etnografía. Métodos de investigación. Barcelona: Paidós.

- Hernández, M. (2013). Rugby para pensar. Buenos Aires: Dunken.

- Hernández, N. y Carballo, C. (2003). “Acerca del concepto de deporte: Alcances de su(s) significado(s)". En Revista Educación Física y Ciencia, Nro. 6. La Plata: Departamento de Educación Física. Facultad de Humanidades y Ciencias de la Educación. Universidad Nacional de La Plata.

- Hogan, E. (2014). Rugby Drills: 125 Activities to improve Your Coaching Sessions. London: The Crowood Press.

- Kerr, J. (2014). Legado. Buenos Aires: Club House.

- Kistenmacher, J. (2000). Rugby: juego de manos. La Plata: Secretaría de Deportes de la Provincia de Buenos Aires. 
- Luger, D. (2004). Complete conditioning for rugby. Champaign: Human Kinetics.

- Mackey, M. (2012). Entrenando Movimientos. Buenos Aires: Unión Argentina de Rugby.

- Mackey, M. (2012). El arte de entrenar. Buenos Aires: Unión Argentina de Rugby.

- Marradi, A. (2000). "Método como arte". En Revista Argentina de Economía y Ciencias Sociales. Vol. IV № 6. Primavera 2000. Buenos Aires: Ediciones de la Universidad.

- Marradi, A., Archeti, N. y Piovani, J. (2007). Metodología de las ciencias sociales. Buenos Aires: Emecé Editores.

- McCaw, R. (2012). The Real McCaw. The Autobiography. London: Aurum Press.

- McGregor, L. (2011). Touch, Pause, engage! Cape Town: Jonathan Ball Publishers.

- McKenzie, A., Hodge, K. \& Sleivert, G. (2011). Smart training for rugby. Auckland: Reed.

- Pampliega de Quiroga, A. (1994). Matrices de aprendizaje. Constitución del sujeto en el proceso del conocimiento. Buenos Aires: Ediciones Cinco.

- Parore, L. (1997). Zinzan Brooke's competitive edge. Auckland: Celebrity Books. 
- Perasso, S. (2008). Rugby didáctico 2, el entrenador. Buenos Aires: Dunken.

- Perasso, S. (2013). Veco Villegas, pasión por el rugby. Buenos Aires: Zona de Tackle.

- Pichot, A. (2012). El juego manda. Buenos Aires: Planeta.

- Pinedo, J. y luliano, R. (2015). "Prácticas sociales". En Carballo, C. (coord.), Diccionario Crítico de la Educación Física Académica: rastreo y análisis de los debates y tensiones del campo académico de la educación física en Argentina. Buenos Aires: Prometeo Libros.

- Pool, G. (1998). Modern rugby. Cape Town: Tafelberg.

- Popinciuc, C. (1975). Manual para profesores y entrenadores. Buenos Aires: Stadium.

- Posthumus, M. (2009). Boksmart. Physical conditioning for rugby. Cape Town: South African Rugby Union.

- Price, R. (2017). Entrenar con pesas para rugby. Buenos Aires: Editorial Sports Workout.

- Real Academia Española. (2001). Diccionario de la lengua española (22da. ed.). Madrid: Espasa.

- Richarson, K. (2014). Coaching Youth Rugby: An Essential Guide for Coaches, Parents and Teachers. London: The Crowood Press.

- Rieder, H. y Fischer, G. (1990). Aprendizaje motor, metodología y didáctica. Buenos Aires: Martínez Roca. 
- Riley, B. (2000). Rugby Law. Auckland: Reed.

- Roberts, M. (2010). Rugby. The player's handbook. London: Sterling Publising.

- Rodriguez, E. (2015). Rugby, The art of scrummaging. Sydney: Meyer \& Meyer Sport.

- Rumin, J. (2006). La escuela del rugby. Buenos Aires: Stadium.

- Rutherford, D. (1993). The Complete Books of Minirugby. London: Patridge Press.

- Saccone, F. (2016). Rugby mental. Buenos Aires: Dunken.

- Salluzzi, D. (2015). El rugby desde sus principios. Buenos Aires: Universidad Maimónides.

- San Pedro, J. (1999). Fundamentos de táctica deportiva, análisis de la estrategia de los deportes. Buenos Aires: Editorial Gymnos.

- Scheiner, W., Spring, H. y Tritschler, T. (1993). Fitness. Teoría y práctica. Barcelona: Scriba.

- Smith, L. (1997). Manual de Coaching. Nivel I. Dublin: International Rugby Board.

- Sheryn, C. (2004). Rugby for real. London: A \& C Black.

- Taylor, S. J. y Bogdan, R. (1990). Introducción a los métodos cualitativos de investigación. La búsqueda de significados. Barcelona: Paidós. 
- Tietjens, G. (2017). Legacy. Auckland: Penguin House.

- Torres Viñas, J. (1980). Siempre en el rugby. Buenos Aires: Ediciones Libros Bonaerenses.

- Turner, A., Crespo, M., Reid, M. \& Miley, D. (2002). "The games for understanding (GFU). Teaching approach in tennis". En ITF Coaching \& Sportscience Review, 26, 2-3.

- Uro, L. (2015). "Habitus, capital”. En Carballo, C. (coord.), Diccionario Crítico de la Educación Física Académica: rastreo y análisis de los debates y tensiones del campo académico de la educación física en Argentina. Buenos Aires: Prometeo Libros.

- Usero, F. y otros (1998). Monitor. Madrid: Federación Española de Rugby.

- Usero, F. y otros (1998). Rugby. Nivel I. Madrid: Federación Española de Rugby.

- Usero, F. (2014). La escuela de rugby, lecciones de rugby. Madrid: XV Ediciones.

- Villepreux, P. (1995). Formación del rugby de movimiento. Buenos Aires: Stadium.

- Viciana, J. (2001). Planificar en Educación Física. Granada: Reprografía Digital Granada.

- Williams, G. (1981). Rugby. Buenos Aires: Lidium. 
- Williams, R. (1976). Iniciación al Rugby y al Minirugby. Buenos Aires: Stadium.

- Williams, R. (1976). Rugby actual. Buenos Aires: Stadium.

- Woods, P. (1989). La escuela por dentro. La etnografía en la investigación educativa. Barcelona: Paidós.

- Wein, H. (1995). Fútbol a la medida del niño. Madrid: Real Federación Española de Fútbol. 